OAK RIDGE

ORNL/TM-2010/328

NATIONAL LABORATORY

MANAGED BY UT-BATTELLE

FOR THE DEPARTMENT OF ENERGY

\title{
National Energy Audit Tool for Multifamily Buildings - Development Plan
}

\section{DUFKL2012}

Mini Malhotra

Michael MacDonald, SRA

Gina Accawi

Joshua New

Piljae Im

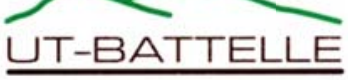




\title{
DOCUMENT AVAILABILITY
}

Reports produced after January 1, 1996, are generally available free via the U.S. Department of Energy (DOE) Information Bridge.

Web site http://www.osti.gov/bridge

Reports produced before January 1, 1996, may be purchased by members of the public from the following source.

\author{
National Technical Information Service \\ 5285 Port Royal Road \\ Springfield, VA 22161 \\ Telephone 703-605-6000 (1-800-553-6847) \\ TDD 703-487-4639 \\ Fax 703-605-6900 \\ E-mail info@ntis.gov \\ Web site http://www.ntis.gov/support/ordernowabout.htm
}

Reports are available to DOE employees, DOE contractors, Energy Technology Data Exchange (ETDE) representatives, and International Nuclear Information System (INIS) representatives from the following source.

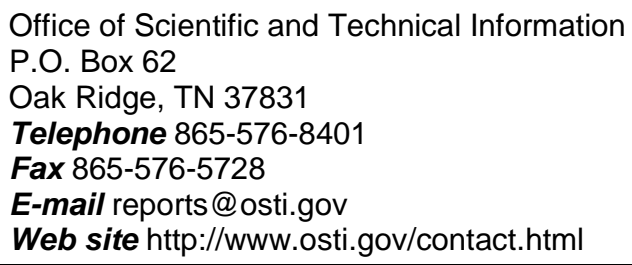

This report was prepared as an account of work sponsored by an agency of the United States Government. Neither the United States Government nor any agency thereof, nor any of their employees, makes any warranty, express or implied, or assumes any legal liability or responsibility for the accuracy, completeness, or usefulness of any information, apparatus, product, or process disclosed, or represents that its use would not infringe privately owned rights. Reference herein to any specific commercial product, process, or service by trade name, trademark, manufacturer, or otherwise, does not necessarily constitute or imply its endorsement, recommendation, or favoring by the United States Government or any agency thereof. The views and opinions of authors expressed herein do not necessarily state or reflect those of the United States Government or any agency thereof. 
Energy and Transportation Science Division

\title{
NATIONAL ENERGY AUDIT TOOL FOR MULTIFAMILY BUILDINGS - DEVELOPMENT PLAN
}

\author{
Mini Malhotra \\ Michael MacDonald, SRA \\ Gina Accawi \\ Joshua New \\ Piljae Im
}

November 2011

Prepared by

OAK RIDGE NATIONAL LABORATORY

Oak Ridge, Tennessee 37831-6283

managed by

UT-BATTELLE, LLC

for the

U.S. DEPARTMENT OF ENERGY

under contract DE-AC05-00OR22725 


\section{ACKNOWLEDGEMENTS}

The authors gratefully acknowledge the support of Cynthia Simonson and her colleagues in conducting the two national experts Web meetings on multifamily energy audits held in November 2010, as well as developing the two extensive transcripts provided in Appendices B and $\mathrm{C}$ to this report. The contributions of all the Web meeting participants are also gratefully acknowledged. The meeting transcripts are valuable resources in themselves for anyone wishing to understand the current state of the art in energy audits for multifamily buildings, as well as for viewing all the good ideas for improving energy audits in the future. Input from the national experts meetings provided the basis for most of the scope of capabilities proposed in this plan for the Weatherization Assistant suite component (or possibly components) for multifamily buildings.

\section{FOREWORD}

This development plan is based on extensive input from experts and practitioners from around the country involved in energy audits of multifamily buildings. The ideas from these meetings on means for improving energy auditing of multifamily buildings provided important direction to formulating the recommendations here, and also show a view of possible future improvements to the multifamily audit tools.

The complexity of energy systems in multifamily buildings leads to complexity in options available to improve energy audits and analysis of energy efficiency measures. As an example, control systems adaptations are often needed to improve energy efficiency, but the wide range of possible configurations in multifamily buildings, together with the wide range of potential options for improving a controls arrangement or setup, lead to potential combinations of both that cannot be easily tabulated. Similarly, a wide range of operational changes or maintenance improvements, some of which might be needed in any given building, are not readily handled in any easy way. This plan lays out the main path for development of the proposed national multifamily energy audit tool. The planned development will meet the needs of the Weatherization Program for an improved tool. However, some portions of the development will be set up to allow later additions that go beyond basic needs. 


\section{CONTENTS}

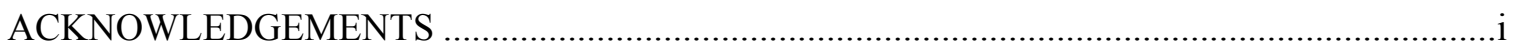

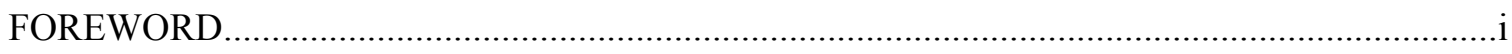

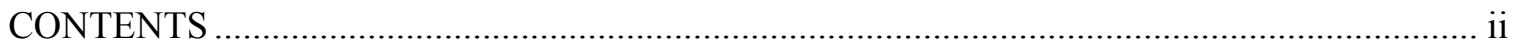

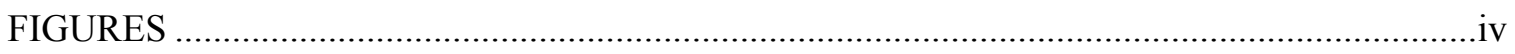

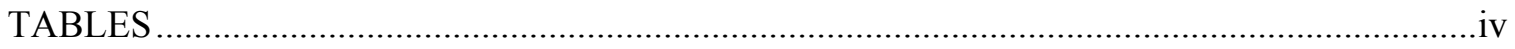

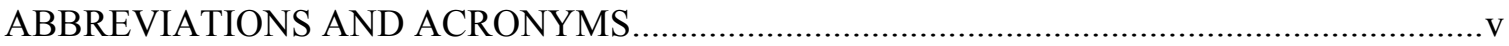

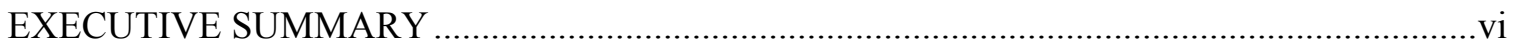

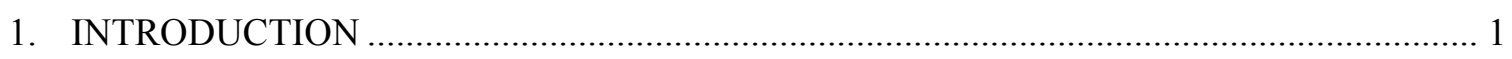

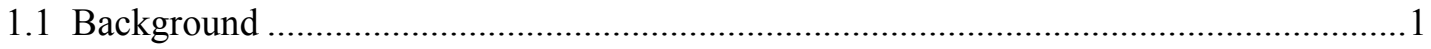

1.2 Development Framework — Weatherization Assistant ................................................

1.2.1 Web Application of the Weatherization Assistant ............................................

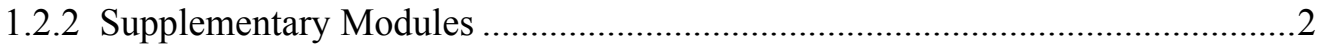

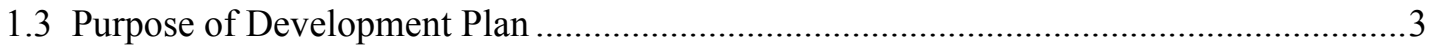

1.4 Parallel Development with Home Energy Saver...........................................................4

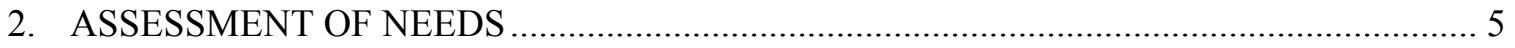

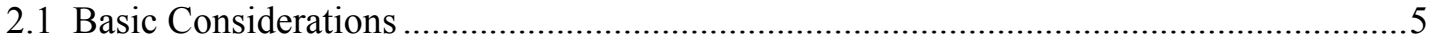

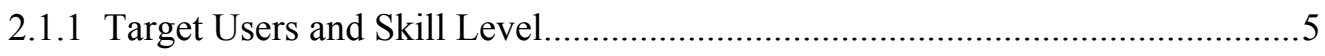

2.1.2 Target Building Characteristics and Energy Audit Levels ...............................5

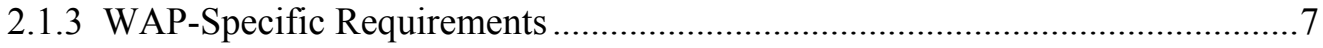

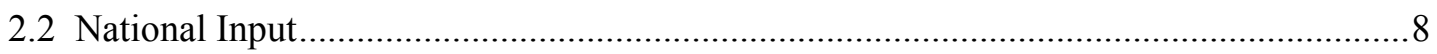

2.2.1 Types of Multifamily Buildings Audited.................................................

2.2.2 Experience with Existing Audit Tools ............................................................. 9

2.2.3 Desired Improved Analysis Capabilities....................................................

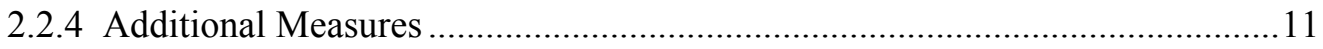

2.2.5 Integration of Other Features/Capabilities .....................................................13

2.3 Currently Used Tools for Multifamily Energy Audits .................................................15

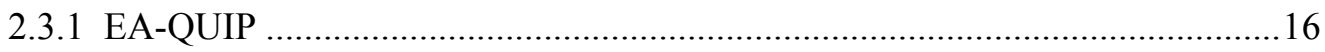

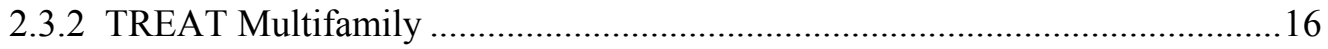

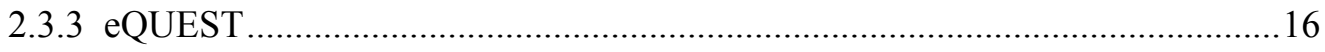

2.3.4 Other Simulation Programs and Tools...................................................... 17

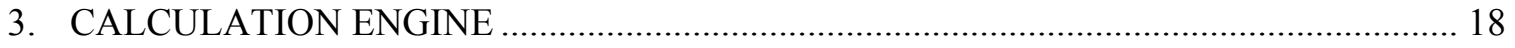

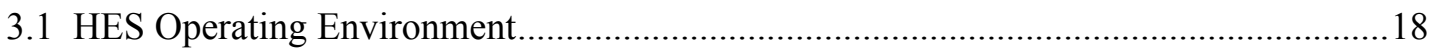

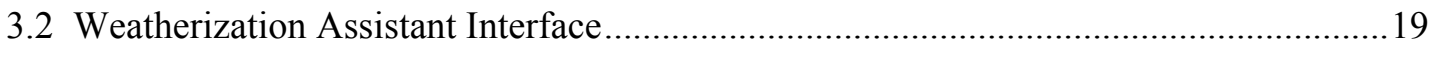

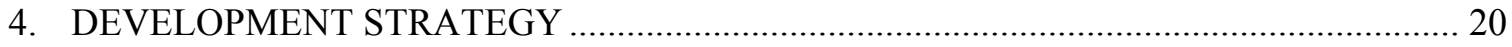




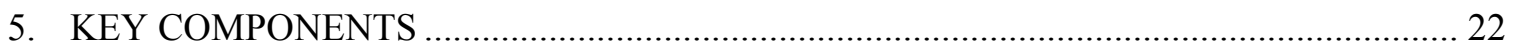

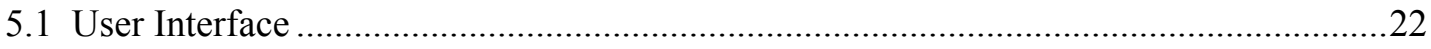

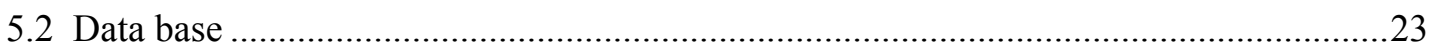

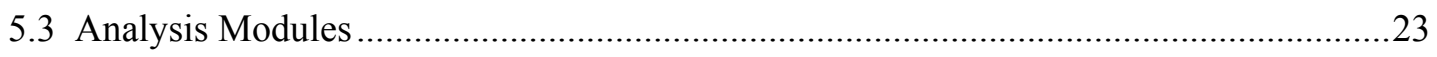

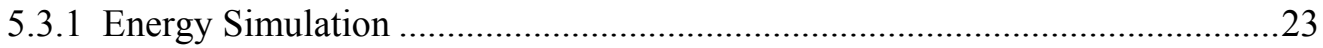

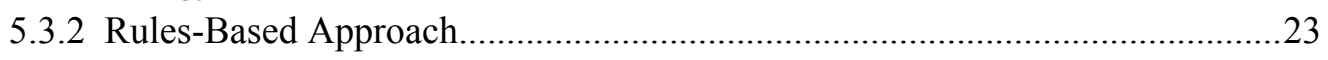

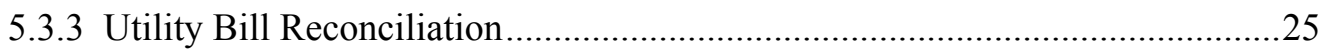

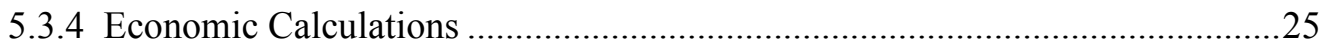

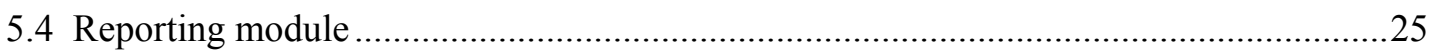

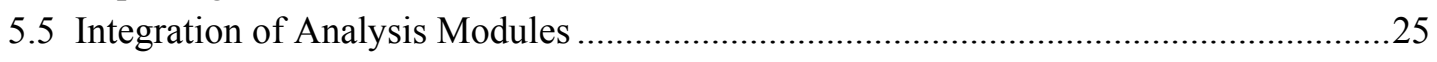

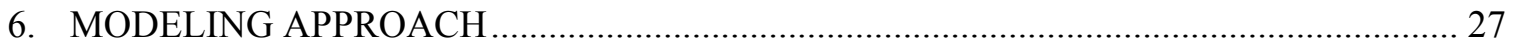

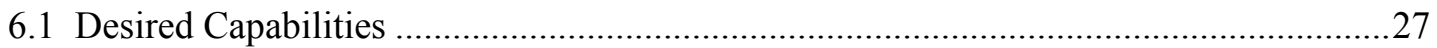

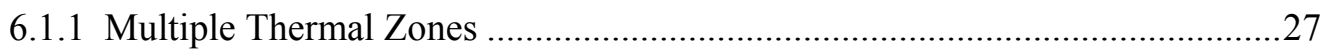

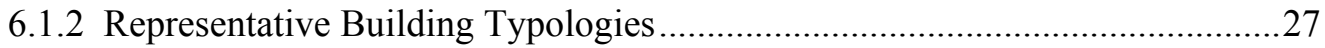

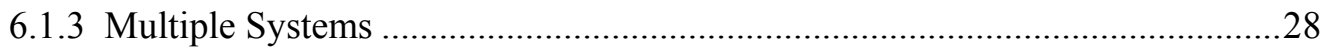

6.1.4 Infiltration / Ventilation ..........................................................................28

6.1.5 Representative Internal Load Schedules .....................................................28

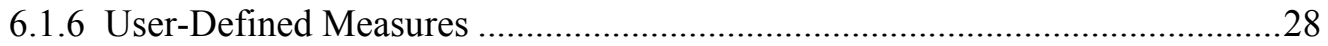

6.1.7 Electricity and Fuel Rate Structures ............................................................28

6.2 Criteria for Selecting Modeling and Analysis Approach ..............................................29

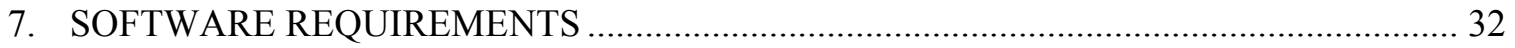

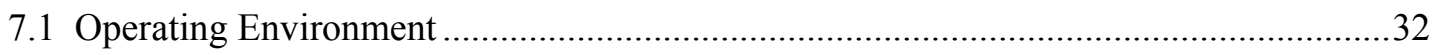

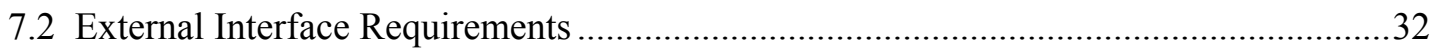

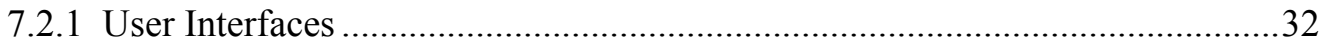

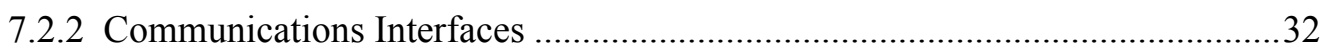

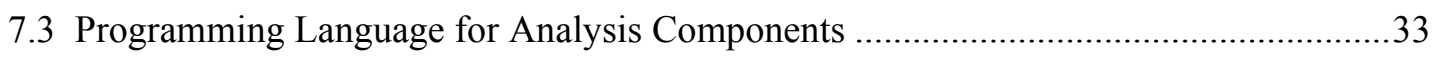

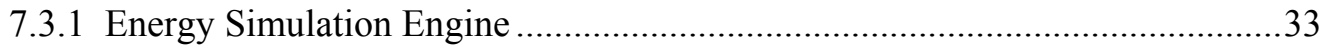

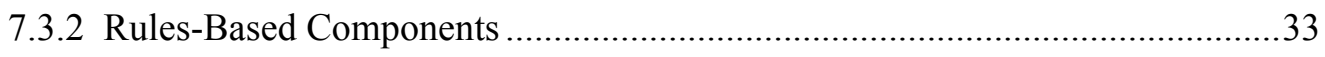

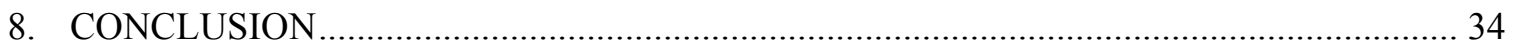

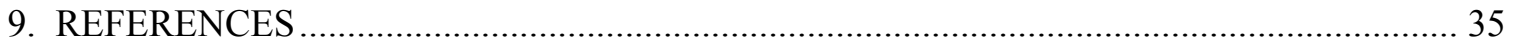

APPENDIX A Agendas of the Two Multifamily National Energy Audit Web Meetings .......... A-1

APPENDIX B Transcript of the November 10, 2010 Multifamily National Energy Audit

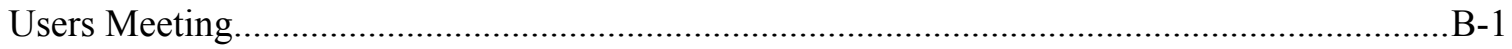

APPENDIX C Transcript of the November 4, 2010 Multifamily National Energy Audit

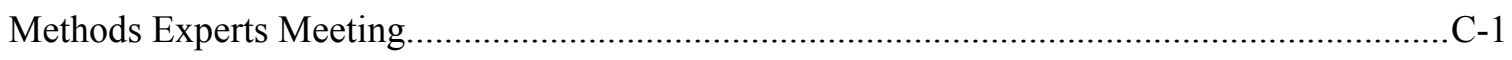




\section{FIGURES}

Figure 1. Existing components and use of Weatherization Assistant..................................................2

Figure 2. Planned components and use of Web-based Weatherization Assistant. ...................................2

Figure 3. An example screen of Web-based Weatherization Assistant (NEAT audit)..............................3

Figure 4. Distribution of MF 5+ dwelling units across the U.S. by major census region. ..........................6

Figure 5. Distribution of MF 5+ dwelling units by system types in major U.S. census regions.................6

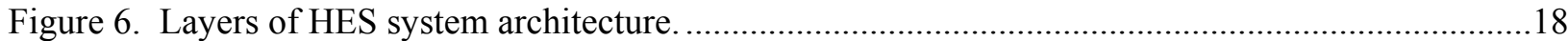

Figure 7. Desired capabilities and proposed components of the multifamily audit tool. .........................22

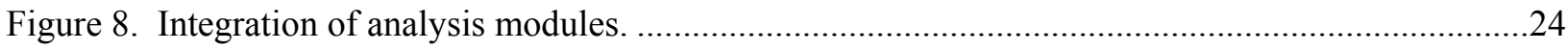

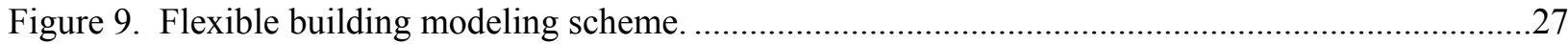

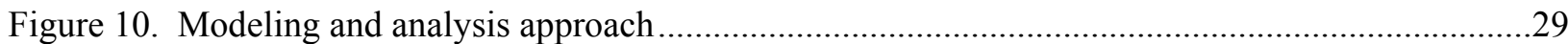

\section{TABLES}

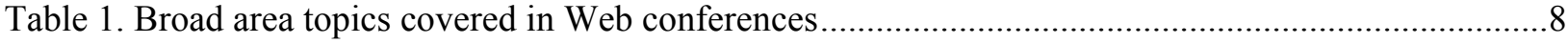

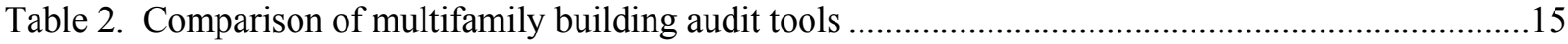

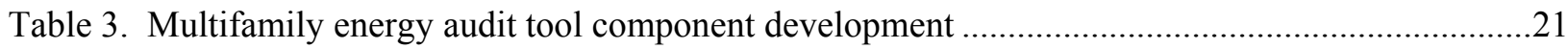

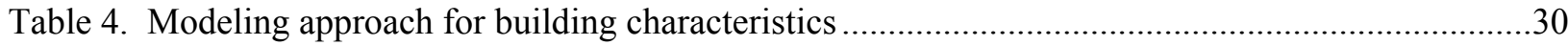

Table 5. Analysis approach for weatherization measures …................................................................... 


\section{ABBREVIATIONS AND ACRONYMS}

ACEEE American Council for an Energy Efficient Economy

AJAX

AEA

API

ASHRAE

ASPE

BTU

CBECS

CEDA

CSS

DHW

DOE

DOM

eQUEST

EA-QUIP

EPA

EUI

GUI

$\mathrm{H} \& \mathrm{~S}$

HES

HUD

HVAC

LBL

LED

MHEA

NEAT

NEBs

NREL

NYSERDA

O\&M

ORNL

PSD

RECS

RETScreen

SIR

T\&TA

TREAT

WAP

WSDL

XML

XSD
Asynchronous JavaScript and XML

Association for Energy Affordability (New York City)

Application Programming Interface

American Society of Heating, Refrigerating and Air-Conditioning Engineers

American Society of Plumbing Engineers

British thermal unit (unit of energy)

Commercial Buildings Energy Consumption Survey

Community and Economic Development Association of Cook County, Incorporated

Cascading Style Sheets

Domestic hot water

U.S. Department of Energy

Document Object Model

Energy QUick ESTimator

Energy Audit using the Queens Information Package

U.S. Environmental Protection Agency

Energy use index

Graphical user interface

Health and safety

Home Energy Saver

U.S. Department of Housing and Urban Development

Heating Ventilation and Air Conditioning

Lawrence Berkeley National Laboratory

Light-emitting diode

Manufactured Home Energy Audit

National Energy Audit Tool

Non-energy benefits

National Renewable Energy Laboratory

New York State Energy Research and Development Authority

Operations and maintenance

Oak Ridge National Laboratory

Performance Systems Development

Residential Energy Consumption Survey

Renewable-energy and Energy-efficient Technologies Screening tool

Savings-to-investment ratio

Training and Technical Assistance

Targeted Retrofit Energy Analysis Tool

Weatherization Assistance Program

Web Services Description Language

The Extensible Markup Language

Extensible Markup Language Schema Definition Language 


\section{EXECUTIVE SUMMARY}

This development plan is presented as part of the initial planning that is directing the development of a new multifamily building energy audit tool for the U.S. Department of Energy's (DOE's) Weatherization Assistance Program. The Weatherization Assistant is a DOE-sponsored energy audit approved for performing energy audits in site-built single-family homes (using the National Energy Audit Tool, NEAT) and mobile homes (using the Manufactured Home Energy Audit, MHEA), but there is no DOEsponsored audit tool for multifamily housing types. The development of an energy audit tool for multifamily housing types for the Weatherization Assistant would expand the scope of its use and allow weatherization agencies to use an integrated approach to manage their weatherization projects.

An assessment of needs was conducted to examine existing multifamily audit tools and obtain input from multifamily audit methods experts and practitioners regarding audit methods, issues, potential improvements, and desired capabilities. The assessment of needs is translated into capability and performance descriptions for the proposed new multifamily energy audit. Two national Web-based meetings were held with two groups of participants: (1) multifamily energy audit method experts on November 4, 2010, and (2) multifamily audit users on November 10, 2010. The national input was an important part of the needs assessment, and the agendas, full transcripts, and attendee lists for the two national Web meetings are presented in the appendices to this report.

At present, the Weatherization Assistant is a desktop program that is installed and used locally, but its transition to a Web-based application is in progress that should allow better documentation of progress and accomplishments. The new multifamily tool will be Web-based also. DOE has directed that the Home Energy Saver (HES) tools be upgraded to also handle multifamily buildings. As a result of the concurrent upgrades to both the Weatherization Assistant and to HES to cover multifamily buildings, DOE has also directed that both use the same energy-savings-calculation engine.

In HES, the energy consumption for most types of heating and cooling equipment is calculated using the DOE-2 building simulation program (version 2.1e). The national input on potential development of a multifamily energy audit tool indicated that DOE-2.1e is also the calculation engine that would best meet the needs for the multifamily audit tool identified by users and experts. These factors led to DOE-2.1e being chosen as the basic, underlying energy calculation engine.

Based on WAP priorities, national input, and conformance with NEAT and MHEA methods, the proposed tool can be conceptualized as being comprised of four components: the user interface, the analysis modules, the data base, and the reporting module. The user interface will be integrated into the Weatherization Assistant. The data base is a Weatherization Assistant data base and includes all the data settings and flows, as well as being a repository of libraries, user inputs, custom settings and preferences, and analysis outputs. All data flow among other components and modules will be through the data base. The inputs and output data will be stored as permanent records for each audit. The analysis component will include integrated modules to perform the several steps required for a complete audit. The analysis modules considered for the first version of the tool are energy simulation, rules-based calculations, utility data reconciliation, and the economic calculations. 
A simple presentation of desired capabilities and the key components of the proposed tool is shown in the figure here. Desired capabilities lead to needed components. Data flows through the data base are seen as blue arrows. The primary user inputs to the analysis will be the utility data and building and site details. The Utility Data Reconciliation module will compare the modeled end-use energy values with the billed end uses. For the analysis of individual measures, a built-in routine will modify the parameters of the base-case model corresponding to the selected / applicable measures and run the model to simulate the energy use. The Economic Analysis module will use the energy consumption for the base case and revised models with individual measures, cost data, and other economic parameters stored in the library to calculate the savings-to-investment ratio for individual measures.

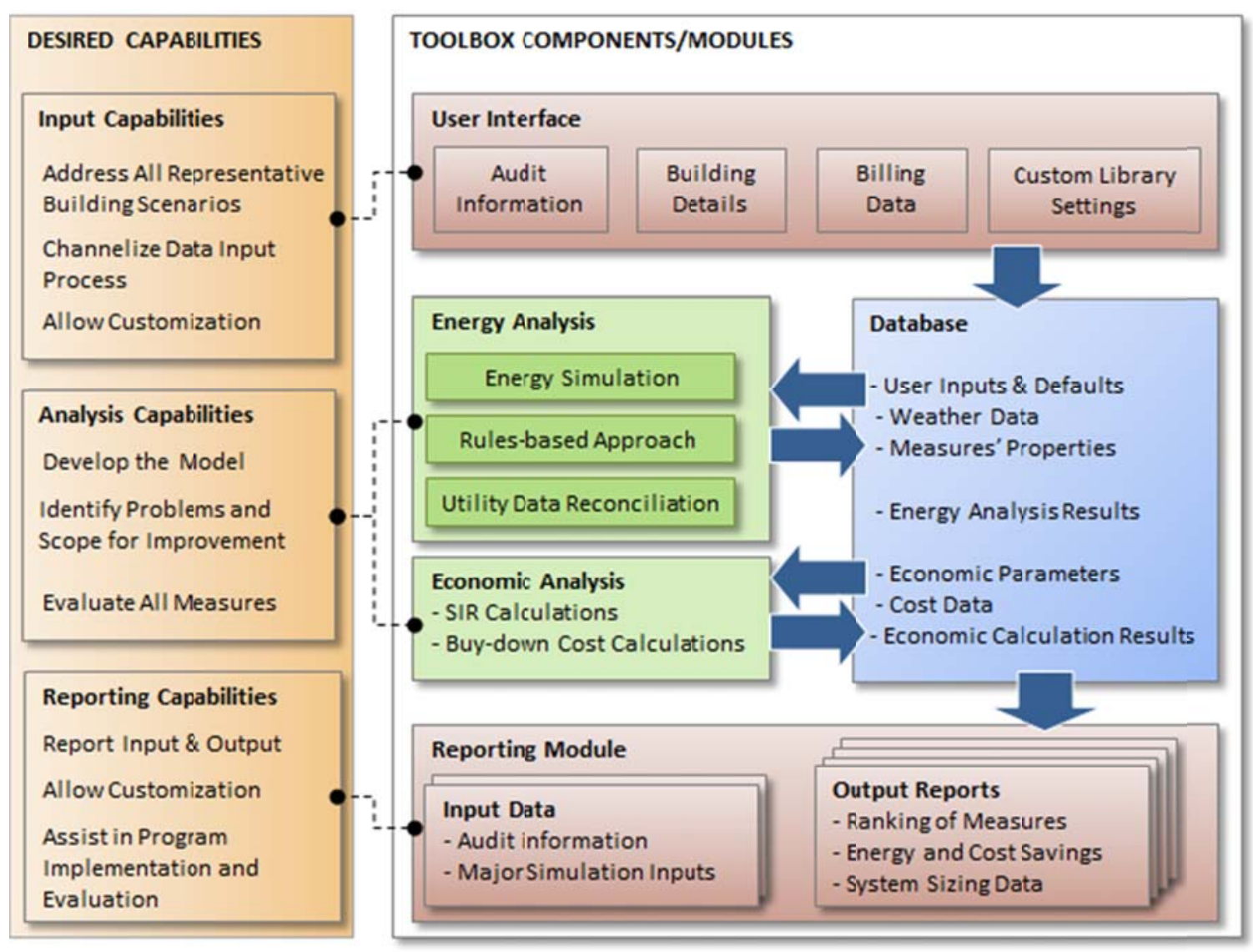

The multifamily energy audit tool is planned to be developed in two versions. Version 1 will handle buildings with simpler configurations, mostly low-rise buildings. Version 2 will increase the energy calculation capabilities to handle more complex configurations and systems. The initial version of the Web-based tool will be simpler, since extensive work is required to develop the initial tool and integrate it into the HES and WAP environments. 


\section{INTRODUCTION}

\subsection{BACKGROUND}

The U.S. Department of Energy's (DOE's) Weatherization Assistance Program (WAP) enables lowincome families to reduce their energy costs by providing funds to make their homes more energy efficient. In addition, the program funds Weatherization Training and Technical Assistance (T\&TA) activities to support a range of program operations. These activities include measuring and documenting performance, monitoring programs, promoting advanced techniques and collaborations to further improve program effectiveness, and training, including developing tools and information resources. The T\&TA plan outlines the tasks, activities, and milestones to support the weatherization network with the program implementation ramp up efforts. Weatherization of multifamily buildings has been recognized as an effective way to ramp up weatherization efforts. To support this effort, the 2009 National Weatherization T\&TA plan includes the task of expanding the functionality of the Weatherization Assistant, a DOEsponsored family of energy audit computer programs, to perform audits for large and small multifamily buildings [1], Project 10.3.5].

\subsection{DEVELOPMENT FRAMEWORK - WEATHERIZATION ASSISTANT}

The Weatherization Assistant comprises the National Energy Audit Tool (NEAT) for energy audits of site-built, single-family homes, and the Manufactured Home Energy Audit (MHEA) for audits of mobile homes, and has been adopted by a substantial number of states in the United States. This instrument has capabilities to help the weatherization agencies administer their work and manage a data base that can be used by the states and DOE to evaluate the program's effectiveness. There are several other tools approved for auditing single-family homes and multifamily buildings that have also been adopted by states. The development of an energy audit tool for multifamily housing types for the Weatherization Assistant would expand the scope of its use and allow agencies to use an integrated approach to manage their weatherization projects.

The development of a Web-based application of the Weatherization Assistant and integration of the components described below into the suite of tools would streamline the process of evaluating and reporting all weatherization activities performed by the networks of local community action agencies, nonprofit organizations, and local governments that provide weatherization services under WAP. A common data base and management capabilities would allow better oversight and management by the states and DOE.

\subsubsection{Web Application of the Weatherization Assistant}

At present, the Weatherization Assistant is a desktop program that is installed and used locally. The current version of the program allows the local weatherization service providers to maintain records on a local server within the agency, which can be accessed and used by several client computers (Figure 1). ORNL is developing a Web-based application of Weatherization Assistant that will allow the program, with all its capabilities, to be hosted on a remote server that is accessed by agencies to run audits, manage their work, and store data (Figure 2). This will allow agencies to be automatically updated about program 


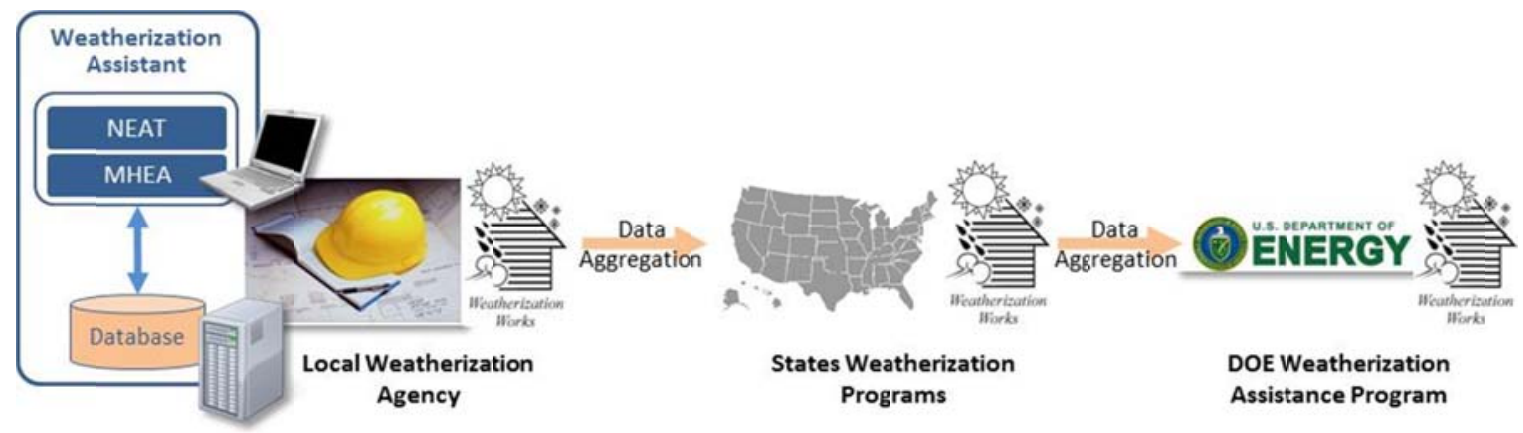

Figure 1. Existing components and use of Weatherization Assistant.

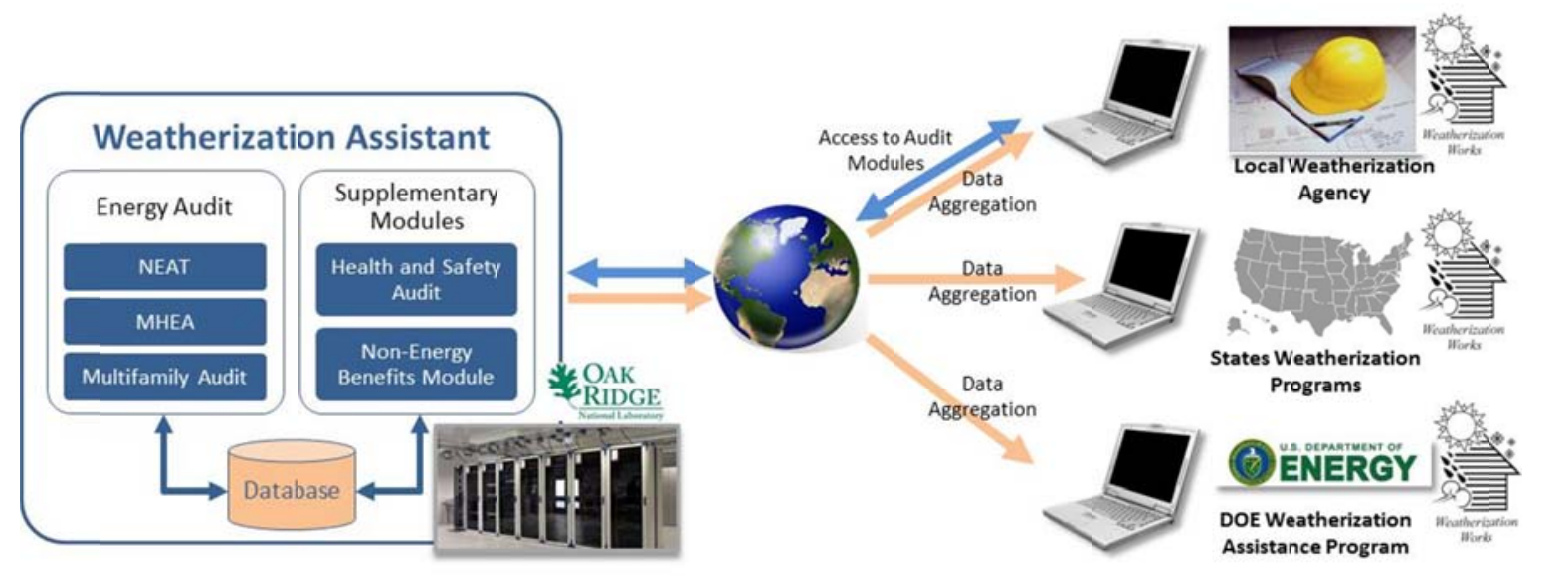

Figure 2. Planned components and use of Web-based Weatherization Assistant.

enhancements and allow the states and DOE to access the data base directly for program evaluation purposes.

The Web-based version of Weatherization Assistant is currently undergoing initial internal testing and is expected to be released for wider testing in Summer 2012 and for use by agencies in late 2012. A screen shot of the current Web-based overall graphic interface frame, with initial NEAT sub-frames, is shown in Figure 3.

\subsubsection{Supplementary Modules}

Health and Safety (H\&S) Module

ORNL is partnering with the HUD Office of Healthy Homes on the development of a health and safety audit tool for use by weatherization service providers. The tool is designed as a stand-alone module that would later be integrated with the Weatherization Assistant. The health and safety items addressed in this module are in line with those that are included in EPA's Healthy Indoor Environmental Protocol [2]. The items include those that (1) are affected by weatherization (e.g., indoor air quality issues aggravated by 


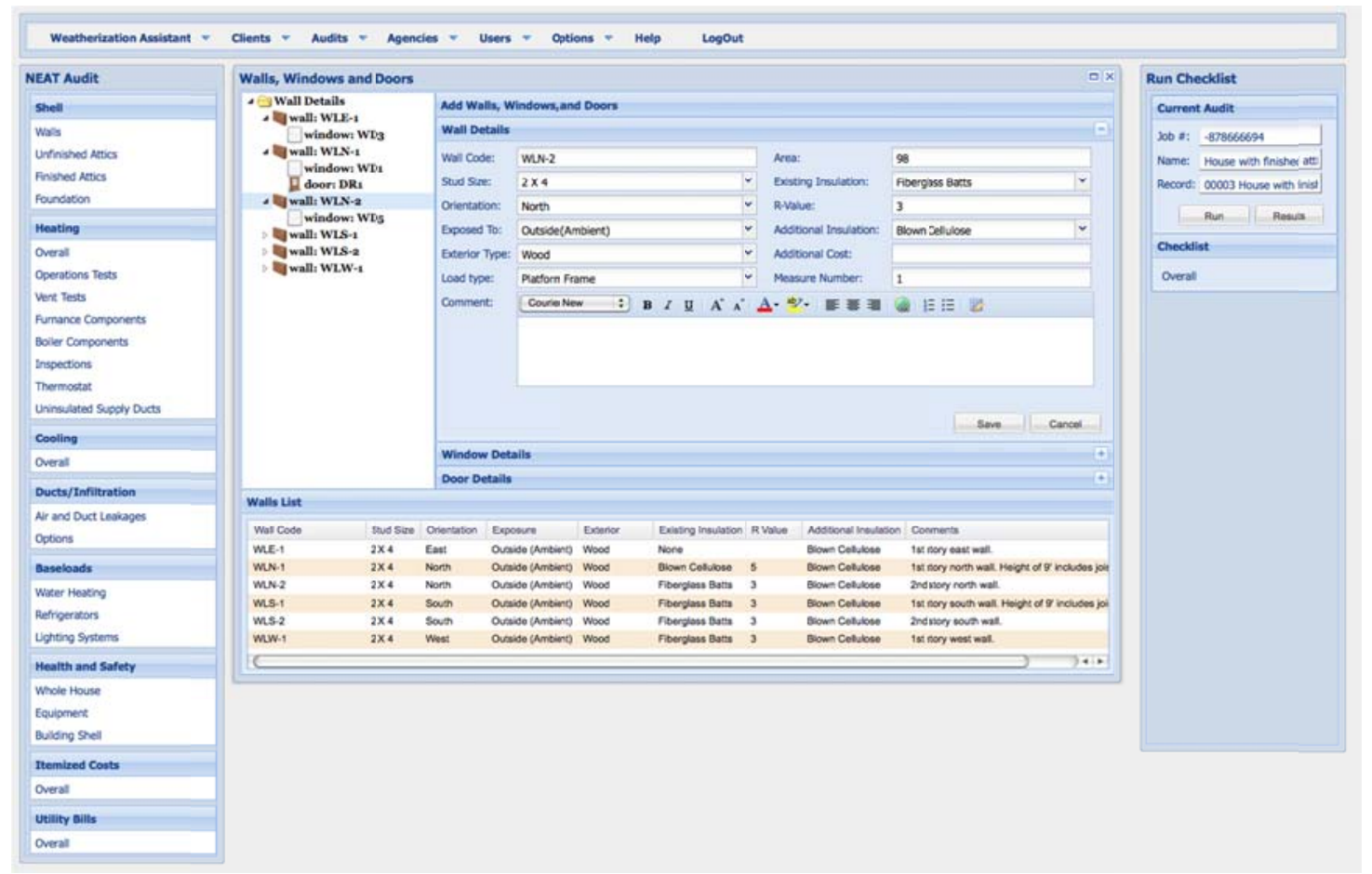

Figure 3. An example screen of Web-based Weatherization Assistant (NEAT audit).

increased air-tightness), (2) affect the way weatherization work is performed (e.g., presumed existence of lead-based paints and asbestos that may require lead-safe weatherization or asbestos abatement), or (3) expose the occupants or weatherization workers to unsafe conditions during or after weatherization. This module will address the H\&S issues that are found in all housing types addressed by the Weatherization Assistant.

\section{Non-Energy Benefits (NEBs) Module}

Several non-energy benefits to the household and society are attributable to the weatherizing of lowincome homes, such as making housing more affordable; improving safety, health, and comfort; positive impacts on household budgets; employment and economic impacts; and environmental impacts [2], 4]. To quantify these benefits, ORNL will develop a non-energy benefits module that will be integrated into the Weatherization Assistant and help the states and DOE with program evaluations.

\subsection{PURPOSE OF DEVELOPMENT PLAN}

The purpose of this development plan is to set the direction for the design and development of the multifamily audit tool. The objectives for the development plan are the following:

1) Identify basic requirements for the multifamily audit tool in view of the target users and their skill levels, characteristics of target buildings, and WAP-specific requirements

2) Gain insights about multifamily audit methods, issues, potential improvements, and desired capabilities through inputs from multifamily audit experts and practitioners 
3) Investigate currently used multifamily audit tools to understand their capabilities and the contexts of their applicability

4) Synthesize the findings in terms of defining the scope and purpose of the tool and prioritizing the needs identified

5) Formulate a conceptual scheme for the design and development of the multifamily audit tool

\subsection{PARALLEL DEVELOPMENT WITH HOME ENERGY SAVER}

The Home Energy Saver (HES) Web site ( http://hes.lbl.gov) is an interactive, do-it-yourself, singlefamily-home energy-assessment tool developed by Lawrence Berkeley National Laboratory (LBNL) to allow homeowners and others to quantify energy savings and environmental benefits from home energy improvements. DOE has directed that HES be upgraded to also handle multifamily buildings, and has directed that both the Weatherization Assistant and HES should use the same engine for calculating energy savings.

While the HES tool and the Weatherization Assistant multifamily tool will use the same energy-savings calculation engine, their input requirements and output reporting requirements are different. Weatherization providers need a user interface specific to their needs, one that integrates with the NEAT and MHEA interfaces. HES users have different needs and require different interfaces and reporting. A handshaking method between the Weatherization Assistant and HES will allow the same calculation engine to be used for both, while maintaining separate user interfaces and output reporting.

The multifamily calculation engine will build on the current HES engine to expand it to cover multifamily buildings. The current engine only treats single-family houses and uses DOE-2.1e integrated with several specialized models for domestic hot water and some appliances. This plan describes the WAP multifamily tool that will be integrated into the HES modeling environment. 


\section{ASSESSMENT OF NEEDS}

This section addresses the first four objectives of the development plan (as listed in Section 0), i.e., to assess the needs of the weatherization program network related to multifamily energy audits and define the scope and purpose for any new tools. Potential needs were examined relative to capability requirements for multifamily audit tools in terms of both functionality (what the tool would be used for) and usability (how the tool would be used). Basic requirements of target users, characteristics of target building types, and target program (WAP) requirements were considered in this examination. Input was also obtained from multifamily audit methods experts and practitioners regarding audit methods, issues, potential improvements, and desired capabilities. Currently used multifamily audit tools were also reviewed relative to issues and desired improvements. The findings form the basis for defining desired capabilities of the audit tool, as well as a development strategy and conceptual scheme of the tool.

\subsection{BASIC CONSIDERATIONS}

\subsubsection{Target Users and Skill Level}

A multifamily audit tool would primarily be used by energy auditors in weatherization agencies for conducting energy audits in multifamily buildings. Related data base functionality is expected to provide data aggregation at the agency, state, and/or national levels to evaluate WAP program effectiveness.

An audit tool should be able to address the needs of target users who have different skill levels and require varying degrees of guidance for use, including level of detail for entering and using diagnostics data. In general, the skill level of a multifamily building energy auditor can be assumed as advanced, meeting the national workforce guidelines for multifamily building energy upgrades (Technical Standards for the Multifamily Building Analyst Professional of the Building Performance Institute [5]) and passing required certification(s) on the national training platform ${ }^{1}$. Multifamily building auditors are expected to be proficient or reasonably proficient in most of the work categories covered in this standard for all modules (though some of the categories under communication and reporting go beyond typical weatherization energy auditor efforts). However, there may be instances when agencies/auditors mostly dealing with single-family weatherization begin to audit small multifamily buildings and require more guidance for performing the audits.

\subsubsection{Target Building Characteristics and Energy Audit Levels}

For WAP energy audit purposes, DOE considers multifamily buildings to be those containing five dwelling units or more. DOE's criteria for further classification of multifamily building type is based on the number of units (less than 25 units as small multifamily and more than 25 units as large multifamily buildings) and system type (central versus individually heated and cooled units); these classifications determine the selection of an energy audit tool. Small multifamily buildings with individually heated and cooled dwelling units can sometimes be audited using single-family audit tools. Large multifamily

\footnotetext{
${ }^{1}$ The workforce guidelines and training platform modules of the technical standards are currently in development. Until they are finalized, the interim standards document can be consulted to understand the skill levels required.
} 
buildings or small multifamily buildings with central heating and cooling systems require audit methods with broader capabilities.

Microdata from the 2005 Residential Energy Consumption Survey (RECS) were used to estimate some building and system type populations for multifamily buildings with five or more units ("MF 5+" buildings). Figure 4 shows the distribution of dwelling units in the U.S. by major census regions. There are approximately 17 million dwelling units in MF 5+ buildings in the United States, with about $35 \%$ of these being in the South region, and less than $20 \%$ of these being in the Midwest region. Although RECS data do not address multifamily buildings directly in the data, a check of the data using derived parameters indicates that the distribution of buildings by region appears to be

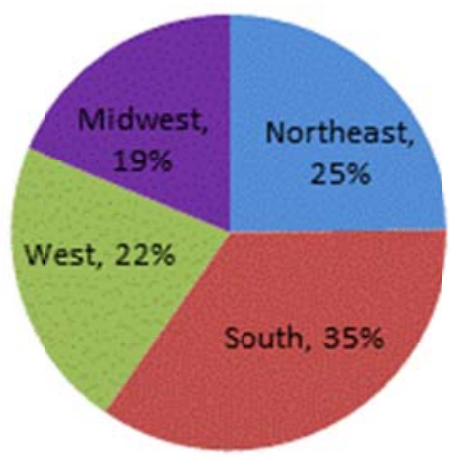
approximately the same as the distribution of the dwelling units by region. Thus, it can be deduced that the average number of dwelling units in MF 5+ buildings is about the same in all four regions. Furthermore, according to DOE's definitions of small and large multifamily buildings (see Section 2.1 .2 ), $70-80 \%$ of all MF 5+ dwelling units are in "small" buildings in all four regions.

The complexity of heating and cooling systems in residences is addressed partially in RECS by the heating system type. The population of complex systems was estimated by adding the EQUIPM parameter data (i.e., type of heating equipment, question D-2 of 2005 survey questionnaire) [6] for steam/hot water systems and "some other equipment." This approach should give a reasonable estimate of the actual populations, as all the remaining types of heating systems are fairly simple and are almost always individual to each dwelling unit. This method shows that about one-fourth of all dwelling units in MF 5+ buildings have more complex systems, and about three-fourths have simpler systems. The distribution by region shows some more important differences. Figure 5 shows a distribution of dwelling unit populations with simpler and complex systems by major census region. It indicates that complex systems are dominant in the Northeast, with decreasing prevalence in the Midwest, South, and West.
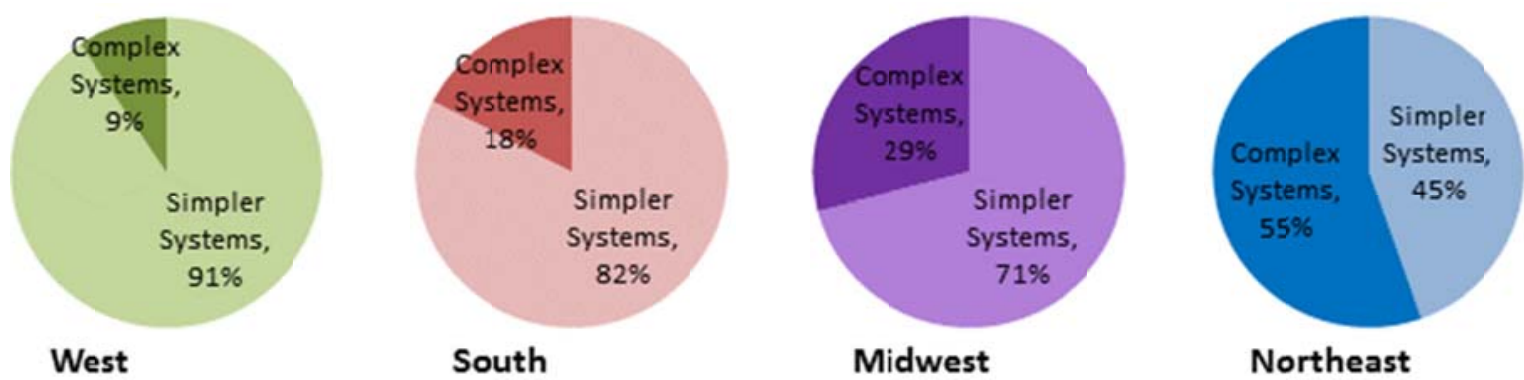

Figure 5. Distribution of MF 5+ dwelling units by system types in major U.S. census regions. 


\subsubsection{WAP-Specific Requirements}

The requirements indicated in the Weatherization Assistance Program rules and regulations (in 10 CFR Part 440, Ref. 7) and program guidance documents (i.e., Weatherization Program Notices, or WPNs) that are relevant to the development of the multifamily audit tools are the following:

- Allowable measures: Only weatherization measures which are listed in Appendix A to 10 CFR Part 440 [8] and which meet or exceed standards prescribed therein can be installed with federal funds, although DOE can approve an unlisted material upon application from any state. Incidental repairs necessary for the effective performance or preservation of weatherization measures can be performed as long as the package of measures installed in the building has a savings-toinvestment ratio (SIR) greater than or equal to 1.0. Health and safety measures can be implemented following the state's health and safety plan. Costs for health and safety measures are NOT included in the SIR calculation for the package of measures. These rules indicate the type of measures to be included in the audit tool and requirements for economic calculations.

- Considerations for energy analysis and selection of measures: WAP requires that the energy audits must take into account the local climate, be based on generally accepted engineering calculations or energy requirements of the dwelling from actual bills, address significant heating and cooling needs, utilize advanced diagnostic and assessment techniques, identify health and safety measures to be handled with DOE funds, treat the dwelling unit as a system, and account for the interaction between architectural and mechanical measures. Energy measures must be cost-effective (have an SIR greater than or equal to 1.0), and their selection must be in the descending order of their cost-effectiveness.

- Use of prevailing labor rates for calculating the cost-effectiveness of measures: WAP work has historically not been subject to Davis-Bacon Act (DBA) prevailing wage requirements, but the American Recovery and Reinvestment Act of 2009 introduced new requirements for DBA reviews and surveys (per WPN 09-9, Ref. 9). In cases where a wage determination leads to higher wage categories than weatherization worker being required for some types of measures, WPN 1004 [10] allows grantees and subgrantees to use the weatherization worker wage to calculate the cost of installing measures for purposes of SIR calculation.

- Allowance for using non-federal resources as a buy-down for meeting SIR: WAP guidelines allow states to require owner contribution or use non-weatherization funds towards implementing measures that have an SIR of less than 1.0 (WPN 10-17) [11]. Thus, the intent is to allow the SIR for a specific measure to be calculated using just the federal investment rather than the total cost, which in some cases may make the measure cost-effective (with an SIR greater than or equal to 1.0) when it would not have been cost-effective if the SIR had been calculated using the total cost.

- Health and Safety measures: ASHRAE Standard 62.2-2007, Ventilation and Acceptable Indoor Air Quality in Low-Rise Residential Buildings, must be followed starting in 2012 (see Ventilation in the table in WPN 11-06 [12]). The applicability of this to multifamily buildings needs to be determined. Rules and guidance regarding how to apply other health and safety measures under the Weatherization Program are also outlined in WPN 11-06. 


\subsection{NATIONAL INPUT}

To gain a better understanding of the scope of issues, the strategy for completing the development plan on the multifamily national energy audit included obtaining input about potential improvements to multifamily building energy audit tools from people from around the country who currently conduct or manage multifamily energy audits. The objective of obtaining pertinent inputs on functionality and usability aspects of the audit tool indicated a need to gather information on energy audit methodologies and field practice of energy audits. Thus, two national Web-based meetings were held with two groups of participants: (1) multifamily energy audit method experts, on November 4, 2010, and (2) multifamily audit users, on November 10, 2010. Table 1 shows the topics covered in the two Web meetings. The topics discussed in the users group meeting were partially based on some of the comments made during the meeting of audit method experts. Further feedback from the participants was requested through email. Highlights from these meetings are presented in the following sections of this report by major categories: building types audited, experience with existing audit tools, improved analysis capabilities, additional measures, and other features. The agendas, full transcripts, ${ }^{2}$ and attendee lists for the two national Web meetings are presented in appendices A, B, and C. Certainly the expertise, as well as the topics of discussion, overlapped in both meetings. However, the inputs were provided from two different perspectives.

Table 1. Broad area topics covered in Web conferences

\section{Audit Methods Experts Group $\quad$ Audit Users Group}

\begin{tabular}{lll}
\hline - Fundamental issues & $\bullet$ & Discussion of users' work on multifamily \\
o Audit tools - pros and cons & & energy audits \\
o What basic approaches or methods should a & - Energy measures \\
$\quad$ proposed new national audit consider? & - Pre-audit issues: toolbox, setup, financial \\
o Simulation tools vs. expert-system-rules- & - Energy use calculations: baselines, measures \\
based methods & - User interface / input capabilities \\
- Baseline utility bill analysis & - Non-energy measures \\
- Energy use calculations & - Financial calculations \\
- Energy measures & - Reporting capabilities \\
- Non-energy measures & \\
- Financial calculations & \\
- Reporting capabilities & \\
\hline
\end{tabular}

\subsubsection{Types of Multifamily Buildings Audited}

The users group meeting included discussions about the audit experience of the attendees and received input in the contexts of Chicago, Wisconsin, Colorado, California, and New York. The input indicated that small multifamily buildings to high-rise apartments are found in almost all states. Small multifamily

\footnotetext{
${ }^{2}$ The transcripts are edited to improve reading flow and eliminate redundant starts and stops and thought restatements or change of word choice in spoken discourse, while maintaining the unaltered premises of participants' statements.
} 
buildings being audited range from up to three-story walk-up buildings with central steam heating systems to garden style apartments with individual HVAC systems (and sometimes a central system for common areas).

\subsubsection{Experience with Existing Audit Tools}

The users group indicated that TREAT (Targeted Retrofit Energy Analysis Tool) appears to work well for states that are in heating-dominated climates, have smaller multifamily buildings, and where allowable heating system measures may be limited. EA-QUIP (Energy Audit using the Queens Information Package) works well for larger multifamily buildings with a single primary central heating system and no cooling. AEA (Association for Energy Affordability) indicated that work on incorporating capabilities for handling ventilation systems in EA-QUIP is in progress. (Descriptive information on these audit tools is found in Section 2.3.)

TREAT and EA-QUIP are likely to continue to be used where they are most helpful, and the proposed new tool should have an important goal of providing improved (extended) simulation capabilities that can handle multiple heating or cooling systems, as well as providing integrated capabilities for handling rulesbased savings analyses.

For measures that are not readily modeled using energy simulation, e.g., heating or cooling control system and distribution system measures, savings are typically handled using rules on expected savings, and then the analysis is "tricked" into providing the correct results.

\subsubsection{Desired Improved Analysis Capabilities}

The limitations of the existing tools in handling the following areas indicated the need to consider addressing these concerns in the proposed new audit tool.

- Multiple heating systems: Existing DOE-approved multifamily audit tools require that a building be modeled as having one heating system, and the building may need to be analyzed as one major heating zone. Practitioners must now devise methods of "tricking" the energy calculation tools into providing a correct "one-system" answer, when multiple heating system types would allow better and easier energy modeling.

- Ventilation (natural and mechanical) and associated measures: There was concern about how to handle ventilation system measures and treating issues of adequate or excessive ventilation with existing tools.

- Distribution systems (pipes, ducts, tank losses): Methods of modeling distribution systems and components are limited in most energy simulation tools, and specialized methods are often needed to handle energy impacts of system components and potential savings for proposed improvements. Improved methods of handling distributions systems were considered important, and more development work may be needed to do this effectively.

- Impact of sensor location and controls: Many control measures cannot be modeled directly with typical energy calculations found in energy audit tools or energy simulation programs. 
Improper control sensor location is one example: substantial energy savings may be possible through correction, but standard energy calculations do not handle this issue directly. This is an example of where rules-based savings calculation methods can be important.

- System degradation and tune-up/maintenance-type measures: Another example of an area where rules-based estimates of savings are important is degradation of energy system performance with increasing age. Similarly, if system tune-up or maintenance-type measures are appropriate, rules-based estimates of savings are usually needed.

- Effect of water main temperature on domestic hot water energy use: Domestic hot water energy use is affected by incoming water main temperatures, especially when surface water is the source, so methods of handling water source temperature were considered important. Some means of requiring audit inputs to reflect the type of water source would help in this area.

- Comparable system efficiency input: The tool should make heating and cooling equipment efficiencies readily apparent to allow the user to ensure that the correct (comparable) efficiencies are being used in any savings calculations.

- Multiple-fuel systems: Some means of simplifying the handling of multi-fuel systems would be useful, but this may simply be some type of added feature that converts fuel use data to appropriate tool input data.

- High-quality heating or cooling load calculations: The capability to perform high-quality heating or cooling load calculations for system sizing calculations was recommended, and we anticipate that the proposed improved simulation engine will include this capability.

- Utility bill analysis: For utility bill analysis, disaggregation of end-use energy was identified as an important need. Having access to reasonably recent weather data, especially outdoor temperature data, is valuable for supporting ease of data analysis in these areas. Extensive work is in progress around the country to make "real-time" simulation tool weather data available to potential users, and these efforts may allow easy access by users to such data, possibly at no charge.

- Thermal short-circuits: A special concern was raised about some types of concrete building construction, where major thermal shorts in the building structure have been observed, such as floor slabs that are not thermally isolated. ${ }^{3}$ Special rules may be needed for modeling of such constructions.

- Financial calculations: Concerns were raised about using actual utility rates for financial calculations, and also allowing multiple rates at one time (e.g., where common areas and dwelling units are on different rate schedules). Auditors may need to be able to specify different options for handling financial calculations, depending on the situation.

\footnotetext{
${ }^{3}$ Dennis Nelson of BC Hydro has results from thermal studies of 39 high-rise apartment or condo buildings in Vancouver that indicate large heat losses from thermal shorts.
} 
Financial calculations for multifamily buildings can also have process issues and impacts, depending on how important it is to influence the building owner to invest in buy-down of certain measures.

- Expert system for rules-based savings estimation: A fundamental issue identified in the national experts meetings is the need for integration of simulation calculations with rule-based savings calculations. Simulations cannot handle many types of retro-commissioning or redesign types of measures, except by "tricking" the simulation to calculate expected "rule-based" savings. Most of these hard-to-quantify or hard-to-model loads and system components and associated measures are currently handled by the judgment of the auditor. Integration of rule-based methods into the overall energy audit and energy calculation methods should be made a direct part of the process.

Expert-system-type rule-based savings derive from research studies, field verification of savings studies, or simple direct savings calculations where savings calculations are known to be reliable (e.g., some lighting measures). An important advance in tool capabilities for multifamily buildings would be to integrate simulation and rule-based calculations in a useful way in one tool. Most simulation tools, including EnergyPlus, do not presently integrate rule-based methods with simulation methods. NEAT and MHEA currently do integrate both methods.

- Expert system for audit guidance and process adaptation: The audit method experts felt that auditors must have additional training and expertise to be able to handle multifamily buildings and that auditor judgment was important in the overall process. The user group indicated that expert-system-type capabilities would be helpful for tasks such as guiding diagnostics on the heating system, sensor placement, and evaluating the ventilation system. Also, such guidance might take auditors through some aspects of the audit process, including selection of the correct building configuration and modeling requirements.

For some energy efficiency measures, energy audit process flow may also require adaptations. For example, if controls and sensor placement measures are addressed directly, system testing procedures and checks may need to be inserted into the overall process. Similarly, enhanced capabilities for ventilation systems may require process adaptations, and blower door methods may also need alternate processes. Again, these potential needs suggest a need for some expert rules-based guidance through the process.

- Caution about doing too much: Concern was also raised about trying to have any new multifamily audit tool try to do too much, as it could become unwieldy and possibly too large to keep functioning well. Therefore, development should be approached with some caution about trying to do too much at once.

\subsubsection{Additional Measures}

The user group meeting had fairly extensive discussion of potential energy measures. Concern was voiced about the need to allow state-by-state configuration of the multifamily tool relative to measures covered, and introduction of this tool may raise issues for some states regarding exactly what measures are 
included for the state, since use of the tool is likely to suggest that state measures for multifamily buildings should be broader than currently approved, possibly in many cases.

California also had some recommendations that appear to be primarily applicable there, but also might apply elsewhere:

- Adding conversion of steam heating systems to hot water heating systems as a measure: Estimating energy impacts of converting heating systems from steam to hot water may require energy use index (EUI) comparisons for acceptable savings estimates to be generated, as some steam systems are very efficient. The benefits of hot water conversion often arise from correction of major steam system zoning or balancing faults. This measure may not be possible to include unless field studies can verify some means of savings determination that are reliable enough to allow rules-based savings methods to be developed.

- Adding retro-commissioning (retro-cx) as a meta-measure: Energy-based retro-cx addresses several scheduling, controls, distribution system, pump, and other operational-type measures at one time in a package. Since controls systems are part of the package, retro-cx typically has a lifetime of about four years, which is why continued performance tracking is often recommended as part of retro-cx activities. For the WAP, the controls-based measures probably need to remain as controls-based measures, and any system component / repair items that would be covered under retro-cx activities would be part of required repairs to make the efficiency measures work. Some program guidance would probably be needed from DOE to allow this meta-measure to be included in the program.

- Co-generation systems: Co-generation (or possibly tri-generation) systems in multifamily buildings produce both electric and thermal energy. Combined heat and power (co-generation or CHP) in multifamily buildings has been an initiative of the HUD Energy Action Plan, and several CHP analysis tools have been developed by HUD. Version 2.1 of a level 1 analysis tool (HUD CHP Screening Tool) can be found at: http://portal.hud.gov/hudportal/HUD?src=/program offices/comm_planning/library/energy/software.

The HUD portal Website also has case study information on CHP systems in multifamily buildings (search on "CHP"). CHP systems require a significant investment but also can produce major savings in energy, carbon, and cost. WAP guidance on these measures is not available currently, but if owners are interested in investing and energy auditors wish to evaluate CHP systems, they should check the level 1 HUD tool to be able to present a first-level report. Firstlevel analyses are typically used to determine whether specialists in CHP should be brought in to perform a level 2 analysis. More information on CHP project development can be found in the most recent version of the EPA CHP partnership guide (http://wwwl.eere.energy.gov/industry/ distributedenergy/pdfs/chp project development handbook.pdf), and HUD has also introduced an initial version of a level-2 analysis tool. See links to ORNL Level-2 tool and CHP Guide \#3 at http://portal.hud.gov/hudportal/HUD?src=/program_offices/comm_planning/library/energy .

CHP system analysis is complicated, especially since some electric utilities have punitive rate features that have the effect of making CHP systems hard to justify. Incorporation of CHP 
systems into the multifamily energy audit tool is probably not appropriate, since the HUD tools can be used.

- Solar thermal systems: While energy analysis of solar systems has been greatly simplified with the development of tools such as f-chart, the wide range of potential incentives (rebates, tax exemptions, etc.) makes analysis of solar systems complicated. Solar water heater systems are already part of WAP program measures, but guidance has only been developed so far for singlefamily systems. Rules-based approaches for specific locations are probably the best way to handle multifamily solar hot water systems, and calculations probably have to be developed state by state. The extra development effort within the new multifamily tool project is not expected to be feasible given available resources at this time. NEAT and MHEA do not handle these systems, and high maintenance requirements indicate caution before recommending this measure.

- Photovoltaic (PV) systems: PV systems are not currently allowed as part of regular WAP efforts. DOE began providing grants for pilot projects in 2010 for high-performing WAP agencies to include installation of PV systems, but it appears to be too early to try to incorporate this type of measure into a standardized energy audit tool. Without subsidies of some type, the SIR is not likely to be greater than 1.0 for PV systems, and typical SIRs for PV systems will be less than 0.25 without subsidy.

- Swimming pool measures: Circulation pump and pool sweep measures, chlorination system measures, solar pool heating, pool covers, and possibly others could be effective energy-saving measures in multifamily properties that have pools, but at this time it does not appear that WAP should be handling such measures.

\subsubsection{Integration of Other Features/Capabilities}

- Ability to add or modify calculations, probably using expert rules-based approaches: Some means of allowing rules-based calculations to be added may be desirable at some point for the standard multifamily audit procedure, but the most reasonable way to handle such cases appears to be as a calculation external to the energy audit, as is needed for some special measures now, such as solar hot water.

- Energy benchmarking: Capabilities for energy benchmarking, either to generate building performance ratings, for comparisons of energy use indexes (EUIs) before and after energy measures are installed, or to identify savings potential and scope for improvements, received strong support in the users group meeting. However, a source of acceptable data to develop a benchmarking tool was not readily identified. HUD has developed a tool, but discussion indicated that a better tool with more types of indicators was desirable. Data may be available for the Chicago area, but some development work is needed before that data could be adapted to a benchmarking method.

Heating energy EUI has been found to be the best indicator of potential energy savings in the Chicago area, and use of EUIs can be important for presentation to building owners to indicate performance of their buildings compared to peers, as well as likely savings to be achieved. The 
most appropriate index to use may vary by location. Tracking of EUI following energy measure installation can also be important for verifying savings to building owners.

Several types of EUI data can be valuable to practitioners in comparing baseline energy use for buildings to an external reference, such as an EUI data base. The Energy Star program ${ }^{4}$ uses such EUI data bases to develop tools, and a multifamily EUI comparison tool is reported to be in development. Other types of EUI than typically used by Energy Star may also be important.

\section{- Tracking of utility bills for continuous evaluation of building energy performance:}

Capabilities for tracking performance over time could be helpful for reporting performance for individual buildings, and to the extent that many buildings have performance tracked over time, potential exists to streamline program evaluation efforts. Since control system measures usually have a lifetime of 2-7 years before problems begin to occur, continuous tracking of energy performance can be important for buildings with more complex energy systems to maintain efficient performance of the building. The energy audit process might take on a more continuous nature that blends with continuous evaluation, if utility bill tracking can be made easy to use and manage.

- National and state data bases on expert-based energy-savings factors: For many measures, savings estimates rely on rules-based approaches based primarily on results from research studies or local savings verification studies. A national data base on savings and installation costs of energy measures would allow more sharing of results, as well as improved understanding of the basis of expert rules-based savings calculations. Such a data base might also provide regional or building type breakdowns if savings vary by region or building type. NREL is already maintaining a data base on installation costs of residential energy measures, but a data base on multifamily buildings may be more complicated and is likely to emphasize different types of measures. Such a data base is not expected to be directly included in current tool development efforts, but the concurrent data base capabilities to support such a resource could be expanded if DOE should choose to support such an effort.

- Health and safety measures: Diagnostics on health and safety issues were also discussed. It was recognized that the integration of a health and safety module or non-energy benefits module with the multifamily audit process may have impacts on how the process flows. The addition of health and safety measures is expected to be handled incrementally (most important types of measures

\footnotetext{
${ }^{4}$ The Energy Star Portfolio Manager currently allows multifamily buildings to be entered as a space type by users to receive energy performance information or results, but multifamily housing communities are unable to receive a 1100 rating at this time. Alyssa Quarforth, Energy Star National Program Manager for Commercial Properties, told us that the program is currently exploring potential multifamily housing data sets for use in development of a 1-100 energy performance rating. The performance information provided by Portfolio Manager at this time does allow comparisons across a portfolio, and covers energy and water performance over time using various metrics, including weather normalized energy use index (annual energy use per square foot of floor area), percent energy reductions over time, water performance tracking, and energy and water cost tracking. Portfolio Manager also now allows users to designate their "metering scenario" (e.g., master metered, directly metered, etc.) so that they can better compare like properties.
} 
as soon as feasible, and other measures later). The addition of non-energy benefits capabilities is not expected to occur until a multifamily tool has been used in the field for a while.

\subsection{CURRENTLY USED TOOLS FOR MULTIFAMILY ENERGY AUDITS}

As stated in WAP guidance (WPN 11-01, Ref. 13), DOE has given general approval for use of EA-QUIP and TREAT for multifamily audits under WAP. For multifamily buildings containing up to 25 individually heated and cooled dwelling units, certain single-family energy audits may be used, including NEAT. Up to this point, DOE has not developed a tool for audit of multifamily buildings, as it did for single-family and mobile homes, but has relied on commercially available tools for the Weatherization Assistance Program. Input from several states indicated that eQUEST was used at times or its approval by DOE had been requested. DOE handles requests for special approval on a case-by-case basis. Outside WAP, use of eQUEST is more common, but EA-QUIP and TREAT-MF are also used, as well as other tools, including special-purpose proprietary tools. A comparison of some characteristics of these tools and NEAT is provided in Table 2.

Table 2. Comparison of multifamily building audit tools

\begin{tabular}{|c|c|c|c|c|}
\hline & eQuest & EA-QUIP & TREAT-MF & NEAT \\
\hline $\begin{array}{l}\text { WAP } \\
\text { applicability }\end{array}$ & $\begin{array}{l}\text { Case-by-case } \\
\text { basis }\end{array}$ & $\begin{array}{l}\text { Allowed for small and } \\
\text { large multifamily } \\
\text { buildings }\end{array}$ & $\begin{array}{l}\text { Allowed for small and } \\
\text { large multifamily } \\
\text { buildings }\end{array}$ & $\begin{array}{l}\text { Allowed for small } \\
\text { multifamily buildings }\end{array}$ \\
\hline $\begin{array}{l}\text { Calculation } \\
\text { engine/ } \\
\text { method }\end{array}$ & $\begin{array}{l}\text { DOE-2.2 hourly } \\
\text { simulation } \\
\text { program }\end{array}$ & $\begin{array}{l}\text { CIRA, based on } \\
\text { variable-base degree } \\
\text { day calculations }\end{array}$ & $\begin{array}{l}\text { SUNREL thermal } \\
\text { network model }\end{array}$ & $\begin{array}{l}\text { CIRA, based on } \\
\text { variable-base degree } \\
\text { day calculations }\end{array}$ \\
\hline Developer & Jeff Hirsch & $\begin{array}{l}\text { Association for } \\
\text { Energy Affordability, } \\
\text { Inc. }\end{array}$ & $\begin{array}{l}\text { Performance Systems } \\
\text { Development }\end{array}$ & WAP / ORNL \\
\hline Features & $\begin{array}{l}\text { Capable of } \\
\text { handling multiple } \\
\text { zones and } \\
\text { multiple systems }\end{array}$ & $\begin{array}{l}\text { Single-zone model, } \\
\text { central systems focus }\end{array}$ & $\begin{array}{l}\text { Capable of handling } \\
\text { multiple zones and } \\
\text { multiple systems }\end{array}$ & $\begin{array}{l}\text { Single-zone model, } \\
\text { multiple HVAC } \\
\text { systems }\end{array}$ \\
\hline $\begin{array}{l}\text { Utility bill } \\
\text { input }\end{array}$ & Not available & Required & Required & Optional \\
\hline Availability & Free & $\begin{array}{l}\text { License fee by } \\
\text { number of buildings }\end{array}$ & License fee by year & Free \\
\hline Software use & Desktop & $\begin{array}{l}\text { Developed as desktop, } \\
\text { converted to Web }\end{array}$ & Web & $\begin{array}{l}\text { Desktop, Web-based } \\
\text { under development }\end{array}$ \\
\hline Source & www.doe2.com & www.ea-quip.com & www.psdconsulting.com & weatherization.ornl.gov \\
\hline
\end{tabular}




\subsubsection{EA-QUIP}

EA-QUIP (Energy Audit using the Queens Information Package) is a tool for analyzing energy use and energy efficiency measures in multifamily buildings. EA-QUIP was adapted from the Computerized, Instrumented, Residential Audit (CIRA) developed in the early 1980s at LBNL. It has recently been migrated to an entirely online format.

EA-QUIP determines economically optimal mixes of energy-saving measures for a given building. It has retrofit measure and cost libraries. The program analyzes potential energy savings applicable to a building and presents the measure results in the order of decreasing SIR. EA-QUIP provides preformatted energy and economics reports. Advanced features include a three-stage automated process of measure package selection, economic optimization, and presentation of combined package results.

The current Web-based system has increased user interaction and friendliness and helps users through the process of using the tool. As described previously, the Weatherization Assistant is also migrating to a Web-based system because of the advantages of the Web interface.

The full on-line version of the EA-QUIP software is available from the Association for Energy Affordability, Inc. (AEA) for a user license fee. The license fee is based on the number of buildings modeled with the software, and is pre-paid based on the number of buildings the user expects to model.

\subsubsection{TREAT Multifamily}

The Targeted Retrofit Energy Analysis Tool (TREAT) was developed and is supported by Performance Systems Development (PSD) in Ithaca, NY. The New York State Energy Research and Development Authority funded initial TREAT development as part of their Building Performance Market Enhancement Initiative. The TREAT environment integrates fuel bill analysis, weather data, and building modeling information into a data base environment, as well as handling tracking of energy use and savings. TREAT includes an extensive built-in library of building components for quick selection of existing and improved building components and handles calculation of electrical energy breakouts for appliances and lighting.

TREAT is available from PSD in single-family or multifamily versions. The single-family version is designed to handle smaller, 1-4-unit buildings and manufactured homes, and the multifamily version (TREAT-MF) is designed to handle buildings with more units, but is also capable of modeling singlefamily homes and manufactured homes.

\subsection{3 eQUEST}

eQUEST® (Energy QUick ESTimator) is billed as a sophisticated, freeware building energy use analysis tool based on a DOE-2 engine (version 2.2) for those who have less energy analysis experience and need some help starting and/or those who want a quick answer to energy simulation questions (http://www.doe2.com). This software provides multiple wizards, including schematic and design development building creation wizards and an energy efficiency measure wizard. Extensive tabulated and graphical results are provided. Although it is billed by providers as a quick-answer tool, it is routinely used by sophisticated energy professionals for extensive analyses on buildings of all sizes, including the 
energy analysis for the recent multi-million square foot renovation of the United Nations complex in New York City.

The popularity of eQUEST arises partly from its wizards and partly from the extensive DOE-2 output that is available, and its availability as a free download is also a major cause for user selection. One important issue is that the default values of the base tool are often not acceptable for more sophisticated analyses, but the tool allows use of more flexible DOE-2 input that "bypasses" the defaults. eQUEST was developed because DOE-2 input is complicated and tricky, and eQUEST uses input/output code templates to help make the automation of the simulations more tractable.

\subsubsection{Other Simulation Programs and Tools}

DOE-2 is the "Granddaddy" of building energy simulation software and is available in many versions, several of which have been compiled into graphical environments. DOE-2 was developed by DOE and others over more than 20 years until the late 1990s, when EnergyPlus, which was - very roughly - a melding of BLAST and DOE-2, began to be developed as the energy simulation software of choice for DOE. BLAST was an energy simulation program developed by the Department of Defense for their use and was originally derived from software developed by the predecessor of the National Institute of Standards and Technology. Development of DOE-2 by DOE was discontinued because, among other reasons, it was becoming very difficult to upgrade and maintain. Some development of DOE-2 has continued by private entities $[14,15]$. One minor irritation with EnergyPlus is the continual upgrades that often cause disruptions in continuity.

EnergyPlus coding is, in many ways, more complicated than DOE-2, although usually not more tricky; and since EnergyPlus coding is highly verbose, typically requiring thousands of lines more than DOE-2 input, DOE has had code input generators (called "Example File Generators") developed. DOE has relied on national labs and third-party developers to create front-end and back-end automation of EnergyPlus, but publicly available automation capabilities are lagging current tools developed using DOE-2.

DOE and others have developed several highly automated tools for energy audits or assessments that use DOE-2 as the simulation engine, including:

1. Buildings Cooling, Heating, and Power Systems (BCHP) Screening Tool - Assesses the economic potential of these systems and a wide array of energy measures in commercial buildings. The tool features data bases for HVAC equipment, electric generators, thermal storage systems, prototypical commercial buildings, and climate data. It also includes a highly automated DOE-2.1e engine to calculate heating, cooling, and electrical loads. Available as a free download.

See http://www1.eere.energy.gov/industry/bestpractices/software facilities.html and http://www.coolingheatingpower.org/about/bchp-screening-tool.php.

2. Multifamily Cooling, Heating, Power (CHP) Level 2 Tool, Beta 3 - Structured to perform parametric analyses between a baseline building, typically a conventional multifamily building without a CHP system, and up to 25 alternative scenarios with varying selections for building mechanical systems and operating schedules, including CHP systems. Uses DOE-2.1e as the simulation engine. Available as a free download.

See http://eber.ed.ornl.gov/MF_CHP/. 


\section{CALCULATION ENGINE}

Development of Home Energy Saver (HES) began in 1994, and the HES Website first went online in 1996. This tool was originally sponsored by the Energy Star program, operated by EPA and DOE. HES uses multiple calculation applications for its purposes. The energy consumption for most types of heating and cooling equipment is calculated using the DOE-2 building simulation program (version 2.1e). National input on potential development of a multifamily energy audit tool indicated that DOE-2.1e is the calculation engine that would best meet the needs identified by users and experts.

Given the previous extensive development of HES and direction from DOE to base both a new HES multifamily tool and the proposed Weatherization Assistant multifamily tool on the same energy-savings calculation engine, use of DOE-2.1e was strongly indicated. Since expert and user input from across the country also indicated the same, DOE-2.1e was chosen as the basic, underlying energy calculation engine.

\subsection{HES OPERATING ENVIRONMENT}

LBNL is expanding HES capabilities to handle multifamily buildings, and ORNL is upgrading the Weatherization Assistant. Both the HES and Weatherization multifamily tools will use the HES energy calculation engine, which will operate in the HES computing "cloud." The following description of application programming interfaces (APIs), which comprise the bridges between the modeling capabilities of HES and the user interface for the user interface for the Weatherization Assistant tools, is from the online, public documentation of HES, at https://sites.google.com/a/lbl.gov/hes-public/apis.

HES uses what are called "APIs" (or application programming interfaces) to power its own Websites and to make underlying data and calculations available to others.

From a high level, the HES system architecture is divided into layers (Figure 6). At the base of the system (bottom of the diagram) is the data layer. The data layer contains internal data bases and external data services that allow the data to be tapped and used in calculations.
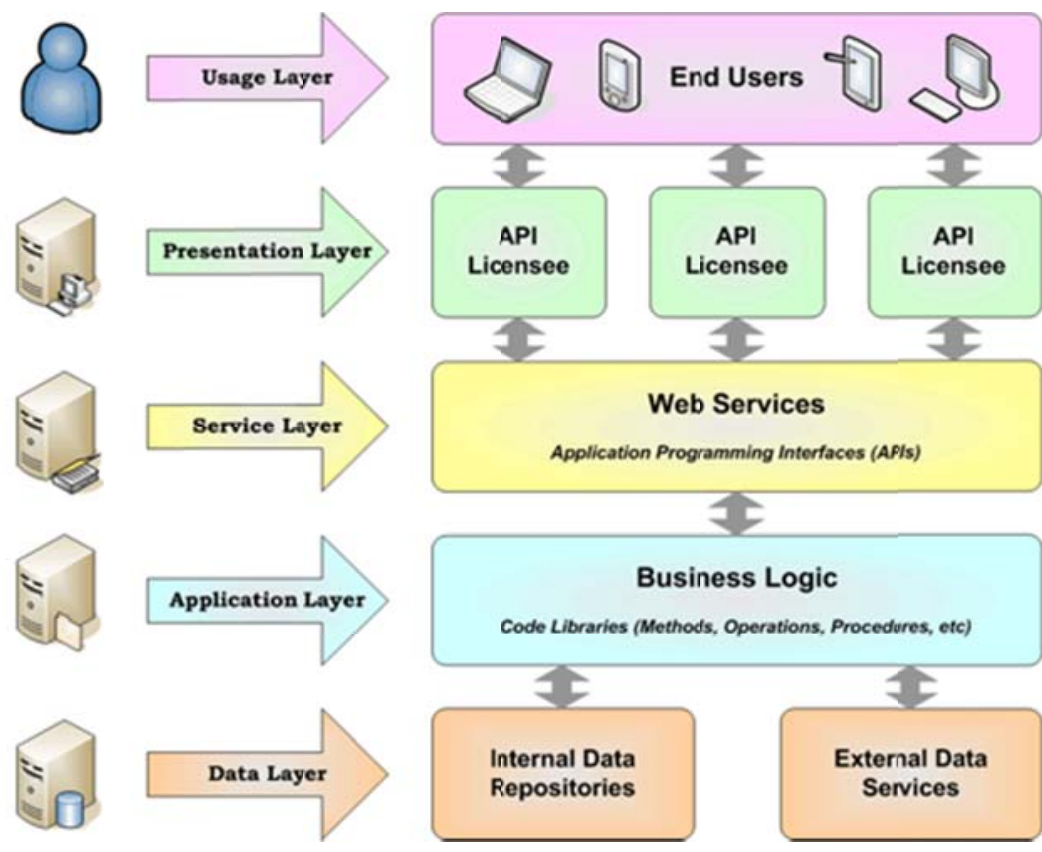

Figure 6. Layers of HES system architecture. Source: Home Energy Saver: Engineering Documentation, https://sites.google.com/a/lbl.gov/hes-public/apis 
Directly above the data layer is the application layer, which contains libraries of software elements ("code libraries") and is the heart of the system. The "business logic," i.e., the rules that govern how the system operates, reside in the code libraries in the application layer. The term "software" usually refers to the application layer.

Above the application layer is the service layer, which manages third-party interactions with the underlying software and data. External systems interface with this system via Web services, which are a type of API. API licensees are given a unique key that grants access to Web services and defines usage rights (or multiple keys are granted in some cases). Key holders can use the entire system or pick and choose particular elements that are of interest. Any number of developers and Websites can be created on top of a given API.

Websites or other Web services created by API licensees ultimately reside in the presentation layer, directly above the service layer. This layer is referred to as the "presentation layer" because this is where the end-user interfaces are developed and hosted by third parties. The HES project uses this layer as well, making its Websites (HES, HESPro, and the Home Energy Scoring Tool) clients of the Web service just like the API licensees.

LBNL is developing a new HES API to handle multifamily buildings. The Weatherization Assistant will interface with the HES multifamily API, not as a licensee, but as a DOE API key holder, similar to the planned new HES multifamily Web application. Both the new HES multifamily tool and the WAP multifamily tool will be clients of the same new multifamily API. Because the API is new, $L B N L$ and ORNL are collaborating extensively on defining the API requirements.

\subsection{WEATHERIZATION ASSISTANT INTERFACE}

As mentioned in the introduction to this plan, the Weatherization Assistant is migrating to a Web-based environment, and the NEAT and MHEA applications will then have Web-based user interfaces. The new WAP multifamily audit tools will also have a Web-based interface that will be handled through the Weatherization Assistant, while the primary energy calculation engine will be part of the HES environment. The multifamily part of the Weatherization Assistant thus becomes part of the presentation and usage layers of HES. NEAT and MHEA will reside completely within the Weatherization Assistant environment. 


\section{DEVELOPMENT STRATEGY}

Based on the assessment of needs, input from experts across the country, and WAP requirements, the plan is to develop the multifamily energy audit tool in two versions. Version 1 will handle buildings with simpler configurations, mostly low-rise buildings. Version 2 will have greater energy calculation capabilities to handle more complex configurations and more complex energy systems.

The initial version of the Web-based tool will not have all the features and capabilities of the second version, because:

- the software development work required to make the initial version functional is extensive,

- the coordination work to make the Weatherization Assistant user interface work seamlessly with the HES API is very detailed and must be correct,

- the engineering coding required for the DOE-2.1e Building Description Language multizonal multifamily modeling templates is very detailed and requires special macro coding, and

- $\quad$ work required to handle all the additional features planned for Version 1 is also fairly extensive.

By making the initial version of the tool simpler, more effort can go into making sure everything is working well and that future upgrades can be handled more readily. The addition of features and capabilities in Version 2 should be easier as a result. Table 3 provides a tentative itemization of potential or needed features and capabilities components, with expected timing for availability (Version 1, Version 2, or later). "WA" in this table means the component is handled by the overall Weatherization Assistant software, which will handle NEAT, MHEA, and the new multifamily tool together. 
Table 3. Multifamily energy audit tool component development

\begin{tabular}{|c|c|c|c|c|}
\hline Component & $\begin{array}{c}\text { WA } \\
\text { feature }\end{array}$ & $\begin{array}{c}\text { Initial } \\
\text { version } \\
\text { (V1) }\end{array}$ & $\begin{array}{c}\text { Later } \\
\text { version } \\
\text { (V2) }\end{array}$ & $\begin{array}{c}\text { Future } \\
\text { capabilities }\end{array}$ \\
\hline Job, client, agency & $\mathrm{X}$ & & & \\
\hline Bldg / equip templates / input (simpler) & & $\mathrm{X}$ & & \\
\hline Basic loads and schedules & & $\mathrm{X}$ & & \\
\hline Weather (TMY2) & & $\mathrm{X}$ & & \\
\hline DOE- 2 engine (2.1e) & & $\mathrm{X}$ & & \\
\hline Libraries (basic) — materials, windows, equipment, ... & & $\mathrm{X}$ & & \\
\hline System sizing (existing and new) & & $\mathrm{X}$ & & \\
\hline Utility rates & & $\mathrm{X}$ & & \\
\hline Utility bills / calibration (manual) & & $\mathrm{X}$ & & \\
\hline Wx measures (basic) [ ID and costing method] & & $\mathrm{X}$ & & \\
\hline Analysis methods for basic measures (simulation, rules) & & $\mathrm{X}$ & & \\
\hline Reporting to meet basic program needs & & $\mathrm{X}$ & & \\
\hline Extra job features (WO, status tracking) & $\mathrm{X}$ & & & \\
\hline Mapping interfaces & & & $?$ & \\
\hline Bldg / equip templates / input (complex) & & & $\mathrm{X}$ & \\
\hline Expanded loads and schedule capabilities & & & $\mathrm{X}$ & \\
\hline Weather (actual for bill analysis) & & & $\mathrm{X}$ & \\
\hline Expanded utility bill calibration guidance & & & $\mathrm{X}$ & \\
\hline Diagnostic test integration & & & $\mathrm{X}$ & \\
\hline Building owner cost calculations and reports & & & $\mathrm{X}$ & \\
\hline Libraries (complex) & & & $\mathrm{X}$ & \\
\hline Complex Weatherization measures & & & $\mathrm{X}$ & \\
\hline Complex Rules & & & $\mathrm{X}$ & \\
\hline Expanded reports and exporting & & & $\mathrm{X}$ & \\
\hline Basic back-end state data rollup to national & & & $\mathrm{X}$ & \\
\hline Report customization capabilities & & & & $\mathrm{X}$ \\
\hline Mapping interfaces & & & & $?$ \\
\hline DOE-2.2, open-source, EnergyPlus engines & & & & $\mathrm{X}$ \\
\hline Automatic utility bill calibration & & & & $\mathrm{X}$ \\
\hline Complex utility rates & & & & $\mathrm{X}$ \\
\hline Energy Index comparisons and ratings & & & & $\mathrm{X}$ \\
\hline Retro-commissioning packaging & & & & $\mathrm{X}$ \\
\hline H\&S and NEBs modules & & & & $\mathrm{X}$ \\
\hline Auditor entered measures or calculation methods & & & & $\mathrm{X}$ \\
\hline Solar measures & & & & $\mathrm{X}$ \\
\hline Performance tracking & & & & $\mathrm{X}$ \\
\hline Back-office national data interface & & & & $\mathrm{X}$ \\
\hline
\end{tabular}




\section{KEY COMPONENTS}

Based on WAP priorities, national input, and conformance with NEAT methods, the proposed tool can be conceptualized as shown in Figure 7, comprised of four components: the user interface, the analysis modules, the data base, and the reporting module.

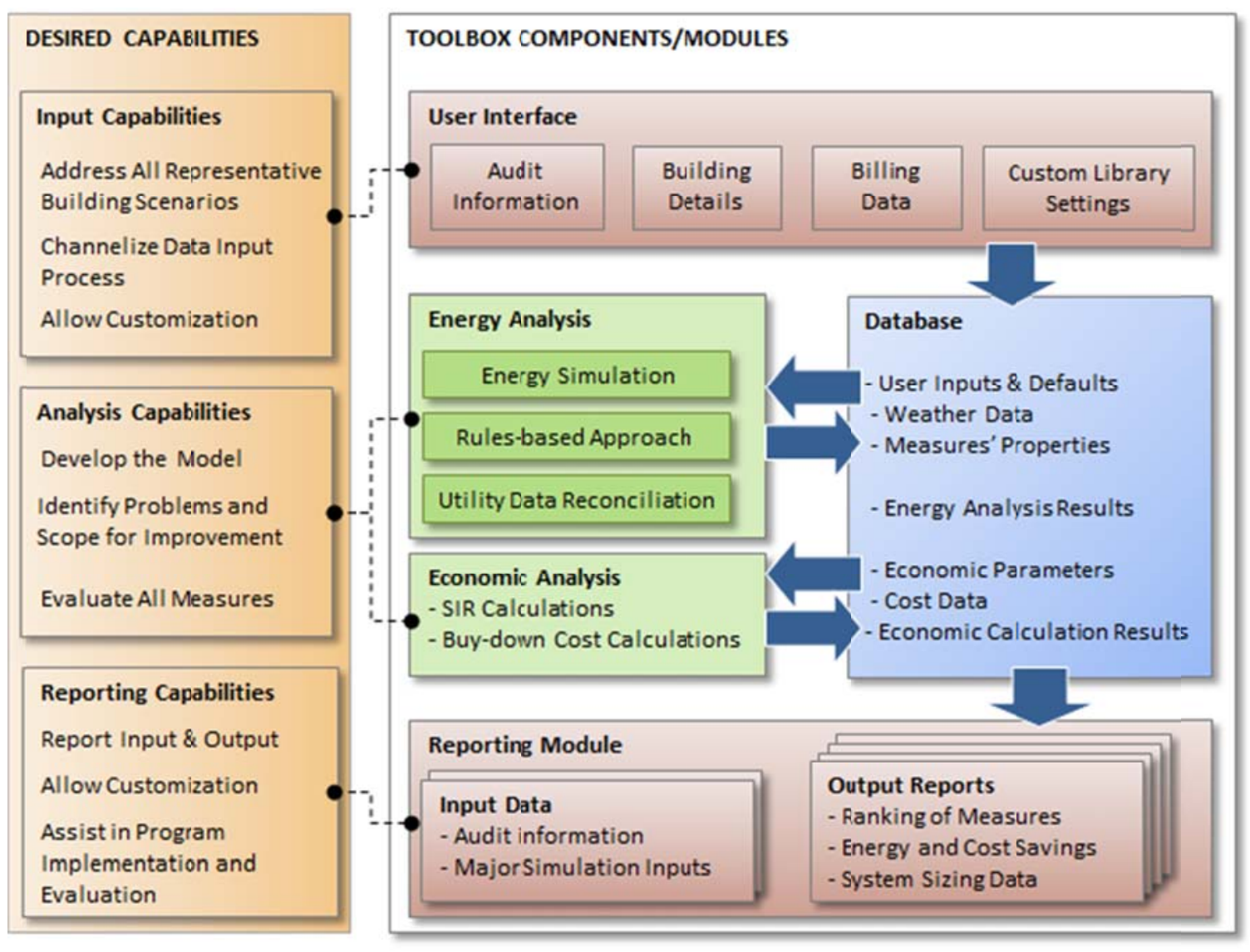

Figure 7. Desired capabilities and proposed components of the multifamily audit tool.

\subsection{USER INTERFACE}

Some of the user interface is handled by the Weatherization Assistant suite, as indicated in Table 3. Efficiently incorporating all relevant building inputs for a wide range of possible building scenarios will require a judicious use of input defaults and modeling assumptions, combined with techniques for conditional data input. The input process will be simplified and automated using cascade logic for generating the forms specific to the configuration of the building and systems being audited. The use of defaults and assumptions would be limiting unless combined with the ability to customize, which will require access to libraries through the user interface to modify the defaults and assumptions as well as the audit settings and preferences, cost data, measures list, and reporting format. 


\subsection{DATA BASE}

The data base is a Weatherization Assistant data base and includes all the data settings and flows, as well as being the communication center for all audits and tools. It will be a repository of libraries, user inputs, custom settings and preferences, and analysis outputs. All data flow among other components and modules will be through the data base. The inputs and output data will be stored as permanent records for the audit. The intermediate outputs will be stored as temporary or permanent data, depending on their need to be reported or to be used for model calibration and refinement.

Energy calculations and complete DOE-2.1e run results handled by HES will be stored and archived in the HES environment, while key results, including access information for full DOE-2.1e output reports if desired, will be stored in the Weatherization Assistant data base.

\subsection{ANALYSIS MODULES}

The analysis component will include integrated modules to perform the several steps required for a complete audit, which mainly include developing a theoretical model, verifying it against the billing data, and performing energy and economic analyses of individual and combined measures. The entire process should be automated, yet stepped to allow the auditor to review the intermediate results and make decisions as the analysis progresses. The analysis modules/approaches considered for the first version of the tool are energy simulation, rules-based calculations, utility data reconciliation, and the economic calculations, as described in the following sections. The energy and economic analysis modules outlined in Figure 7 are expanded in Figure 8 to demonstrate the functional and procedural linkages within each module as well as among the modules.

\subsubsection{Energy Simulation}

Several energy interactions among the building elements, system components, and the outdoors can only be analyzed readily using whole-building energy simulations. For example, energy interactions between attached zones, variations in the space conditions, solar loads, operation of systems under part-load conditions, system controls based on outdoor conditions, etc., are best analyzed using hourly simulation. Multifamily buildings are sometimes treated as commercial buildings and are billed for energy consumption against commercial rate structures. In such cases, an hourly estimation of energy use may be important to analyze the cost-effectiveness of measures. Thus, simulation will be used as the core of the analysis.

\subsubsection{Rules-Based Approach}

Several building details and retrofit measure inputs cannot be specified as direct modeling inputs, or cannot be simulated for their energy impacts. To compensate for these limitations of energy simulation, rules-based methods are needed in combination with simulations to develop the base-case model and evaluate certain measures. Rules-based methods can also be used for lessening the effort required for developing and refining the model wherever feasible (i.e., when well-established rules-based estimates or simplified calculation methods are available and detailed modeling provides only marginal benefits). 


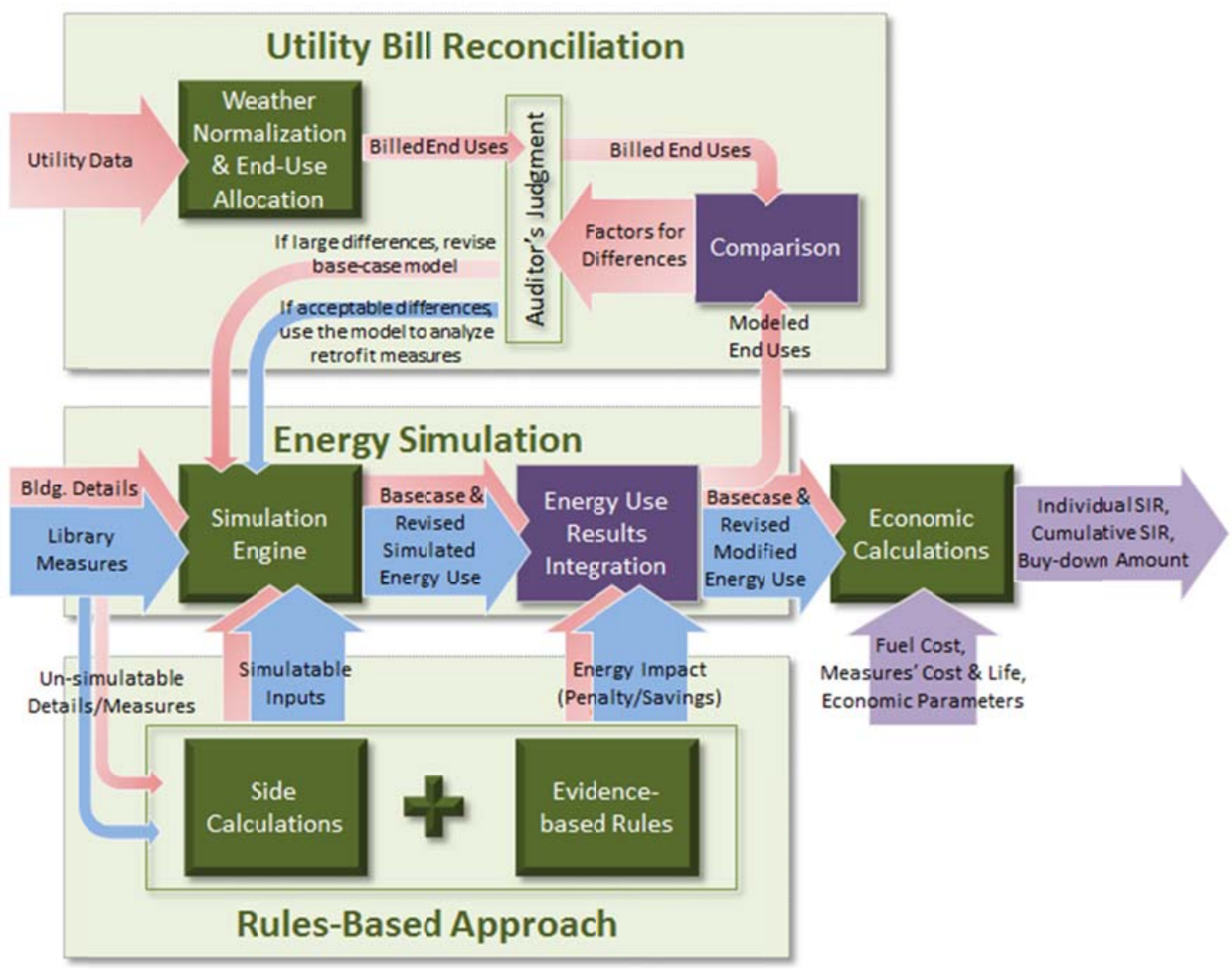

Figure 8. Integration of analysis modules.

The rules-based approach will use two methods: evidence-based rules established using the knowledge and experience accumulated over time about the energy performance of building and system components under certain operating conditions, and side calculations based on simplified methods.

The rules-based approach will first be used in either or both of the two stages of the base-case model development - pre-simulation and post-simulation. After the base-case model is deemed "fit" against the utility data, the rules-based approach will be used for providing the pre-simulation inputs and/or postsimulation savings for the retrofit measures. For unsimulatable inputs critical for the building model which significantly influence the energy interactions within the building (e.g., corrective or tune-up type system measures), the rules-based approach will be used to determine simulatable inputs (e.g., an efficiency factor in the above example). For other inputs that do not affect other energy end uses, the rules-based approach can be used to calculate/estimate their energy impact. It is important that the impact of measures' interaction be accounted for when using post-simulation estimates for measures' energy impact. 


\subsubsection{Utility Bill Reconciliation}

An energy model of a multifamily building is created using a limited number of building inputs and several assumptions for the unknowns. Therefore, the multifamily audit tool must use at least one year's monthly billing data to make the theoretical model "fit" the actual usage, so that the energy savings predictions are not overestimated or underestimated.

For reconciliation with billing data, the tool should be able to perform (or rather, assist in performing) the following functions: weather normalization of the billing data, end use allocation, identification of factors for differences between simulated and billing data, and adjustment to modeling inputs. Several limitations restrict the usefulness of an automatic analysis of billing data and adjustment to modeling inputs.

Therefore, a more open and step-wise procedure is needed that would use built-in routines for each stage, present intermediate results or graphical clues to the auditor about the "fit" of the energy model, and allow the auditor to make adjustments to the model.

To incorporate this capability, access to actual weather data, integration of available toolkits for weather normalization and segregation of major end-uses, and development of routines to identify factors for differences would be required. How much of the capabilities described here can be included in Version 1 of the tool is uncertain, but a focus on including as much as possible will be maintained.

\subsubsection{Economic Calculations}

Economic calculations are required to evaluate the cost-effectiveness of individual and combined measures. For weatherization projects, the evaluation criterion is that the savings-to-investment ratio (SIR) should be greater than or equal to 1.0 for individual energy measures as well as a package of selected energy and incidental repair measures. In addition, the WAP guideline allows buy-down of measures not meeting the SIR criteria using non-weatherization funds. Other state or utility programs may have different evaluation criteria.

To address the Weatherization Program requirements and guidelines, two calculation routines will be incorporated. For SIR calculations, energy savings results obtained from energy analysis (above) will be used with the fuel, material and labor cost data, and other economic parameters stored in a customizable library. For calculations of measure buy-down amounts, installation costs of desired measures will be computed that give a measure SIR equal to 1.0. For addressing other program requirements, additional calculation routines will be required.

\subsection{REPORTING MODULE}

The reporting module will obtain the desired information from the data base, including the user preferences for the format of reporting, to generate the tool output.

\subsection{INTEGRATION OF ANALYSIS MODULES}

The modules described above will be integrated through the dataflow in the manner shown in Figure 8 . All dataflow will be through the data base (Figure 7). 
The primary user inputs to the analysis will be the utility data and building and site details. Other optional inputs include custom settings for the analysis such as activation/deactivation of certain measures, material properties and cost data, fuel cost and rate structure, economic parameters, and reporting preferences. These user inputs will be stored in the data base along with default libraries, analysis defaults and assumptions, and weather data.

The Utility Data Reconciliation module will process the utility data through weather normalization and end use allocation routines or third-party software to segregate the energy end-uses. It will allow the auditor's judgment to confirm or modify the end-use energy estimates. These estimates will be used for the verification of the base-case model.

The building and site details will be used for the Energy Simulation, Rules-Based Approach (Side Calculations and estimations based on Evidence-Based Rules) to develop a base-case model. The simulatable inputs will be used directly in the Energy Simulation module for developing the base-case model. The Rules-Based Approach will provide simulatable input (pre-simulation) and/or energy impacts (post-simulation) corresponding to the unsimulatable building details. Both types of data will be treated as part of the base-case model. The base-case model thus developed will be run to simulate energy use and extract/bundle the end uses in the same manner as billed end uses.

The Utility Data Reconciliation module will compare the modeled end-use energy values with the billed end uses. It will use built-in routines to identify the factors for differences and possible adjustments for the base-case model to fit the actual consumption. Again, the module will allow auditor's judgment for determining adjustments to the base-case model. The adjustments confirmed by the auditor will be used for the revised base-case model, and the model will again be run and verified against billed end uses. This step may be iterative until no further adjustments are deemed necessary by the auditor and the base-case model is accepted by the auditor for the analysis of measures.

For the analysis of individual measures, a built-in routine will modify the parameters of the base-case model corresponding to the selected/applicable measures and run the model to simulate the energy use. As explained previously, pre-simulation or post-simulation estimates (simulation inputs or energy impacts) for the unsimulatable measures will be determined from the Side Calculations and EvidenceBased Rules.

The Economic Calculations module will use the energy consumption for the base case and revised models with individual measures, cost data and other economic parameters stored in the library to calculate the SIR for individual measures. With an individual SIR calculated, the cost-effective measures will be implemented to the base-case model in the order of highest to lowest SIR and the combined costeffectiveness will be evaluated after every addition of measures. The cost-effective measures will also be available to the auditor to be included in customized packages of measures to be considered. 


\section{MODELING APPROACH}

\subsection{DESIRED CAPABILITIES}

The following discussion presents some of the specific modeling and analysis capabilities desired and initial thoughts on how they should be incorporated.

\subsubsection{Multiple Thermal Zones}

Multiple thermal zones are required to adequately model the impact of energy interactions of a zone with the outdoors and the adjacent atypical conditioned or unconditioned zones, and to evaluate zone-specific retrofit measures. Modeling of the energy interactions of a zone with the outdoors requires separate zoning for corner units versus embedded units, and units facing different orientations. Modeling of the energy interactions of a zone with adjacent zones requires separate zoning for apartment units versus common areas and all typical floors. It is noted that an increase in the number of zones may increase modeling errors. Therefore, the level of detail in thermal zoning is an important decision to be made.

\subsubsection{Representative Building Typologies}

Multifamily building typologies vary widely and cannot all be analyzed using one model. For example, compact, box-shape buildings with double loaded corridors and protected entrances in cold climates, apartments with a breezeway or open verandah in warm climates, and garden style apartments similar to single-family units are all different. To address these types, the tool will include a flexible building model with the automatic ability to activate or deactivate zones, floors, or surfaces (as shown in Figure 9) depending on user input about the number of units, number of floors, space types, or other building features.
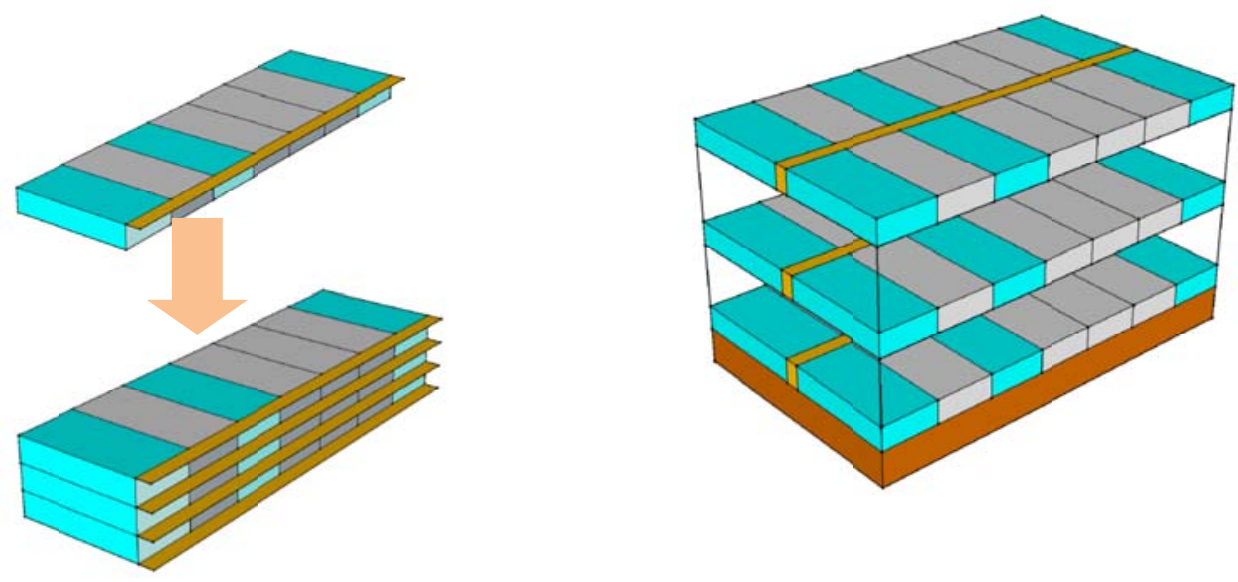

Figure 9. Flexible building modeling scheme. 


\subsubsection{Multiple Systems}

The DOE-2.1e energy simulation tool allows multiple types of plant equipment as well as associated operating sequences and load management. In addition, systems serving different zones of the building or individual systems serving each apartment can be specified separately. This takes into account the actual operating efficiency of a mix of equipment under part-load conditions.

\subsubsection{Infiltration / Ventilation}

Infiltration in mid- and high-rise multifamily buildings is largely driven by stack effects. Techniques to reduce infiltration include sealing not only major leakage paths on the top and bottom envelope components but also small leakages in the apartments to achieve compartmentalization. Ventilation systems, when present, often limit infiltration. The best means of handling infiltration and ventilation systems will be evaluated and methods developed to guide the auditor through evaluation of infiltration and ventilation. Continued improvements to modeling methods over time are likely to be needed, as modeling these airflows is highly complicated.

\subsubsection{Representative Internal Load Schedules}

To account for the time-coincident loads (pre- and post-retrofit), which impact energy use during different times of the day and different days of the week, hourly schedules for major or typical energy end uses and controls for which retrofit measures will be evaluated should be modeled. To incorporate these, representative schedules will be specified in the library with some user selection options.

\subsubsection{User-Defined Measures}

To incorporate the ability to allow the auditor to add measures that are not addressed by the tool, methods of allowing the auditor to enter details of a measure's energy savings, installation cost, and measure lifetime will be evaluated. The saving estimates can be determined using an external tool or auditor's experience-based rules. The tool will perform economic calculations as for the library measures. This capability will not be available in Version 1, may be available in Version 2, or might have to be developed later.

\subsubsection{Electricity and Fuel Rate Structures}

Multifamily buildings may not be billed against fixed average electricity rates or a uniform rate for the whole building. Using actual rates is important in determining the cost-effectiveness of measures. The user interface should offer the option to specify meters and associated end uses separately, so that some type of analysis using different rates or rate structures might be possible. This type of analysis is expected to be performed outside the actual energy audit tool, but the energy breakout is needed to perform the analysis. The results of the analysis would then have to be converted to some type of input that the tool can use (see "Side Calculations" in Figure 8). 


\subsection{CRITERIA FOR SELECTING MODELING AND ANALYSIS APPROACH}

As discussed previously, the modeling and energy analysis will be performed using energy simulation, evidence-based rules, and side calculations. Prior to discussing specific modeling and analysis capabilities desired in the tool and how they will be incorporated, it is pertinent to discuss the criteria for selecting a particular approach from among these.

Energy simulation is a very powerful approach. The benefits of energy simulation are often enticing. Excessive focus on detailed modeling may provide only marginal benefits and compromise the usability of the tool. At the same time, oversimplification of audit inputs may undermine the benefits of simulation efforts. Therefore, determining the optimal levels of detail and simplification of modeling inputs are critical decisions. Although both the terms may seem to imply the same thing, they are approached from two directions: top-down and bottom-up, respectively, as shown in Figure 10.

For determining the level of detail (top-down approach), we start from the audit outcome - the energy savings. The components of energy savings (end-use energy use and savings) are examined, together with if/how they interact and to what degree. The examination identifies the influencing elements, and finally, based on the level of interaction, a decision about whether the parameters need to be analyzed using simulation or pre-simulation inputs, or post-simulation energy impacts.

For determining the level of simplification (bottom-up approach), we start from individual components and corresponding modeling inputs, and categorize them as variable or fixed inputs based on whether or not the components are candidates for retrofit. The variable or fixed inputs are studied to see if they can be bundled or specified by a representative single input without compromising the modeling benefits.

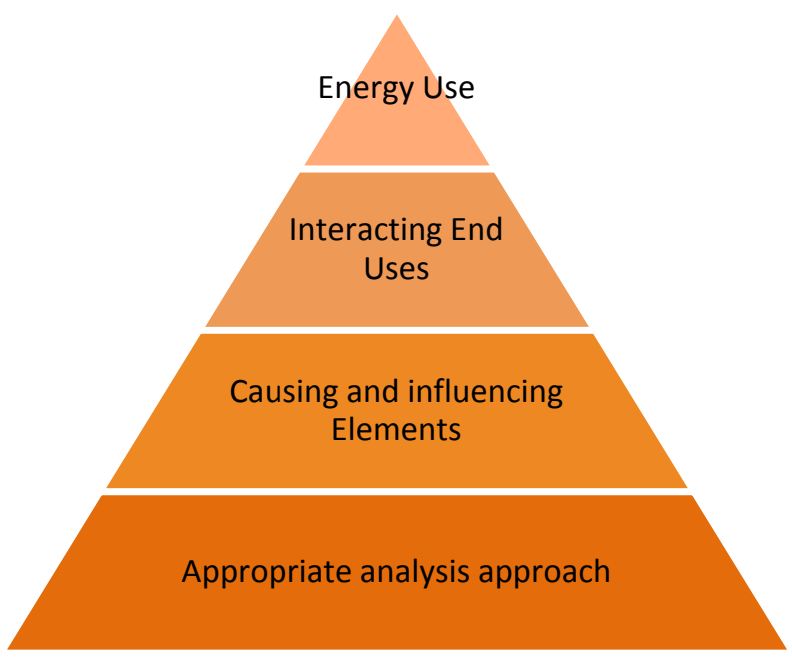

Top-down Approach

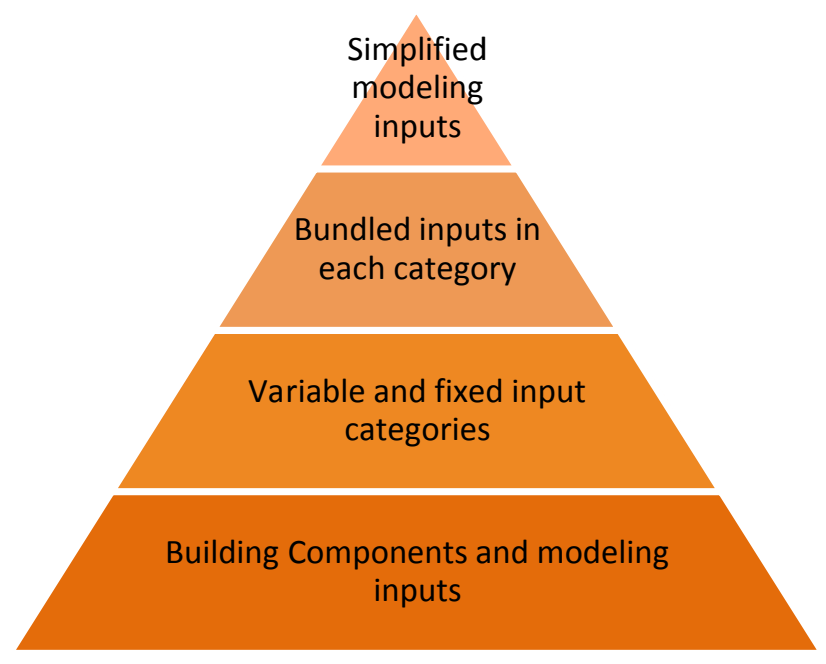

Bottom-up Approach

Figure 10. Modeling and analysis approach 
Using these criteria, decisions about the modeling and analysis approach can be justified. The following tables list (1) major building characteristics and how they will be modeled (Table 4), and (2) broad weatherization measure categories that will be evaluated using the proposed tool, the analysis approach, and the level at which they will be integrated to other approaches (Table 5).

Table 4. Modeling approach for building characteristics

\begin{tabular}{|c|c|c|}
\hline Building characteristics & Input type & Modeling approach \\
\hline \multicolumn{3}{|l|}{ General } \\
\hline Building geometry & Fixed & Bundled dimensions \\
\hline Interior spaces, attached surfaces & Fixed & Bundled/averaged area \\
\hline Construction & Variable & Detailed (layers) \\
\hline Leakage & Variable & $\begin{array}{l}\text { Detailed (space-specific air change } \\
\text { rate) }\end{array}$ \\
\hline Solar shading (self-shading) & Fixed & Ignored in version 1 \\
\hline Windows and doors area & Fixed & Bundled/averaged area \\
\hline Windows and door construction & Variable & Detailed (performance parameters) \\
\hline Windows and door leakage & Variable & $\begin{array}{l}\text { Detailed (component-specific air } \\
\text { leakage) }\end{array}$ \\
\hline Interior shading & Variable & $\begin{array}{l}\text { Detailed (shading coefficient and } \\
\text { schedule) }\end{array}$ \\
\hline \multicolumn{3}{|l|}{ Interior Elements } \\
\hline Lighting & Variable & $\begin{array}{l}\text { Detailed (space-specific lighting } \\
\text { density) }\end{array}$ \\
\hline Appliances & $\begin{array}{l}\text { Variable (refrigerator, plug } \\
\text { loads), fixed (other) }\end{array}$ & $\begin{array}{l}\text { Bundled separately for fixed and } \\
\text { variable }\end{array}$ \\
\hline Occupancy & Fixed & Bundled/averaged \\
\hline Schedules & Fixed & Representative \\
\hline \multicolumn{3}{|l|}{ System } \\
\hline Type & Fixed & From available options \\
\hline Efficiency & Variable & Detailed \\
\hline Distribution system & Fixed & Approximated \\
\hline Setpoints & Variable & Detailed \\
\hline Controls & Variable & Detailed \\
\hline Schedule & Fixed & Representative \\
\hline \multicolumn{3}{|l|}{ Plant Equipment } \\
\hline Type, fuel type & Variable & From available options \\
\hline Efficiency & Variable & Detailed \\
\hline Controls & Variable & Detailed \\
\hline Schedule & Variable & Detailed \\
\hline
\end{tabular}


Table 5. Analysis approach for weatherization measures

\begin{tabular}{|c|c|c|c|}
\hline \multirow[b]{2}{*}{ Measures } & \multicolumn{3}{|c|}{ Analysis approach/saving estimation method } \\
\hline & $\begin{array}{c}\text { Pre-simulation } \\
\text { rules }\end{array}$ & Energy simulation & $\begin{array}{l}\text { Post-simulation } \\
\text { rules }\end{array}$ \\
\hline \multicolumn{4}{|l|}{ Mechanical System Measures } \\
\hline Entire unit replacement/modification & & $\mathrm{X}$ & \\
\hline Tune-up or repair & Efficiency factor & $\mathrm{X}$ & Energy impacts \\
\hline Control improvements & Modified set points & $\mathrm{X}$ & \\
\hline Chiller/boiler sequencing & & $\mathrm{X}$ & \\
\hline Distribution system improvements & & & Energy Impacts \\
\hline Thermostat setpoints & & $\mathrm{X}$ & \\
\hline Energy management system & Modified set points & $\mathrm{X}$ & Energy impacts \\
\hline Supply temperature reductions & & $\mathrm{X}$ & \\
\hline Pipe or tank insulation & Heat loss estimate & $\mathrm{X}$ & \\
\hline $\begin{array}{l}\text { Hot water demand reduction (low- } \\
\text { flow fixtures) }\end{array}$ & $\begin{array}{l}\text { Hot water demand } \\
\text { estimate }\end{array}$ & $\mathrm{X}$ & \\
\hline \multicolumn{4}{|l|}{ Lighting and Appliances Measures } \\
\hline Lamp replacement & Lighting wattage & $\mathrm{X}$ & \\
\hline Timers and sensor controls & $\begin{array}{c}\text { Schedule } \\
\text { modification }\end{array}$ & $\mathrm{X}$ & \\
\hline Refrigerator replacements & Load estimate & $\mathrm{X}$ & \\
\hline Smart outlet strips & Load estimate & $\mathrm{X}$ & \\
\hline \multicolumn{4}{|l|}{ Building Envelope Measures } \\
\hline Insulation & & $\mathrm{X}$ & \\
\hline Air sealing & Leakage coefficient & $\mathrm{X}$ & \\
\hline Windows and doors Replacement & & $\mathrm{X}$ & \\
\hline Storm windows and doors & Effective U-value & $\mathrm{X}$ & \\
\hline Window films and shades & & $\mathrm{X}$ & \\
\hline Window and door air leakage control & Leakage coefficient & $\mathrm{X}$ & \\
\hline Major envelope / stack leaks & Air change/hour & $\mathrm{X}$ & \\
\hline \multicolumn{4}{|l|}{ Additional Measures } \\
\hline Solar hot water system & $\begin{array}{l}\text { Reduced hot water } \\
\text { use }\end{array}$ & $\mathrm{X}$ & \\
\hline PV system & & $\mathrm{X}$ & $\begin{array}{l}\text { Reduced electricity } \\
\text { needs }\end{array}$ \\
\hline Pool measures? & & & \\
\hline
\end{tabular}




\section{SOFTWARE REQUIREMENTS}

Software development will not be covered in detail here. New multifamily national energy audit tools will be Web-based and will integrate into the Web-based Weatherization Assistant. Design and implementation of the software will need to successfully implement the rules of the Weatherization Assistance Program. An auditor's final selection of building parameters, selected simulation results with projected savings, auditor notes/changes, and any job or other data will be transmitted to and stored on a secured server. HES API development will proceed independently, but the Weatherization Assistant graphic user interface (GUI) and the HES API must have agreement on parameters and methods having direct interaction.

\subsection{OPERATING ENVIRONMENT}

The operating environment targeted is a platform- and language-agnostic Web service interface using standard XML-based document interchange. XSD and XML documents will be developed and made available to assist external developers in the extension of new functionality and interfaces for the Weatherization Assistant tool suite. Weatherization Assistant interaction with the HES environment will also be based on XML and XSD documents, but users will not be directly aware of this interaction.

Standardized outputs to Word- and Excel-supported formats will be developed, but the exact specifications must await testing of export workability.

\subsection{EXTERNAL INTERFACE REQUIREMENTS}

Since the new multifamily tools must be integrated into the new Web-based Weatherization Assistant, the information in this section indicates the interface requirements already considered as expected interface languages and capabilities for the Weatherization Assistant.

\subsubsection{User Interfaces}

The user interface itself will be a Web portal and is anticipated to include modern Web technologies for dynamic hypertext markup language (DHTML) including HTML Document Object Model (DOM) [16], cascading style sheets (CSS) [17], asynchronous JavaScript and XML (AJAX), and the personal homepage language (PHP) [18]. These technologies involve execution of the client-side for interactive Web applications while communicating asynchronously with the server in such a way as to not interfere with the display of the page. JavaScript library jQuery [19] is the most popular currently, being in use at over $43 \%$ of the 10,000 most-visited Websites [20]. The input and output of the interface will be mediated by the Web service XML / XSD definition. The final user interface is expected to adhere to modern Web design principles $[21,22,23]$.

\subsubsection{Communications Interfaces}

The set of inputs and outputs will be viewable as a set of XML [24, 25, 26, 27] request and response documents, allowing potential external developers to understand the user interface requirements. In addition, a set of XSD [28] definitions will be provided, defining the expected elements, types, and data 
constraints required for performing an audit. These XSD entities will be useful for any modeling tools capable of generating base classes for implementation. Examples of tools capable of consuming XSD and generating code are Hibernate [29], JAX-B [30], and tools provided within the .NET framework [31] on Microsoft platforms. Additionally, new languages such as Ruby [32] are also readily able to work with these constructs.

XML and XSD artifacts provide a platform-neutral, programming-language-independent basis for application construction. Once an end user application developer has had an opportunity to inspect the XML / XSD interface definition for the inputs and outputs, they may next study the WSDL documents for the service. Where the XML and XSD define "what" is consumed, the WSDL will specify "how." Where the XML and XSD define the "nouns," the WSDL will specify the "verbs." The WSDL will utilize document-oriented design. In this way, the messaging can focus on the information required and provided, and does so in a very coarsely grained manner.

The WSDL will provide a lightweight message referencing an identifier. In this way, passing in all the inputs required to perform the audit is the first option for using the service. In the second, the service may be used by passing in an identifier to an audit stored in a data base, along with the reference to the data base connection required to retrieve the information.

\subsection{PROGRAMMING LANGUAGE FOR ANALYSIS COMPONENTS}

\subsubsection{Energy Simulation Engine}

DOE- $2^{5}$ has been selected as the most appropriate energy simulation engine for this Web-based application. Front-end automation of DOE-2 is accomplished through use of code templates and extensive macro coding, using the DOE-2 macro language. Back-end automation can be accomplished in several ways, depending on the amount of output data needed, with the final output going to the required XML file.

\subsubsection{Rules-Based Components}

Although several references have been made to "expert-system-type" capabilities and to "rules-based" systems in this plan, the types of rules-based approaches that will most often be needed in the proposed tool should not be considered as in the typical vein of artificial intelligence expert systems. Many of the rules-based features likely to be included should more properly be considered as expert "guidance" through a process, demanding that a certain level of expertise be available from the energy auditor, with the guidance through specific sub-processes acting as an additional aid to effective auditing.

Although no recommendation is made at this point, the rules-based programming is likely to be in Java.

\footnotetext{
${ }^{5}$ There is concern that a DOE2-based engine, since it is written in FORTRAN/77, will lack the reuse capability, flexibility, and comprehensibility of more modern programming languages. The existing code is not modularized, making extension and code reuse impractical. DOE-2.1E consists of about 80,000 lines of code, meaning that translation to a modern programming language would be a significant development effort. White Box Technologies, Inc. is currently in negotiations with LBNL to make DOE-2.1E fully open source. Despite concerns, DOE-2 is still the most appropriate engine for the proposed toolbox.
} 


\section{CONCLUSION}

This report describes the planning effort for a new multifamily energy audit tool for DOE's Weatherization Assistance Program. The functionality of the Weatherization Assistant is being expanded to also perform energy audits of small multifamily and large multifamily buildings. The process covers an assessment of needs that includes input from national experts during two national Web conferences.

The assessment of needs is then translated into capability and performance descriptions for the proposed new multifamily energy audit, with some description of what might or should be provided in the new tool. The assessment of needs is combined with our best judgment to lay out a strategy for development of the multifamily tool that proceeds in stages, with features of an initial tool (version 1) and a more capable version 2 handled with currently available resources. Additional development in the future is expected to be needed if more capabilities are to be added. A rough schedule for development of the version 1 tool is presented.

The components and capabilities described in this plan will serve as the starting point for development of the proposed new multifamily energy audit tool for WAP. 


\section{REFERENCES}

[1] U.S. DOE Weatherization Assistance Program, National Weatherization Training \& Technical Assistance Plan, U.S. Department of Energy, December 2009, http://www1.eere.energy.gov/wip/pdfs/wap tta plan.pdf.

[2] U.S. Environmental Protection Agency, Healthy Indoor Environment Protocols for Home Energy Upgrades, EPA 402/K-11/003, October 2011, http://www.epa.gov/iaq/pdfs/epa_retrofit_protocols.pdf .

[3] Marilyn A. Brown, Linda G. Berry, Richard A. Balzer, and Ellen Faby, National Impacts of the Weatherization Assistance Program in Single-Family and Small Multifamily Dwellings, ORNL/CON-326, Oak Ridge, Tenn.: Oak Ridge National Laboratory, 1993, http://weatherization.ornl.gov/pdfs/ORNL_CON-326.pdf.

[4] Martin Schweitzer and Bruce Tonn, Nonenergy Benefits from the Weatherization Assistance Program: A Summary of Findings from the Recent Literature, ORNL/CON-484, Oak Ridge, Tenn.: Oak Ridge National Laboratory, 2002, http://weatherization.ornl.gov/pdfs/ORNL_CON484.pdf.

[5] 13-5 Building Performance Institute, Inc., "Technical Standards for the Multifamily Building Analyst Professional," interim standards document (2/20/2008), http://www.bpi.org/Web\%20Download/BPI\%20Standards/Multi\%20Family\%20Building\%20An alyst $\% 20$ Prof $\% 20 \mathrm{FD} \% 203.0 \% 202-20-08$.pdf.

[6] U.S. Energy Information Administration, Residential Energy Consumption Survey ( RECS), RECS Public Use Microdata Files, http://www.eia.gov/emeu/RECS/recspubuse05/pubuse05.html (Nov. 29, 2011).

[7] 10 CFR Part 440: Weatherization Assistance Program for Low-Income Persons [Code of Federal Regulations, available online from US Government Printing Office].

[8] Appendix A to 10 CFR Part 440.

[9] DOE Weatherization \& Intergovernmental Program, Weatherization Program Notice (WPN) 0909, Guidance on Implementation of the Davis-Bacon Act Prevailing Wage Requirements in the American Recovery and Reinvestment Act of 2009, 2009.

[10] DOE Weatherization \& Intergovernmental Program, WPN 10-04, Davis-Bacon Commercial Labor Rates in Large Multifamily Buildings Impact on Savings-to-Investment Ratios, 2010.

[11] DOE Weatherization \& Intergovernmental Program, WPN 10-17, Guidance on Using NonFederal Resources as a Buydown for Meeting the Savings-to-Investment Ratio for Materials Used in the Weatherization Assistance Program, 2010.

[12] DOE Weatherization \& Intergovernmental Program, WPN 11-06, Weatherization Health and Safety Guidance, 2011.

[13] DOE Weatherization \& Intergovernmental Program, WPN 11-01, Grantee Monitoring Guidance for Weatherization Innovation Pilot Program Grants, 2011.

[14] James J. Hirsch, Welcome to DOE2.com, The Home of DOE-2 based Building Energy Use and 
Cost Analysis Software, http://www.doe2.com (Nov. 29, 2011).

[15] LBNL, Where to Purchase the DOE-2 Program, gundog.lbl.gov/dirsoft/d2 vendors.html (Nov. 29, 2011).

[16] World Wide Web Consortium (W3C), "HTML 4.01 Specification," http://www.w3.org/TR/html4.

[17] World Wide Web Consortium (W3C), "Cascading Style Sheets," http://www.w3.org/Style/CSS.

[18] Rasmus Lerdor, "PHP: Hypertext Processor," http://php.net/index.php.

[19] John Resig, “jQuery project,” http://jqueryui.com/themeroller and http://jquery.com/.

[20] Wikipedia, “jQuery,” http://en.wikipedia.org/wiki/JQuery.

[21] Vitaly Friedman, "30 Usability Issues to be Aware of," http://www.smashingmagazine.com/2007/10/09/30-usability-issues-to-be-aware-of.

[22] Ben Shneiderman and Catherine Plaisant, Designing the User Interface: Strategies for Effective Human-Computer Interaction. ISBN 0321197860, 2004.

[23] Jakob Nielsen, "Jakob Nielsen on Usability and Web Design,” http://www.useit.com/alertbox.

[24] World Wide Web Consortium (W3C), Extensible Markup Language (XML) 1.0, Fifth Edition, http://www.w3.org/TR/xml/.

[25] World Wide Web Consortium (W3C), Namespaces in XML 1.0, Third Edition, http://www.w3.org/TR/xml-names/.

[26] World Wide Web Consortium (W3C), XML Schema Part 1: Structures, Second Edition, http://www.w3.org/TR/xmlschema-1/.

[27] World Wide Web Consortium (W3C), XML Schema Part 2: Datatypes, Second Edition, http://www.w3.org/TR/xmlschema-2/.

[28] World Wide Web Consortium (W3C), Web Services Description Language (WSDL) Version 2.0 Part 1: Core Language, http://www.w3.org/TR/wsdl20.

[29] JBoss Community, Hibernate, "Relational Persistence for Java and .NET," http://www.hibernate.org/.

[30] JAXB: JAXB Reference Implementation, https://jaxb.dev.java.net/.

[31] Microsoft Download Center, "Microsoft .NET Framework Version 2.0 Redistributable Package (x86)," http://www.microsoft.com/downloads/en/details.aspx?FamilyID=0856eacb-4362-4b0d$\underline{8 \mathrm{edd}-\mathrm{aab} 15 \mathrm{c} 5 \mathrm{e} 04 \mathrm{f} 5 \& \text { displaylang=en. }}$

[32] Ruby, "Ruby is...," http://www.ruby-lang.org/en/. 


\title{
APPENDIX A \\ Agendas of the Two Multifamily National Energy Audit Web Meetings
}

\author{
Multifamily Users Group Input — November 10, 2010 \\ for the development of the \\ MULTIFAMILY NATIONAL ENERGY AUDIT
}

\author{
AGENDA \\ Introduction about this meeting to group \\ Background \\ Purpose and Potential Scope of Multifamily Tool \\ Purpose of Users Group \\ Proposed Process for Meeting \\ Buildings Being Audited \\ What types are you auditing / upgrading now? (size, stories, number of units) \\ What types are being considered or will be considered in the future? \\ Are current MF audit tools causing issues now? If so, what? \\ How common are "deemed" savings for measures? \\ What mix of heating, cooling, hot water systems? Fuels? \\ What are major common area issues? \\ What are most common energy measures? Repair? Health / safety?
}

Audit Set-Up

Building and system configuration - NEAT and MHEA will be available on-line, webbased by Summer 2011 — suite of tools - if MF tool added, are other tools needed?

Utility / fuel bills analysis - What tools are used now? How to handle metering splits (common areas vs units)? How to integrate into audit process? What capabilities are needed to handle this type of analysis? Is it needed?

Utility / fuel bill reconciliation with calculations - how should this work?

Pre-qualifications - if needed, should there be some integration with the audit tool?

Do incentives programs create issues the tool should address?

Are specific capabilities related to cost-sharing and economic analysis needed up front?

'Building Input Capabilities

How automated should building and system description input be?

What configurations / features cause problems for you now?

Garages? How to handle?

What key capabilities are most important?

Would default templates be helpful? If so, can we define some? How much should they cover?

For whole-building analysis, how should zoning be handled? Building shape?

How should infiltration / ventilation measurement results be handled?

Any special needs for heating or cooling systems? Hot water?

What capabilities are needed for appliance inputs?

How much detail is needed for lighting system input?

How detailed should control systems inputs be?

Should cogen systems be handled? 
Energy Measures Selection and Analysis

What measures should be covered? (see separate list)

Ability to add measures? How to address?

Any special requirements for whole buildings vs individual units?

Any important features/ capabilities needed for: infiltration/ventilation measures?

1) sealing/control of major air leakage paths and ventilation?

2) Stack flow control / reductions?

3) ... lighting measures?

4) ... distribution system measures?

5) ... hot water system measures?

6) ... appliances?

7) ... laundry?

8) ... elevators?

9) ... building cooling-heating-power integration options?

10) ... load management options?

11) Other?

Non-Energy Measures

How should EHS measures be integrated into audit?

Should comfort issues be handled in some way? If so, how to present?

How to select/analyze health or safety (or other) measures? Inputs?

What measures should be covered? (see separate list)

Are any IAQ issues critical to cover? (might wish to check a HUD Healthy Homes

Other?

module being developed for NEAT, http://hyperion.ornl.gov:8080/HealthyHomes/)

Should there be requirements inputs for some non-energy measures?

Financial Calculations

What options to offer for LCC results? Wx program requires SIR

Any options for cost escalation methods (differentials)? Wx program uses regional approach and annual update of escalation parameters

How to handle energy costs? How much detail?

How should installation costs be handled? What options? Specific measure issues?

Should fuel switching be handled? Any special requirements for this if handled?

Should any special utility rate capabilities be offered?

How should owner contributions be handled?

Rebates / other incentives? Issues?

Davis/Bacon issues, deemed labor rates? How to handle?

Other?

Reporting

Preferences for results presentation?

Suggestions about format?

Major topic areas for report? 


\section{Options for LCC results?}

Other

WRAP-UP

Summary of results for the meeting

Next Steps

What would participants like to see as far as feedback? 


\section{Multifamily Energy Audit Methods Experts Input — Nov 4, 2010}

for the development of the

\section{MULTIFAMILY NATIONAL ENERgY AUdiT}

\section{AGENDA}

Introduction about this meeting to group

Background

Purpose and Potential Scope of Multifamily Tool

Purpose of Experts Group

Proposed Process for Meeting

Fundamental Issues

What tools are you using now for baseline energy analysis? Energy measure savings?

What are the pros and cons of these tools? Wx-program-approved tools?

What basic approaches or methods should the proposed new national audit consider? Simulation tools vs expert-system-rules-based? Are most measures handled with rules-based approaches now? If simulation engine needed, what engine(s) have the best recommendation? By building type / size?

Building and system configuration issues - what building configurations cause the most difficulties - how to integrate? - NEAT and MHEA will be available on-line, web-based by Summer 2011 — suite of tools — if MF tool added, are other tools still needed?

Development path recommendations? Should both near-term and long-term strategies be adopted?

Utility / fuel bills analysis - what should it be used to do? Or is it needed at all?

Methodological issues? e.g., difficult to obtain time-coincident degree-day data? Monthly variation in fuel costs? Anomalous data? User specified inputs? Meter splits between common areas and units?

How to integrate into audit process?

Whole building vs end-use results, how much? When? At all?

Annual and monthly results - when needed? Prioritization?

Metering and Billing Issues - Utility cost issues?

Reconciliation with calculations - how much? How detailed? Methods? What simulation parameters are targets and what are priorities for changing?

Energy Use Calculations (with some rollover into measures)

$\gg>$ Main tools questions are handled above under Fundamental Issues $<<<$

Infiltration measurement and/or handling? Ventilation measurement?

Whole building vs individual units

Are different tools needed for heating, cooling, ventilation, lighting (hot water?)

Zoning recommendations for whole-building models? Plenums?

Configuration options - handle all buildings as basic rectangle OK?

People loads, loading, or impacts - do we need ways to handle?

Handling of common areas? Hallways?

Large vs small building issues? (large, medium, small?) What is "small?"

Methods for other uses like appliances - what are key items to cover?

Controls measures - how to handle? Separate meeting on this to share methods?

Should CHP be included? (separate tool? finalize HUD MF CHP tool for this?) 
Energy Measures Selection and Analysis (with some rollover into financials)

How to select/analyze heating and cooling measures?

What measures should be covered? (see separate list)

What about ability to add measures? Rules-based approach?

Whole building vs individual units?

How to handle infiltration/ventilation measures? Integrate into heating / cooling?

How to handle sealing/control of major air leakage paths and ventilation? Stack flow control / reductions?

How to handle garages? Parking? Exterior lighting? Security lighting?

... lighting measures? Integrate into heating / cooling?

... distribution system measures?

... hot water system measures? . . laundry?

... appliances?

... elevators?

... building cooling-heating-power integration options?

... load management options?

Other?

How to integrate into financial calculations? Issues?

Non-Energy Measures

Only documentation of issues/measures? Or quantitative and qualitative analysis (e.g., minimum ventilation rate calculation, measure selection, etc.)?

Comfort issues?

How to select/analyze health or safety (or other) measures?

What measures should be covered? (see separate list)

Are any IAQ issues critical to cover? (might wish to check a HUD Healthy Homes module being developed for NEAT, http://hyperion.ornl.gov:8080/HealthyHomes/)

Other?

Should there be requirements inputs? Or specific standards requirements selectable?

Other types of criteria?

Integration into energy use calculations when appropriate?

Integration into financial calculations?

Financial Calculations

What options to offer for LCC results? Wx program requires SIR

Cost escalation methods? Wx program uses regional approach and annual update of escalation parameters

How to handle energy costs?

Installation cost issues? Recommended approaches?

Any simplifications useful?

Fuel switching? Time-of-day rates? Declining-block rates?

Owner contributions? Issues?

Rebates / other incentives? Issues?

Davis/Bacon issues, deemed labor rates? How to handle?

Reporting

Issues related to how methods affect reporting?

Preferences for results presentation, including LCC results

Other 


\section{WRAP-UP}

Summary of results for the meeting

Next Steps

What would participants like to see as far as feedback? 


\title{
APPENDIX B \\ Transcript of the November 10, 2010 Multifamily National Energy Audit Users Meeting
}

\author{
Held as a Web Meeting, November 10, 2010 \\ Participant List:
}

Nick Dirr
Asit Patel
Chuck Belk
Norm Bourassa
Andy Brooks
Joe from West Virginia

\author{
Luke Ilderton \\ Piljae Im \\ John Katrakis \\ Mike MacDonald \\ Mini Malhotra \\ Evan Mills
}

\author{
Tara Siegel \\ Cynthia Simonson \\ Kath Straub \\ Brody Vance
}

Comments below do not necessarily represent verbatim comments, but the unaltered premise of comments, credited to individuals, when possible. In some instances, the comments have been modified to reduce repetition of content and extraneous information. Clarifications by the moderator have been inserted as appropriate, but not always, if the content flows consistently without the clarification questions being inserted.

\section{Introduction}

Cynthia Simonson

Hello everyone. This is Cynthia Simonson with SMS. I am a contractor to the Department of Energy provide support services to the Weatherization Program. I'm going to be hosting this today and then I will be turning it over to Mike and Mini to go through all of the details.

\section{Development Plan Mike MacDonald}

- This meeting provides important input to a development plan for a proposed new multifamily national energy audit.

- Sponsored by the Weatherization Program.

- What are issues and needs?

- How to fit in to the current situation?

Ok thanks Cynthia. Alright this meeting is related to a project that we have to look at coming up with a development plan for a proposed new multifamily national energy audit. And the primary contact for this project is Mini Malhotra at Oak Ridge National Lab and her email is up there. If you have any questions or suggestions that you would like to make related to any of the information or material that we cover, please send an email to Mini and let her know what you are thinking. As was indicated, this is sponsored by the Weatherization Program and we'll talk a little bit more about how this potentially fits in with everything else. What we're looking at, we had a meeting last week also, what we're looking at is what are the issues and needs related to what are multifamily energy audit program or tool might do and trying to understand how it potentially fits into the current multifamily energy audit situation in the country. So that's the simple summary of what's going on and I think we will go to the next slide and let Mini give you a little bit of the background.

\section{Background \\ Mini Malhotra}

Weatherization Assistant suite of tools includes NEAT and MHEA now, multifamily (MF) tool to be added.

- Web-based version of Weatherization Assistant by summer.

- Other planned tools - Health and Safety (H\&S) module, Non-energy benefits (NEBs) module.

- With limitations, NEAT can be used for individual units with their own systems in small MF buildings.

- Inputs form weatherization $(\mathrm{Wx})$ community articulate the need for MF audit tool, yet beyond-Wx capabilities will not necessarily be excluded.

I can see several names who were in the last meeting but for those who are new to this meeting 
most of you are probably familiar with Weatherization Assistant which is a suite of tools which currently have NEAT and MHEA. These two NEAT and MHEA tools are two approved tools for auditing single family and mobile homes. Under this umbrella program for DOE's weatherization, the umbrella program is just called Weatherization Assistant and several additional capabilities to NEAT and MHEA for management and tracking the status of work and several other things. To expand the scope of this suite of tools ORNL has planned to incorporate a third competent, a tool for auditing multifamily buildings could start the common database in management capabilities of weatherization assistant will be shared by all which will additionally build around NEAT and MHEA. Presently this suite is supported as a desktop version and an effort to create a webbased version by summer 2011 is underway. This will allow the agencies to store data at a central location and let DOE and states access the database and use it to evaluate the program effectiveness. And it also will be easier to keep the agencies informed about added features or new versions. So, with this plan, we are planning to develop the multifamily audit tool as a web-based tool and incorporate in the web-based versions when it is released next year. In addition to that we are also planning for two more modules, one is Health and Safety module which is currently being developed at this time as a new module. With support from HUD this module will later be integrated into the suite which will help auditors investigate and remediate Health and Safety issues in dwelling, multifamily or single family or manufactured homes. The issues that could affect the way weatherization workers perform are the issues which could be items of concern after the unit is weatherized. The second planned module is nonenergy benefit modules which will assess the cycle of economic benefits of weatherization work like occupant's health safety and comfort, environmental benefits, jobs created or avoided cost of several items which could result otherwise. So that's the overview of how we envision the entire suite. This multifamily energy audit capability is one that has been felt very much needed by the states and agencies who use the suite. They have been using NEAT for auditing single, individual in itself, small multifamily buildings. But there are several limitations because NEAT cannot be used for evaluating the different options for building and system competence which are shared between units. Our goal is to incorporate the tools for multifamily audits that address the multifamily weatherization program approaches and consider beyond weatherization capabilities also. So that's the background I wanted to give you all. I guess Mike can explain about the scope and the flow of the meeting, Mike please?

\section{Purpose and Scope \\ Mike MacDonald}

- Initial effort is to complete a Development Plan that lays out recommendations on the development path and capabilities, requirements, and issues.

- Input from this group and an Audit Methods Group that met last Thursday, Nov. $4^{\text {th }}$, will help define what is in the development plan.

- Need is to scope how/if the proposed new MF tool can be an important contribution to $\mathrm{Wx}$ program needs.

- But also how national such a tool might be, beyond $\mathrm{Wx}$.

Ok thanks Mini. So this initial effort is looking at a development program to lay out recommendations and what some of the options are on development path capabilities, requirements, and issues and also how this suite might actually function. We had input from an audits methods group that met last Thursday and then we are going to use the input from this group to help round out a lot of what we learned last week. And we need to understand better exactly how and what a new multifamily tool might or could contribute to weatherization program needs and if it extends beyond just weatherization national such a tool might be.

\section{Proposed Flow of Meeting} Mike MacDonald

- Background on your work - as in agenda.....up to 20 minutes.

- $\quad$ Energy measures - what ones, issues.....up to 40 minutes.

Approximately 60 minutes for all the rest:

- Pre-audit issues - toolbox?, setup, financial.

- Energy use calculations - baselines?, measures?

- User Interface/Input Capabilities

- $\quad$ Non-energy measures - how to handle/options. 
- $\quad$ Financial Calculations - how to handle/options.

- Reporting capabilities - needed/desired.

- Database to allow for building score - how it compares with other buildings...

- Wrap-up discussions.

Ok so what we are proposing for the flow of the meeting, we can change this if folks have something particular they want to go over, is first of all to get an idea from some of the attendees, what they are doing and the work they are doing in multifamily. And then we would like to focus a little bit more on energy measures than the discussion last week. By the time we got to energy measures, folks were a little bit burnt out, so we would like to look at that as the second item. And then look at these other items like audit set-up for pre-audit...if you have any thoughts or ideas about energy calculations. We didn't discuss user interface/input capabilities much last week and if people have particular ideas for that then I can hear those today. And then anything we have on nonenergy measures, financial calculations, and reporting capabilities then we will try to wrap up and I hope we will be done around 3:00pm sometime so that we don't get anybody too strung out trying to go through all of this stuff. So are there any questions or suggestions about the proposed flow before we get started?

\section{John Katrakis}

Ah, I have one suggestion...this is John Katrakis from the Chicago area. Can you hear me? I don't know if this was discussed last week at the last meeting but I'd like to see some kind of work done to develop a database that allows us to do a quick call like an energy score or like an energy star rating of a building to compare it with similar buildings in the weatherization area. And I'm finding well it's not you but, one of the biggest factors that determines the savings from a suite of measures is what is the current energy intensity of the building and in the Chicago area it would be therms per square foot for a normal year of weather. That is the biggest variable that affects the suite of measures and the SIR for the package, so I don't know if this was discussed last week but I think it would be something that would be very helpful to integrate into this audit tool. It also would be helpful as far as performance evaluation and that kind of stuff later on.

\section{Mike MacDonald}

Ok we can go over that in the toolbox piece if you can remind us about it when we get there.

John Katrakis

Sure, sure. Assuming I'm still on at the end.

\section{Mike MacDonald}

Yeah well I hope...

John Katrakis

I can also write up my comments and send them to Mini.

Mike MacDonald

Ok yeah that would be great. Any other questions or comments?

\section{Energy Measures \\ Mike MacDonald}

- Discussion/comments on listed measures.

- We heard about solar DHW and controls coverage: what others?

- Issues:

- Are multiple calculation approaches needed to check against each other? Would you use this feature?

- Ventilation or lack raises major issues: input/model needs?

- Controls measures are hard to model: model options?

- $\quad$ Ability for users to add measures?

- Other

- Cogen or Trigen systems?

Alright so, we are going to try to focus on energy measures when we get going but before we take off, maybe John, since you were just talking, do you want to tell us a little bit more about what you have been doing in the Chicago area and what you know about what others are doing in multifamily?

\section{John Katrakis}

Sure. I've been involved with multifamily energy audits and retrofits since the early ' 80 's in the Chicago area, mostly in Chicago. Most of our work has been the very common three-story walk-up buildings that have mostly steam heating. These are about 100 year old buildings and there are about 20,000 of them in Chicago with an average of about 15-20 apartments per building. More recently 
we've been doing work with larger up to like 25-28 story buildings again in Chicago and they have of course quite a range of HVAC system types. My folks have been doing the heating system assessments and running up scopes of work. Initially I worked on private non-profit programs and in the last, I'd say 10 years, I've been working for the local weatherization provider CEDA for Chicago and it's been ramped up a lot in the last 4 months and again doing a wide range of buildings from the original 3-story walk-ups to 10-20 story buildings. So we do the energy audit and then we do the work order and on the smaller jobs we try to integrate the audit and work order into one package. For other jobs we do a separate...call it a design build spec for the larger systems. So that's it in a nutshell.

\section{Mike MacDonald}

Yeah that sounds great. Let's see, Brody Vance has to jump off. Brody do you want to give a summary again of what you are doing in Wisconsin?

\section{Brody Vance}

Sure. In terms of the two different programs that our company, Franklin Energy, works on, one would be the statewide focus on energy initiative where everything is market rate apartments and condos to low income as well; there is no criteria for income necessarily. Our programs start from 4 units and above so you see anything from small again to large high rises. Our measure mix is anything and almost everything that would save energy. So we have custom projects as well as prescriptive. Building envelope, lighting, HVAC, domestic hot water, are all in the mix. Then the other program is for the weatherization agency and it's actually for DOE. We then start with 20 units and above and the measure mix has to obviously follow federal guidelines, certain things that you can't do such as LED lighting isn't embraced by that program or certain other things that maybe we would with our focus on energy efforts. So that's in a nutshell what we've got going.

\section{Mike MacDonald}

Ok thanks that's helpful. Andy Brooks, you're doing work in California as well as you've done work back east. Do you want to give us a little idea of some of the mix of stuff you have seen?

\section{Andy Brooks}

Sure. Well in New York, AEA is the provider for the weatherization network and we also do a lot of work, we administer multifamily programs for local utilities. We've done one for National Grid and one for Con Edison and we've also done a lot of work under NYSERDA's multifamily program. But primarily we do the audits for the weatherization network on all multifamily buildings in that area, in New York City. And we pretty much, there, have seen absolutely every time a type of building stock there is from garden style apartments up to high rise $30-40$ story buildings. We really have gotten kind of a broad look at all of the different types of multifamily buildings there are. And our focus, our work flow is similar to what Mike was saying in Chicago. We do the audit and then develop the scope of work but then we also provide specifications for like the larger heating system upgrades or really any boiler replacement or anything like that. We write down the specifications for those projects. Now I recently moved out to California and we are doing some work out here as well. I am also working with the weatherization network out here as well and yeah the buildings are different there's no doubt about it. I mean the types of heating systems that I'm encountering out here, you know it's less on the central systems side so just in terms of the tools that are going to be used there has to be a little bit more versatility in terms of... a lot of the limitations on tools that are out there now are based on the fact that you can only deal with single central systems and it's hard to kind of mix heating systems. We talked about it a little bit last week. I'm getting a little more exposure to buildings out here and how they differ from New York and so far that has been the main issue but I'm sure that I'll see more.

\section{Mike MacDonald}

Ok and then Luke in Colorado, do you want to give us a quick summary again?

\section{Luke Ilderton}

$\mathrm{Ah}$, yes so I work for an organization called Energy Outreach Colorado and we are the multifamily weatherization agency for the state serving statewide all high rise and low rise multifamily buildings. We also work with most of the major utilities here in Colorado or demand side management program specifically on low income buildings for those management opportunities and also we deal with the city of Denver retrofitting most of the non-profits in the city limits. And you know basically we are allowed to consider all measures except for cooling in Colorado even though in Denver it gets excessively hot here in the summer time. But we analyze most of our buildings using TREAT and EA-QUIP in the weatherization program and then outside of weatherization we pretty much utilize EQUEST. DOE2 and TRANE 
and HAP for any sizing and load calculations. We generate...we obviously produce all of the models, we produce all of the field reports for the audits, we generate all of the data specs and scope of work, and then we put that out for procurement for subcontractors and manage the implementation of all of the installs.

\section{Mike MacDonald}

Do you ever get requests in the weatherization program to look at adding cooling?

\section{Luke Ilderton}

Last year I petitioned the DOE to consider replacing PTAC units, just because the majority of the PTAC's we see out here are 20 years old or older and they are providing quite a bit of ventilation because they're...most of the buildings you know the passive ventilation of just opening the window really is not an option in Denver in the middle of the summertime especially downtown so...you know and we were given some guidelines and for the most part the guidelines that we had to require were based on the data was based on room air conditioners and it really never was cost effective. Given the guidelines from DOE to really to be able to install any of those units so...we're going to continue the fight but, as of right now we're not allowed to address any cooling measures.

\section{Mike MacDonald}

Ok ok so right now cooling is a potential issue. Ah, does anyone else want to say anything about what is going on in their area and what you're doing or should we jump into measures now?

\section{Evan Mills}

Um, this is Evan Mills from LBL I can introduce myself if you want.

\section{Mike MacDonald}

Yeah go ahead Evan.

\section{Evan Mills}

Ok so I'm at Lawrence Berkeley Lab and me and my team are the developers of the home energy saver websites since the mid '90's. The DOE weatherization program has asked us to come into this work and work with Oak Ridge on weatherization related tools and we will be adding multifamily functionality to the home energy saver pro web calculator and also adding weatherization relevant features and functions to the single family tool and the consumer facing tool called the home energy saver. So that's our interest and our role here.

\section{Mike MacDonald}

Ok, anyone else?...Alright, people who received the meeting notice should have gotten this measures list and I know we have some interesting comments on measures already.

\section{Mike MacDonald}

Ok, but to start out with, we did hear about solar hot water as a measure that needed to be...the analytical capabilities folks are using, ret-screen or f-chart now and that it would be handy to have that integrated into another audit tool so that you didn't have to use as many multiple tools and I think we're going to get into toolbox issues later so some of the stuff is going to go back and forth. But feel free to jump in on things that you would like to mention that maybe, you know, goes later and that's fine. We can move it all over if needed. But one of the things that, I think one of the main issues, like for control measures, usually when we are doing control measures calculations... if you have a simulation engine of some type or audit calculation of some type, you are usually tricking it to try to give you the kind of savings that come from controls because usually we are basing our estimates of savings for controls measures on studies that have been done that indicate the savings that are obtained with different kinds of controls measures. So I wondered if folks had any comments on how that should be handled because the two items, the two methods that came up were...for some kinds of measures you need a simulation engine but for other types of measures you're essentially looking at expected savings. And so does anyone have any comments on controls and the best way to handle those kinds of measures and if the controls and scheduling measures are on the list now and whether anything should be added? I guess maybe for Evan's benefit until he gets this email. The list right now, they're generic, but one is raised cooling set point lower heating set point and then set-up and set-back and then energy management system and humidity control are just on simple controls and scheduling. And then there's a space heating system category that has thermostat or other control retrofit and then in distribution systems we have potential installation or repair of controls or sensors also. So any thoughts from anyone on the ways to handle control measures and the audit setting or even talk about what you are doing now? Anyone want to chime on to begin with?

\section{John Katrakis}


I can make some comments on that. This is John from Chicago. On our steam buildings, back in the ' 80 's we did some detailed comparisons of different controls in the field with some shared, sponsored research money and three or four different options that we either see in the field or implement so we basically come up with a percent savings based on the research that we did and assign that to the measure it's also based on some idea or some measurement that we can't, ideally the actual temperature that's in the space because it's so much determined by what is the current condition in many cases we may have to increase the temperature in the building but the savings that we do have for different controls strategies is based on...primarily it's based on a combination of looking at how to fix the blower cycling and how to fix the average temperature versus the minimum temperature in the building so it's very specific to a type of building and that's the only way that I can see doing this is to find a specific savings to a specific count of improvement is to do some testing as you mentioned in the field to try to from there apply it to a specific situation. There has to be a very specific...specific kind of test on a specific kind of building and control system. We've done this for single pipes steam and we also have results from work done up by the Minneapolis people on how to reset controls and we use that information...pretty much that's the best that we can do like pretty much the approach that you mentioned earlier. Taking the results of similar types of control systems and heating plants.

\section{Evan Mills}

This is Evan at LBL, I second the motion. I think you know that each building is different to a large degree. I come a lot from the commissioning perspective which I know in our field we apply mostly, I mean John I'm sure is the exception, but we apply mostly in commercial buildings but really, that's one thing that's very intriguing about multifamily for us is thinking about bringing the commissioning sensibilities and techniques in there so you know understanding the sequences of controls that are in place for the better or worse and being sure that the tools can kind of properly characterize those just as they are and evaluate their energy implications and evaluate improvements and sequences. There are also things that may be out of scope here but you know are the sensors calibrated, are the sensors accurate. You know part of an audit is part of an assumption certainly that's certainly built in to a model that you know is often blind faith that the sensors are actually doing or controlling the building the way you think they are or providing the feedback that they are. So those are some kind of higher level thoughts that I would have about the controls I guess interfacing also with proprietary systems that are out there and to those...how do you know of get the data out of those systems that are useful for the tool and how much does the tool bend to fit the system, or is there a need for middle-ware so that a variety of systems can be kind of interrogated I guess, right to get the inputs...

\section{Mike MacDonald}

What was that term you used...middle-ware?

\section{Evan Mills}

Middle-ware is just a... if you have a Honeywell system or a Johnson system, whatever they are and you want to get certain information out of them that goes into a tool is that straight forward or do you need some kind of software in the middle to listen to each of those systems you know translate data into inputs that fit, you know fit the energy audit tool.

\section{Mike MacDonald}

Well any comments from anyone just lets touch on sensors briefly for a second does anyone run into situations where they really have to look at sensor issues or do something with sensors from any of the folks we have in the field right now?

\section{Asit Patel}

Um, hi this is Asit Patel. I think that sensors issues are very critical especially like what John mentioned, we also raise issues with the typical multifamily building with a central boiler plant with a controlled system that is outdoor temperature and then one sensor somewhere in the building and typically not in the space is intentionally heated. The mark of penetration in New York is or the control is a heat timer where it has an outdoor sensor but the indoor sensor somewhere in basement. And we don't need figure for a lot of time where the sensor locations are the wrong place. The sensor is supposed to give you a feel of what's going on in the building yet we find sensors installed right next to an open basement window. We find sensors insulated sometimes with the pipes so it doesn't actually reflect what's going on in the building and a lot of times we find sensors right in the boiler room. A sensor that is supposed to reflect what is going on in the building is in the boiler room right next to a boiler. So those are major issues and in the... a majority of the time we are with this type of situation where the projection for energy savings is growing over an expanse and we 
say ok we know the sensors are not calibrated or not installed properly or the control is not setup properly and then we basically are recommending upgrades either to the control settings, relocating the controls, or replacing the control system. The savings are based on reduction in the temperature that we are hoping to achieve by doing multiple of these things in a combination. Just one more point towards what John mentioned and Nick... have a go...

\section{Asit Patel}

In New York City as a master spec, we have started to install the same control system now with capabilities of having space temperature sensors and also some other data points that we collect that give us an idea about if the building bounced and get some different perspectives of that. That's a major challenge in most of our buildings the overheating and under heating is the cause of the major balance issue. So we are actually now distributing the sensors strategically throughout the building so that we can collect the information over a long period of time and continue to help the owner balance the building down the line. We can also continue to monitor the boiler operations and space temperature so they can keep on fine tuning this that is basically the whole idea. But commissioning so that we don't have to back through the buildings over and over again, we can just do that sitting in the office. We are just doing that with a lot of our utility programs that we manage; as a matter of fact we just had a meeting with one of the manufacturers about that.

\section{Mike MacDonald}

Yeah that gets into, I think the LBL folks are calling that measurement based commissioning but, that's very interesting. Um, but...monitoring based, yeah ok. Ah, alright...

\section{Evan Mills}

...the complaint minimization...you know we all know very well if sensors get located in the coldest apartment or something and people would complain less if they were overheating rather than under heating. So some of this seems to point towards, you know there's like a modeling related function that the tool can have or that the data can have but sometimes have more of an expert system kind of approach just to validate the sensors, are there any sensors you know are they located well and a tool could generate savings numbers but it could also generate qualitative feedback in some cases like improving the configuration of the controls. Maybe you punt and you have the tool generate some savings numbers but that may not be necessary to give useful feedback.

\section{Mike MacDonald}

Yes, I think there are two items that come to my mind here, one is that it seems there may be a need for some type of resource, some type of information savings information resource on what some of these measures do and maybe it's something that could be added to if people wanted to share their experience but, there might be some kind of a potential benefit from some type of shared data store, some kind of information base on some of these measures so that people could potentially contribute what they've learned and what they're using and we could summarize any studies that have been reported, possibly. But um one of the other items we had down there was to look at whether we want to be able to add measures and in the sense that this type of expert calculation can be fairly simple as far as what the parameters are or the actual numbers that get put into the calculation...I am wondering if folks think there might be a benefit, because we are wondering whether we should be able to add measures but it almost sounds like some measures need to be flexible so that you could come up with potentially maybe display some defaults parameters that would go into some kind of savings calculation and maybe folks could check what type of a calculation they want it to be what type of parameters there should be, there may be two or three or four choices. And they might also change the percentage values...yeah go ahead...

\section{Evan Mills}

... Norm Bourassa from our team just joined the call, Norm just came to LBL from the California Energy Commission and he's working full time in the home energy saver project and he'll be taking a lead role in the multifamily work and this kind of conversation is very relevant to him and he also has a lot of experience in commercial buildings...you know there's that interesting overlap and crossover here that he'll probably be able to being some good conversation to.

\section{Mike MacDonald \\ Well Norm...go ahead...}

\section{Norm Bourassa}

No I arrived just as you were...I just came from the east coast and my computer was still on east coast time, so I missed the call to join on time. But I 
arrived just as you were discussing about control strategies that we'll pay attention to the most sensitive zone so you don't end up with over cooled or over heated areas of the building. And I expect that what you are discussing is the same methodologies that have been used in large commercial buildings and address those, those control problems...is that what this discussion is about?

\section{Mike MacDonald}

Well no it's about a lot of different things but we're just looking at potential measures and what we have to be considering because we are just coming up with a development plan for a proposed tool that would look at multifamily buildings. And when I say tool that may not be the right term and we'll maybe talk about this more a little bit later.

\section{Norm Bourassa}

Oh we don't need to go back; you don't need to go back, I don't want to hold the discussion. I think I can follow it. I can get enough...

\section{Mike MacDonald}

Well, what I was wondering, yeah that's fine, what I was wondering is do you have any comments about what you know or have learned about MF in California that you think is particularly important to consider?

\section{Norm Bourassa}

At the moment, no. It's been a very underserved segment of the building structure and in here in California when I was running the PIER buildings program we were under-addressing the specific needs in that area. So this is one of the few areas where California really doesn't have a lot to offer at the moment. We are nationally in a very uneven footing. You know Nehemiah Stone has done some work here in California but we have all been, we're all on a very...

\section{Evan Mills}

One thing to interject is that in California, not the research level per se, but the building stock, and California's not unique this way, but it will be very different from what people see on the East coast. Maybe the systems and fuels and just the size of the buildings. We have a gigantic proportion of our quote MF occupants in very small buildings here, even down to five, six, seven units. And they're like single family homes in some respects, some are even converted. Something like seventy-five percent of San Francisco dwellers are in tiny buildings. But there still are central systems in common areas and things that make them true MF buildings. So as far as a tool's ability to characterize geometry and the type of systems, it's important to think about these intermediate or smaller buildings.

\section{Andy Brooks}

It seems like just now California's beginning to really mobilize and take on MF as an issue and there are a lot of groups that have been working really hard to get the whole building programs out right now. One of the issues that has come up is, do we treat the small MF buildings as we would treat a MF building in New York or do we treat them, both from a modeling perspective and an analysis perspective and also - then also from an information and diagnostics perspective, like a large single family home? Do we address each unit individually and go around and do blower doors or do we view it, even if they have a central system, do we blower door each unit, the whole building or not at all? What diagnostics apply and what kind of modeling approach do we take has been one of the big questions that a lot of people are wrestling with out here right now.

\section{Norm Bourassa}

At the Energy Commision we were investing a lot in the blower door testing work and trying to get those methods to work in commercial buildings and those problems have not been worked out. It's incredibly complicated and we're going to find the same kind of complications with MF buildings. Where do you do the blower door testing, at the zonal level or the whole building level, and the interactions get complex very, very rapidly?

\section{Joe from West Virginia}

We're working on a couple of complexes built originally as townhouses and they are, for all intents and purposes, single family. So what I would like to see is an upfront interface that would take you through a decision matrix with one of the intentions is to knock them out of the MF dwelling category and say no, you can address these as individual units. They have their own heating systems, they're significantly isolated, they have their own attics and foundations, there's a good firewall in between them. That would open up more opportunities, particularly for a small weatherization community action partnerships. With our current program, if this is considered a MF unit, we have to complete and inspect every unit in the building before we get paid. But by definition, we're a non-profit so funding that 
becomes difficult. If the goal is to get more of them done, this might be a way of getting them out of that category and into a category where we can more readily do them.

\section{Mike MacDonald}

There are a number of state issues we have heard about and I'm not sure we can address them in the development plan. There may be a need for flexibility in how state issues are handled. For the plan, we'll have to say that we need to address that in some fashion but we're not sure how yet. Any comments on other areas?

\section{Evan Mills}

I don't know if the laundry system one is explicitly recognizing central laundry facilities. I don't know if there are different heat recovery options there, but in any case, they're often not in the individual units. Whether it's in the unit or centralized might be important. I imagine the pools that would come up would be unusual in the properties that are targeted by the weatherization program. That should be treated as a significant other kind of end use. Other common areas, not just stairwells but recreation rooms, common rooms, would be a space type and maybe not the purpose of this list.

\section{Norm Bourassa}

You might want to change that entire category.

\section{Mike MacDonald}

We were hoping for an implicit understanding that this whole list might apply to common areas and the whole list might apply to the balance of the building, but we weren't trying to exclude common areas. There might be some common areas things that would be exterior that would need to be addressed when you're doing the whole building.

\section{Nick Dirr}

There needs to be flexibility for having different kinds of heating systems in one building serving different types of zones. A lot of times we're treating a building as one large box with a central heating plant but it may actually be a combination of three different boxes. Maybe one has a conditioned corridor air and one has hot water system and another part of the building might be baseboard electric heat. Having flexibility on modeling heating systems, what percent of total load they account for and what zones they condition is important. To have a suite of options when using a MF tool; we've already talked about eight different types of buildings you could walk into and to force a rowhouse building through the same sort of process that you do with a high-rise building with mechanical ventilation, it's two different approaches. When you walk into a modeling tool, to have four or five different options and you choose the one for your particular type of building would be really helpful.

\section{Evan Mills}

In the discussion about measures, is there an official list of some sort of the eligible measures?

\section{Mike MacDonald}

It varies by state for the weatherization program so that makes it a lot more complicated. We have to somehow be able to let the state options kick in here. We're not exactly sure what has to kick in and kick out.

\section{Evan Mills}

A great utility to go with these tools would be a web-service, so sort of centralized repository that kept current all that state information of allowed tools or other entities to generate state by state lists, not the savings, just here's what's in, here's what's out. In the administrative context in which the tools are getting run, if they're only supposed to limit their analysis to a certain set, that has to be regulated and hardwired into the software somehow. NREL's developing this list of residential retrofit measures and maybe that's a place if DOE and all of us could ensure the whole universe of measures was in that database and if there was a flag or some way to interrogate that web service and get the names and characteristics of these measures, that would be a great resource for the tool developers rather than each tool having to keep track on its own, they could perpetually be out of sync with each other.

\section{Norm Bourassa}

Those at NREL working on that are Marcus Bianci, David Roberts and Ren Anderson. We're working with them on evolving the tool. Right now it's in $\mathrm{xml}$ lookup, which is kind of a clunky methodology. If this project is interested in it, we might want to look at a more elegant, more extensible fashion for the tool.

\section{Mike MacDonald}

As we move forward here, the whole issue of web services is going to be linked to everything that's happening.

\section{Norm Bourassa}

Yesterday at the scoring rollout there were a couple of industries there that were asking me if the retrofit 
measures will move into a much better web service type of a format. Having the weatherization be interested in that as well will be another push-pull factor to get them to modernize it.

\section{John Katrakis}

I think that district heating in Cogen is a real big thing in Europe for MF. Is that something that's being capitalized or considered being capitalized anywhere in the US?

\section{Mike MacDonald}

I don't think there're too many places where district systems work, but there are some.

\section{John Katrakis}

What we see in Chicago is to go away from dual systems to individual boiler rooms. We did a lot of work with citizens back in the ' 90 s doing just that because the maintenance of the underground steam extrusion systems was just so high. We got savings just by going to individual boiler rooms, hot water boiler rooms rather than steam. You're talking about old technology that's just too hard to maintain and we opted to go to individual versus trying to replace that with a hot water district heating system.

\section{Mike MacDonald}

You have to keep in mind that when you're in a very cold climate and you have a continual need for heat most of the year, then the distribution losses become less of an issue. Distribution losses, maintenance and budgets in general

\section{Evan Mills}

But what John described is a mega measure and we're dealing with the building stock that we've got now and wanting to go better and so it would seem like it would be characterizing those kinds of configurations where you do have a district system and then if we can assess in these tools the savings, that would be the thing to do. It's a higher level kind of measure but it's a really good one.

\section{Mike MacDonald}

But you almost never run into a situation where the district system is even a possibility. I guess my question was a little bit simpler than that: Cogen or Trigen for the individual building?

\section{Andy Brooks ???}

I think there are a lot of applications where Cogen is applicable in MF but I don't know that's it's an approved measure anywhere. But if you included it in the tool and we could analyze COGEN on a building by building basis, then states would begin to adopt it as an approved measure.

\section{Norm Bourassa}

I've done a lot of analysis for Cogen in commercial buildings and the problem is, there's not a lot of need for the heat, you can only use so much hot water in a commercial building. But in a large residential, you could use a lot of that heat for domestic hot water, especially.

\section{John Katrakis}

It's also very much a function of the local utility rates and I would say we're better off focusing on energy efficiency improvements and cost cutting rather than trying to feed an energy hog of a building. I'd make that a last priority, adding a Cogen to a site, after exhausting all the cost effective, energy efficient measures first.

\section{Andy Brooks ???}

One other thing we've been asked about a number of times is steam to hydronic conversions. We've tried a couple of times to do analysis on what the savings would be but it's very complex because there's a lot that you can't really quantify. There are buildings out there that are steam that want to switch over to hydronic and there's definitely going to be savings associated with it. It's certainly a larger measure and a larger opportunity to look at

\section{John Katrakis}

There's been some good studies about that done by the Center for Energy up in Minneapolis and every so often we do that kind of analysis on our buildings in Chicago and it makes some sense in two pipe steam buildings because the piping is pretty close to what you need for hydronic. Payback is typically long and it really depends on the initial condition of the building. If it has a very high energy use index, than it may have a decent payback. But if it's already pretty efficient, than it's not worth it. The initial energy use index is a key factor.

\section{Pre-Audit Issues}

\section{Mike MacDonald}

Let's move on to the next topic which we've already been discussing to some degree. What should this toolbox be? The weatherization assistance has right now the national energy audit for single family and the mobile home energy audit and it's going to be adding this health and safety module and this non-energy module and now we're 
looking at MF. And as we get into MF it seems like it may need to cascade, to a degree, or be flexible and configurable depending on what state it's in. So the general question is, if you think about what this toolbox might look like, if you have a direct access to say NEAT, and you can do individual units in MF where they have their own heating and/or cooling system, that's good for those types of buildings, potentially. And if you had a MF audit tool you might be able to get there. But it could be there are multiple kinds of tools we would want to have available. If anyone has any thoughts on how the toolbox could be configured, throw them out now and if you think of things later, email them to Mini.

\section{John Katrakis}

I think the toolbox should include indices for different types or categories of buildings. The toolbox has to be customized for say, single pipe steam in Chicago, two pipe steam in Chicago or New York, hydronic on the coast of California. You need to have a toolbox with the five or ten most common building types and develop databases of pre- and post retrofit performance along with ECM measures that are the most common basket for each of those groups of buildings. I think it would be helpful to have that kind of structure and organization in the toolbox.

\section{Norm Bourassa}

Something I think is fairly related from the commercial building is I was involved in a group called the California Commissioning Collaborative. And for commercial buildings, building commissioning is one of the best ways of characterizing the needs of the building. And the industry was growing and there was a shortage of providers on the street. We were addressing what you are talking about now, putting together a toolbox of standardized tools for this growing industry because you had certain providers who had their own tools but the new people coming in hadn't grown their ability to deliver services and there was kind of a gap there. But all agreed that there is certain standardized calculation methodology that everybody could capitalize on. So, we might want to look at what was done at the California Commissioning Collaborative because there are a whole bunch of calculation tools, very simple things like how to do pump calculations, how to correlate to utility bills and these kinds of tools that every energy engineer or building commissioning agent would need. And the benefit of this is that it also started working towards standardizing these very basic assessment tools for the industry at large and it really helped to grow the confidence of owners. They were able to evaluate all the providers in a standardized way. I think it's a good proxy for the kind of collaboration that we would want to spark.

\section{John Katrakis}

I think the toolbox has to be customized depending on the kind of delivery programs you're talking about. We have people here; I include myself, who have worked on the weatherization program which is more of a cookie cutter approach to customized work on large commercial and industrial facilities, so the toolbox will have to reflect those various approaches. What's the first priority? Will this be a generalized tool that can be customized for each of these programs?

\section{Mike MacDonald}

I think the question will be, how do we get the tool to have as much functionality as can be done for the resources that are available and that there will be certain ways to have it click into weatherization program mode and exactly what it does when it's not in weatherization program mode is a lot less clear. Fundamentally, this tool has to meet the needs of the weatherization program, but since there's so much overlap for what you do for weatherization and what you do for others, we're not sure how it can potentially work for other programs, but we don't want to rule that out.

\section{John Katrakis}

The first version of the MF program that I worked on in Chicago, we required copayment by the building owners. This new version, affects the stimulus money, does not require any financial involvement on the part of the owner. So that could result in a very different tool. In one case, the audit tool has to be used to convince the owner to invest in the work. The other tool, the more current tool, could be a very simple "here's what the staff need to do" and who cares if the owner really buys into it or not. Another fact is that the tool has to be customized to reflect the particular financial participation of the owners and I think preferably that should be the foundation that we present a tool that provides useful information that helps the owner to make a decision on what to invest in. But then to streamline the program, you'd want to have all the options to basically allow the local provider to streamline the process as much as they can. But I think the base still needs to be a tool that results in a useful, written document so the owner can make 
the best decision possible in how to use their own money in the building.

\section{Energy Use Calculations Mike MacDonald}

For Energy use calculations, any particular comments on how to handle the baseline or the initial calculations of energy use?

\section{Evan Mills}

I think one thing that is important, I don't see here exactly but it may be implied or elsewhere exactly is benchmarking. It's one thing to get the bases load for the building in question but is there an aspiration to also for the user to put it in content.

We obviously just went through a big process with that with developing home energy scoring tool and overlaying other methods to build in context...

\section{Evan Mills}

Benchmark in that part of the base lining process communication of the base line number and building in question.

\section{Mike MacDonald}

Right, okay.

\section{John Katrakis}

I agree, to me I think that is one of the most important things we can do at the national level or centralize it at the database. That has a major effect on the amount of work that can be done in a particular building. To me that's a first priority, to tell you the truth.

\section{Mike MacDonald \\ Interesting, okay.}

\section{Evan Mills}

The way that plays out over time is trend analysis or whatever one might call seeing how the building is trending again with the reference point of that benchmark.

\section{John Katrakis}

We also use that as a selling tool to the owner. For example, in the current audit we do for CEDA, we actually rank the building based on similar buildings and say your building is more efficient than $50 \%$ or $90 \%$ of the buildings in this area. We do that, CNT does that. At the Center for Energy (Note: CEE in Minneapolis) they started up their own private retrofit program for multi-family housing. They do the same thing, it's a very helpful tool, very much like EnergyStar. And we have pretty good idea based on space heating but not as much on domestic hot water. It would be helpful to start developing databases for domestic hot water which would also be more generalizable around the whole country too.

\section{Mike MacDonald}

Okay, and John the Chicago data could be made available if we wanted to sees something to start.

\section{John Katrakis}

I could do what I can. You know by being a private consultant, I don't have much time. I would love to work on this especially if it was contract.

\section{Mike MacDonald}

Okay.

\section{John Katrakis}

But of course, you can also talk to T\&T about resources they have on this. They actually share some of the data.

\section{Mike MacDonald}

Yeah, okay.

\section{Evan Mills}

I always forget, the portfolio manager doesn't do multi-family building, is that correct?

\section{John Katrakis}

No, CBECS has data for that.

\section{Mike MacDonald}

No RECS has data on Multifamily and there is a big HUD database that has been used for some benchmarking tools. And HUD has benchmarking for multi-family. So we can look at that and talk to HUD about data to try and come up with something initially. So that's definitely a possibility. But there is only like 500 observations in RECS for multifamily. But it's a start.

\section{John Katrakis}

You almost want to get the individual service providers to develop their own database because to some respect, ideally you want to have a local tool. Like a New York database, Chicago, LA, to be most useful to the service provider to see what their peers are doing.

\section{Andy Brooks}

I would add that NYSERDA multi-family performance program in New York, they created a benchmarking tool that referenced the HUD database. And as soon as we started using it, we 
were finding that all of our buildings were scoring extremely low on a scale of 1 to 100. Many of them were below 10. And we figured out probably the reason for that is, in many parts of the country where this HUD database was pulling buildings from they didn't have common areas. The type of common area loads that we have in New York. We have very high common area electric loads that weren't accounted for. So you're basically not comparing apples to apples. You're comparing buildings that have high loads that in central areas to buildings that don't have those central areas at all.

\section{Evan Mills}

Plus your comparing, it sounds like Los Angeles to New York and the climate.

\section{Andy Brooks}

Right, right, well no, no, they normalize for weather though. It was really more of building structure factor.

\section{John Katrakis}

Even so, it's hard to normalize because you have different balance point. It's tricky to normalize at very different climatic areas.

\section{Mike MacDonald}

You tend to have local variations in system design, code requirements and that kind of junk. And you don't know...I think maybe what Andy was alluding too, there's a difference in central ventilation versus no central ventilation that might be driving some of that. The HUD tool also had a laundry variable, central laundry variable that tended to drove things around a little bit.

\section{John Katrakis}

Same with the cooling factor.

\section{Mike MacDonald}

The cooling factor. I think it is important that we at least mention the need for local but it can be hard to find resources to do that kind of stuff but we will definitely mention it.

\section{John Katrakis}

Is this something that the local weatherization people are now collecting, I can ask CEDA (note from Mike M: Community and Economic Development Association of Cook County, Incorporated) in Chicago as to what they are doing as far as a database.
What we are finding is that there may be data somewhere but no one knows how to get it. But we can ask.

\section{John Katrakis}

I'll be talking to our manager on this so I can ask and let them know you are interested in the information. See what happens. It should be something that comes from DOE to the Weatherization providers that they start collecting this information because it's important that it can be shared.

\section{Mike MacDonald}

Well, we've got to be able to work it from both ends. We need to be able to frame the questions reasonably. I don't think we have a good idea of what kind of data folks are tracking on multi-family and whether there would be enough information to do some kind of breakout by system types or something. That can be pretty challenging to get down to, but we can ask.

\section{Asit Patel}

In New York, the city just passed a law that any building that is more than 50,000 square feet, has to have a benchmark done every year using the portfolio manager. They are actually building a new multi-family component to that too. But it doesn't actually go into detail about systems types; it's just building types not system types.

\section{Mike MacDonald}

Well that would be a good start.

\section{Asit Patel}

It would be a good start but not in the details that we would like to see. But it would be a good point — that's what we are looking for in that.

\section{Evan Mills}

It's what occurred that EPA is building multifamily into portfolio manager or is this more of an add on that's happening outside the portfolio manager website itself.

\section{Asit Patel}

They are going to build in the component. So right now, for example, in portfolio manager they have components for schools, institutional, retail, they are going to build in a component for multi-family building. It's supposed to come out in October but I haven't check it yet. I'll have to go back and check that.

\section{John Katrakis}


I heard about that also. Question also, I heard that eventually it was to be replaced by the ASHRAE energy label program. And I'm just wondering if we should be talking to ASHRAE about this issue.

\section{Mike MacDonald \\ Well ASHRAE energy label is only looking at commercial for the moment.}

Norm Bourassa

Yes — commercial — doesn't include multifamily.

\section{Mike MacDonald}

Well not really, they're having enough challenge trying to do commercial.

\section{Norm Bourassa}

I believe high-rise residential is included in the commercial standard. So I'm wondering if they will ignore that aspect of it.

\section{Mike MacDonald}

I don't know, since I did generate the table of EUIs that were in the initial document report on the feasibility on the project, I know that I didn't include any data on any kind of residential including multi-family.

\section{Mike MacDonald}

Alright. I think we've talked about some of this other stuff before so unless anyone else has any comments they want to make on energy use calculations. We may move to the next slide. Alright so... I

\section{Evan Mills}

Can I add just one little thing on the last slides. This probably down in the weeds but it's something I've been hearing about recently issue of thermal short circuit for the concrete decks used in balconies that bring heat and cool so to speak into the living space. Sounded pretty interesting, modeling challenge. I don't know what existing methods that accounts for that.

\section{Norm Bourassa}

That just reminded me that Dennis Nelson, for those that were at ACEEE, that particular issue has turned out to be a huge, huge problem in Vancouver, British Columbia. And Dennis Nelson has a database with a lot of work of actual measured data that actually measures that data and he is eager, eager to tap into our work here.

\section{Mike MacDonald}

Mini, can you make a note of that and can you check, is Jan Kosny still at Oak Ridge?

\section{Mini Malhotra}

He has left Oak Ridge National Lab, MIT I guess?

\section{Mike MacDonald}

MIT? Let's check with Andre Desjarlais and mention this issue of the problem with one dimensional modeling versus 2 dimensional or 3 dimensional heat flow issues. Because that is what Jan was working on. I know there has been a lot of work done on it. If there is some way we could plug some of that into these types of expert system calculations, we should at least see what the possibilities are.

\section{Mini Malhotra}

Okay.

\section{Mike MacDonald}

And then this recording will have Dennis Nelson's name mentioned and we'll see whether anybody has talked to him about the issues for multi-family slabs like that but yeah, certainly something we can look into.

\section{Norm Bourassa}

Well I approached him at the ACEEE summer study and mentioned our work coming up, well it was actually Jennifer Somers and I both, we spoke with him and invited him to be invited into this effort. He is just eagerly waiting for us to contact him. What I'll do is I will forward the information to Mini and make sure he is connected into our effort LDL. And hopefully you will do the same thing.

\section{Mike MacDonald}

Don't get him too fired up quite yet. Because the development plan will indicate how things should move forward but we still don't exactly how the development will occur and when we might actually get into the weeds like that.

\section{Norm Bourassa}

He is just willing to provide the data to us. They monitored something like 100 , there is has been an enormous amount of high-rise construction in Vancouver over the last 2 decades. I think in terms of density of high-rise residential, it's second highest to Manhattan and so there is wealth of data and they monitored something like 118 buildings and very detailed monitoring and they have this very rich data set and he is willing to share with us; a very good resource. 
Mike MacDonald

Yeah, that's an interesting topic for sure. Any comments on pre audit or post audit kind of calculations or results integration stuff?

Evan Mills

What are you thinking about?

Mike MacDonald

I'm leaving it pretty open ended here. I don't really want to unpack it right now.

\section{John Katrakis}

I have just one brief comment. I would love to see a post retrofit utility analysis built in to this process and to update the database so we can give people both the audit providers as well as the owners some idea of what to expect as a final energy use index based on real data. I think it's an essential feature to maximize the accuracy and the legitimacy of the all these tools.

\section{Mike MacDonald}

So let's say for argument sake that portfolio manager allowed that if they could do that or if it could be done in portfolio manager, would that be good enough?

\section{John Katrakis}

That would be great.

\section{Mike MacDonald}

So it might just be some way to link to portfolio manager which a number of folks have worked with EPA on. Okay, interesting. Any other suggestions?

\section{Norm Bourassa}

Yeah, I was just going to reiterate that what I mentioned earlier about the commission club and their tools they are real good examples there. One in particular is the ECAM tools (energy charting and metrics) that the peer funding along with the funding put together. It's exactly doing for commercial buildings what he was talking about. The link I already put together already in our comments will get Mini all connected up with these.

\section{Mike MacDonald}

Okay great. Any other suggestions or ideas about these topics. Problems with assumptions or defaults?

Luke Ilderton
This is Luke from Colorado. I just wanted to pose a question to everyone; right now I am currently running all of my load and sizing calculations for what I put in a modulating condensing boiler that's maybe half the size of what its existing condition to ensure that it's going to be able to cover the load in the coldest conditions here in Colorado. Does everyone else rely on subcontractors to do that or are they running their own load calcs? Obviously most modeling softwares aren't really setup for this for existing buildings to do it very well. So just thought I would pose that question.

Mike MacDonald

Any comments from anyone?

Andy Brooks ???

We do our own load calcs.

\section{John Katrakis???}

We do specify the boiler size so it's kind of a quasi fact but we figured that we should have some control over so we do our own load calcs.

\section{Mike MacDonald}

Yeah, I think the whole issue of load calculations is going to be a big one for the potential tool box. And exactly how that fits together we probably don't know right now. That sounds like they are both front end and back end issues that need to be considered in some fashion. Who knows what the development will be over time.

\section{Luke Ilderton}

It would certainly save quite a bit of time. I'm really heading in to put it in the contractors hands which is really where the model we use out here where we have sub contractors do all the work.

\section{John Katrakis}

It's a tricky situation because ultimately you do want the contractor responsible for the job. So if they have strong reasons to have a different size system we review it but we want to be informed with our own calculations so that we can make the best decision.

\section{Luke Ilderton}

Yeah, I'm in the same boat so it's good to hear that. Thank you.

\section{Mike MacDonald}

Okay, so should we move on to the next slide Cynthia? Our next topic is User interface/input. Any thoughts on what a wish list might be for user interface? Additional stuff? We've heard things 
about being able to handle multiple HVAC systems for different zones. We had discussions last week about ventilation systems, templates or specifications so certain kind of systems you may be able to pick them out. Utility rates are a big issue. Then it gets down to that issue, the whole question of if you are selling the owner, you got to get one answer about getting weatherization results. You start dealing with fictitious answer and that kind of junk. So, on those first 2 items, are there any comments or suggestions?

Asit Patel

A couple comments for our audit [ we use EAQUIP and TREAT - a couple of issues ]

\section{Mike MacDonald}

You're breaking up, is he breaking up for everyone else? [ agreement ]

Asit Patel

Let me try...A couple of things, we are limited especially around the heating system, for example but we all know in a multi-family building $<$ hard

to understand, breaking up - lots of static $>$ [one temperature and one efficiency] all those play a big role in the overall efficiency. We are tied to one number. Other parameters use the better heating improvements are in the building. Another things is also in terms of inputs for example uninsulated pipes I think that too we should collect the data and we aren't able to input the data. A more accurate energy savings prediction, rather than average.

\section{Mike MacDonald}

Great, okay any other comments on those?

\section{John Katrakis}

In our heating systems assessments we do calculate the cycle efficiency and use that together with the thermal efficiency to come up with seasonal efficiency and we can do that by using the utility bill information to come up with an average percent on time for the heating plant which has a big effect on cycle efficiency. Just based on experience our research we also adjust that based on short cycling of the boiler, I agree with Asit, that's a very helpful parameter. What we are finding too is the control strategy used by the manufacturers of the different types of condensing boilers when they are modulating as well as has a big effect on the seasonal efficiency of these supposedly very high efficiency boilers. That's at least as important as the energy audit protection coming up with a good control package and a good spec get what you expect to get in the field.

\section{Mike MacDonald}

Yeah, I think we've had other comments from other folks that mentioned there needs to be a fair amount of flexibility on dealing with heating system central plan and maybe overall system efficiency so I don't know how that will all work out. We had a number of comments on that.

\section{John Katrakis}

It would be very helpful to come up with a simple way to package individual measures, as Mr. Patel said earlier, I think you said this; you really need to look at the entire package to come up with a savings. It's hard to rely on individual measures to achieve savings. It's the whole package working together that we have the most confidence in the savings results. Whatever tool you use you have to take into account the interaction of the measures and end up with a final savings that is realistic and not overly ambitious. Again, that ties back to the requirements for having that benchmarking information of post retrofit performance of similar buildings.

\section{Mike MacDonald}

Okay, so there might be a need for some potential way to link measures together so there is some kind of controlling combination savings can be recorded? Or something like that?

\section{John Katrakis}

I think it's essential.

\section{Brody Vance}

Yes, it's critical and most of the programs do that already TREAT, EA-QUIP, EQUEST does that. When you put the package together it does do interactivity between the measures. That's standard.

\section{Mike MacDonald}

Yeah, I think interactivity is standard but it sounded a little bit like beyond the typical interactivity. I think as we go forward if we really need extra detail for development plan, we'll bug you guys again. I'm not sure this is going to be something we need to jump into the guts of for the development plan.

\author{
John Katrakis \\ Calibrate the final savings based on the actual \\ performance data.
}

\section{Mike MacDonald}

Yeah, based on like what you said before, if there is some way to follow up it's really important it 
would be nice to have it all linked together so you don't lose what you did on the front end. Have to sort of resurrect it.

\section{John Katrakis}

It's also like what a performance contractor does, All these large groups -- Honeywell or Johnson controls, they have databases based on actual experience they used to fine tune their savings projections that they give to clients. It's based on actual performance. They can't rely on just the calculations without having that final calibration based on actual performance in the field.

\section{Mike MacDonald}

So some way to track performance over time if it can be done would be great. Okay.

\section{John Katrakis}

Thank you, this has been interesting, I need to sign off now.

\section{Mike MacDonald}

Thanks a lot John appreciate it. The next item is MotorMaster that was mentioned last time, oh I'm sorry, I'm only on the $3^{\text {rd }}$ bullet on this one. MotorMaster integration was raised as a potential issue, any comments on that specifically. Maybe in the south or west, not as much an issue as it can be on the east coast. No comments? Anyone opposed? Okay. Any other comments on any of those other items that are on there? We've been talking about a lot of complex stuff. So I think to some degree we've sort of beaten on a lot of this. Alright, Cynthia let's move on to the next one. For the non energy measures, in the excel file that had the measures list, the energy measures were on one sheet and the non-energy measures was on another sheet. So there is a list of health IAQ measures and safety measures and if anyone had any comments on that right now, fine. There is going to be a separate tool developed that we're not quite sure how it will fit in with the multi-family.

\section{Evan Mills}

What is the history or mandate for this list or is there a prescribed...or is it open ended? What does the client want? What is the driver behind this?

\section{Mike MacDonald}

I think HUD is a sponsor but Mini go ahead.

\section{Mini Malhotra}

We are trying to work for them and develop a standalone tool which can do the assessment of the house. Then recommend measures for remediation on prevention and the items on this list based on our discussion with HUD. So for example, lead, radon, asbestos, all these items are based on our discussion with them. These are the items the auditor should be assessing on the different units.

\section{Mike MacDonald}

If anyone has any suggestions. We are looking for suggestions on this.

Evan Mills

So it's a separate tool potentially?

\section{Mike MacDonald}

Potentially, but it is still going to be part of the Weatherization assistance. We are going to have questions, we don't know how well they will be answered. What is the required level of integration, how separate can it be? If it's normally done separately, that's fine. In the discussion last week, it was mentioned people asked questions about doing combustion spillage in the case of units that are tightened up. It is mainly an issue for unit's who have their own heating systems in the space and needing to do that task. This hasn't gone far enough along, that we have a lot of ideas about exactly how it's all going to fit together.

\section{Evan Mills}

Knowing that, I have a giant one. I would add to a list like this which is urban heat catastrophe, you know heat stress within these buildings.

Mike MacDonald

I thought only California has urban heat catastrophes?

\section{Evan Mills}

John Katrakis just left the phone, he knows 750 people died above the normal rate in Chicago.

\section{Mike MacDonald}

Chicago, yeah.

\section{Evan Mills}

And 50,000 people died in Western Europe a few years ago. It's a big national issue, mostly on the east coast actually.

\section{Mike MacDonald}

So how exactly should this be handled.

\section{Evan Mills}

Massive thermal multi-family buildings, that's where the issue really is. 


\section{Mike MacDonald}

There is always Moscow this past summer, where there are fires all around and no ventilation in the unit's and everyone is choking to death.

\section{Evan Mills}

A broader category would be disaster resilience. So you've got things like what you just mentioned, what I just mentioned, of course there is earthquake, wind and there is all the natural hazards. The building vulnerability to those things very much makes it about Health \& Safety. And the heat catastrophe is one I think about a lot. I work in the climate change community so it's obvious there is an uptake inspected in those? There is also an energy link there, where some of these other things are quite separate from energy attributes of the building. You have a win-win when you are more thermally efficient envelope and the right kind of ventilation and so on.

\section{Mike MacDonald}

Okay, any other suggestions?

Asit Patel

One other thing I would want to see in a tool maybe to try to integrate into the final report in a lot of buildings we do go in and find some O\&M measure. We are having a hard time quantifying the savings. We know there are savings so maybe we can tie some research studies to some of the O\&Ms, typical O\&Ms that we find. Maybe mention in the tools that you select that particular. O\&M has some associated savings connected to it. And make sure the owner sees that and they will be more willing to implement it.

\section{Mike MacDonald}

That's a great suggestion. Okay. And there are so many O\&M measures. How long is your list of potential O\&M stuff that you run into?

\section{Asit Patel}

It all depends on the size and the conditions of the buildings. We do run into some situations where we do have extensive O\&M measures.

Evan Mills

... not about hardware and widgets

Mike MacDonald

I'm sorry, Evan, I couldn't hear the first part

Evan Mills
The same thing could be said about commissioning. Commissioning as it relates to O\&M and vice versa there are two potentially long categories of lifts. That is quite building specific. They're not retrofit's, they're not mechanical retrofit's. They are practices. Getting a higher standard of care on how the building is run to optimize and so on.

\section{Asit Patel}

But if we have the list, make it as a check list. Someone just clicks off potential applicable measures then we should have some savings associated with that.

\section{Evan Mills}

Yeah, oh I'm agreeing with you on that. Adding another category which would be the commissioning types of things that fall under O\&M in the way it's usually thought about.

\section{Mike MacDonald}

Any other comments on non-energy measures? Everybody's getting excited about getting through?

\section{Financial Calculations}

\section{Mike MacDonald}

- Options - needed/recommended?

- Issues

- Geographical/local level.

- Energy escalation rate.

- Complicated utility rates.

- Fuel switching.

- Installation cost.

- Deemed labor vs. Davis-Bacon rate.

- Incentives or rebates?

- Owner contributions.

- Hierarchy of simple to complex.

- Sensitivity range approach.

Financial calculations, we've had a number of issues come up, if you are trying to...certainly if you are trying to give a good answer to an owner to get them interested in something you potentially have to deal with a fair amount of complicated financial parameters...that ah, would affect their decisions and then the Weatherization has a whole different set of methods that they use to decide whether to move forward. So, any comments on 
financial calculations, you know knowing that we've got some of these potential issues related to doing real finances versus...

\section{Asit Patel}

Ah, just one thing, I don't see that on the list but there are times when the tools that we are...or that we used to use before, had all the useful life of the measures in the black box so we weren't able to see exactly what it was and we weren't able to reflect it for the proper measures. So I think whatever the tool is we should have the capabilities of entering the useful life of the measures separately when we are doing the analysis.

Mike MacDonald

Um hmm ok.

Asit Patel

You know not getting into the calculations behind the scenes.

Mike MacDonald

Right so that...

Asit Patel

What we are asking for is that there be a clear indication of what the expectations are in useful life.

\section{Mike MacDonald}

Ok that's good to know. And then some ability also to change it if you think it's a different number.

\section{Asit Patel}

Ah correct...you know the technology is moving, so if the tool is not kept up to date then...I mean I know this will be web-based hopefully it will be easier to update those but, I mean I think that we should give that option as long as its transparent that anybody reviewing the audit can question that, then it should be ok.

\section{Mike MacDonald \\ Yeah...ok...good...}

\section{Norm Bourassa}

That kind of gets us back to the NREL database idea...I mean right now for a single family they actually do put a measure like this in there. You know opening it up so everybody could modify that, that would, programmatically I that could probably be a, I'm guessing, could be a problem for the weatherization program.
No I don't think so, I think people choose to have that flexibility and I think Asit is also saying that if anyone wanted to go back and look at it that the equipment life would actually be documented. So that you...

\section{Norm Bourassa}

I totally agree, in some the market is really going to be determining the actual, the effective life of these measures. So there ought to be a way to feed that back in.

\section{Mike MacDonald}

Yeah...

Evan Mills

NREL database has an equipment life field right?

Norm Bourassa

Yeah.

Evan Mills

How well those numbers are derived...

\section{Norm Bourassa}

Yeah, that's exactly my question...how often and how well connected it is to market feedback from the experts. We'd have to look into that.

\section{Mike MacDonald}

Yeah I had to look into this whole issue recently, and it's interesting but ah the best table I found was at the state of Washington for when they are doing, when they're evaluating existing buildings and this is their state buildings they have a table of equipment life that came from three sources. And then ASHRAE has an equipment database, equipment life database that they're developing where users can put information but we are still waiting for that to be populated enough. So yeah it's a very interesting issue. Ok, are there other comments on financial calculations?

\section{Reporting \\ Mike MacDonald}

- What reporting capabilities are important?

- $\quad$ Are there examples of reporting formats you could share?

- Results presentation recommendations: order, type, financials, summaries.

- Formatting recommendations. 
OK, move on to the next one, reporting. We had a comment last time that we wanted to make sure that any reports that were generated would be exportable to typical office software so that you could, I guess export reports to Word or maybe tables to Excel and that kind of stuff. But I asked the group last week and I'll mention it again this time if you have any examples of reporting formats hat you think are valuable and you can share them, send those to Mini. Any recommendations you have...go ahead...

\section{Norm Bourassa}

Are the, does the Weatherization program have some prescriptive reporting requirements that are going to be limiting us anyways?

\section{Mike MacDonald}

Well certainly for the Weatherization approach. And I have to admit, I'm not familiar with that anymore, I haven't dealt with it for a while but, we don't necessarily want to limit it to just what the Weatherization program will do so if you have...I mean the comments we had from John Katrakis already about benchmarking and follow-up benchmarking and projections of expected performance are good examples and the kind of recommendations we are looking for. So anything else like that you think can be helpful and can be sent along to Mini easily, that would be great.

\section{Evan Mills}

That said, it would be nice to see the current... whatever you call it kind of spec for the weatherization reporting, just to inform the conversation and it is something that we know the tool needs to include at a minimum like you said.

\section{Mike MacDonald}

Well you know I think it varies by states but...

\section{Evan Mills}

...is there any type of comment standard or like a minimum requirement...

\section{Norm Bourassa}

Yeah there is.

\section{Evan Mills}

I would think so yeah.

\section{Norm Bourassa}

There are some common... at the weatherization website there are some common guidelines but yeah depending on how the states participate I can see how there would be a variation...

\section{Evan Mills}

Do we know if over the next few couple of years while all of this is going on and all of the programs are being ramped up and re-visited, is there a sense that those requirements are being discussed themselves or receptive to groups like this to improve or expand the kind of core required reporting or getting certain metrics in there things that a tool like this method like this would be able to generate. I bet you guys at Oak Ridge have a sense about that or is it very fixed?

\section{Mike MacDonald}

I think, well I think that would be a different form but it's certainly a good idea. Cynthia go ahead...

\section{Cynthia Simonson}

This is Cynthia, do you want me to just go ahead?

\section{Mike MacDonald}

Yes go ahead.

\section{Cynthia Simonson}

So, in the application package that the states apply each year for the grants, it actually lays out specifically what the federal reporting requirements are for the grant and you are correct in that states often do add on to those reporting requirements when they pass those requirements down to their local agencies but, in terms of the federal reporting it's very straight forward and it's very specific what is allowed. There are some additional reporting requirements that are happening right now related to monthly reporting and in terms of being able to address changes in the reporting, I'm sure you are all more aware than I am about the OMB requirements and the paperwork reduction and ability and the disability to collect information and see required reporting from the grantees and subgrantees. The national evaluation is the mechanism that they are using in order to collect those metrics and to collect the information that probably is more in line with what you are talking about and there is discussion not related to the federal grants but in terms of setting up mechanisms so that this reporting happens or that they are collecting this data and they are collecting it in a more routine fashion so that we don't have to undergo an incredible effort of a national evaluation in order to sort of see what's happening out there in the field. So some of those mechanisms are being embraced and many of the grantees and subgrantees are excited about having something that's along that line. But it is being proposed as a voluntary 
aspect in order to not have to go through the OMB requirements.

\section{Mike MacDonald}

Yeah and I think if you looked at the actual reporting, the federal reports that go back, there's not much information and they're pretty simple. And they are summary...

\section{Cynthia Simonson}

It's really not very deep, it's estimated energy savings and it's pretty thin in terms of what is required. It has more to do with units and expenditures.

\section{Mike MacDonald}

So the idea of this, even down to agency level reporting, it does have some traction right now but it does have to be voluntary like Cynthia said, so we'll see, we'll see how it goes. But anyways we're interested in ideas that folks have on reporting and the easier it is for the individual agencies to generate this stuff in the tool, potentially the more likely it is that we're going to have some of these results available, and I think in the front end we mentioned that there's interest in having databases developed that take care of some of this stuff more automatically but we don't know where it's going, but there is interest.

\section{???}

It should also; it should be able to generate those types of custom reports. But it should also, kind of a basic functionality of most of the tools, is to output all the data in some basic format, usually a CSV file that would then allow the user to create their own custom reports. So I think that's pretty important to include.

\section{Mike MacDonald}

Right yes. Some of the data should go into CSV files so that it can be imported or...it's possible you can maybe dump it into an excel file or a word file that...

\section{???}

Well that's what I mean, to be able to export as a CSV so we can then take the raw data and create tools around that CSV file.

\section{Mike MacDonald}

Yeah ok. I'm glad that was mentioned because that's also something to consider. Alright, any other comments on reporting? Ok Cynthia, want to jump to the end here?

\section{Wrap-Up \\ Mike MacDonald}

We're hoping to have a draft of this development plan in early to mid December to send out for comments. We may only be able to give you a week to look at it. We'll at least let you know that that's available and try to give everyone a copy and you can give us some feedback on it before we generate the final. Maybe it will be done by the end of December. We've talked about different ways that input can be provided in the development plan. We may not be able to be real specific. I think there were a number of items that came up that I'm not actually sure how we're going to coordinate as time goes forward, like the idea of the NREL database or measures database or benchmarking database, that need to be handled in the future. To the extent that those don't get described to the extent that you would like to see them in the development plan, please holler. And if you have ideas on how they should be handled outside of the development plan, please send those to Mini and she'll send them to the rest of the weatherization team and we'll try to see if something can move forward. Any other comments on where things are going next or what you'd like to see for feedback?

\section{Norm Bourassa}

One comment back to the scope of these meetings that you had last week and today, was the invited list principally those within weatherization assistance providers?

\section{Mike MacDonald}

No, it was wider than the weatherization program. A lot of times the folks that do this work, we hear quite a bit, they do weatherization and they do other programs. So when they do weatherization work, they're following weatherization rules and probably working for one customer, and when they're doing non-weatherization work, they're working for other customers.

But we mainly wanted to get a fairly broad set of national input so that people can have this as a reference. We're going to try to put these transcripts in the development plan so people have them for reference because we hope it's valuable. It's been pretty useful to me. It's been an interesting discussion and it really wraps your head around all these issues in a quick timeframe.

\section{Norm Bourassa}

So is this going to be the extent of the stakeholder and domain expert input that you're putting in or 
are you going to use this and put together a framework that then expands into a larger group, because there are some other players.

\section{Mike MacDonald}

There are some other players. What I think you're implying is that there's this huge follow-up issue which I've been bringing up on our end. We write this development plan and that gives some idea of how things are going to move forward. There's a lot of potential for national involvement in the actual development and exactly how that's going to occur, we don't know at this time. If there's some way to maintain continuity between the folks who have been brought together for the development plan and the actual development, I think it would be useful and certainly, folks have mentioned a number of topics. I'm not sure we want to have a lot of web meetings like this but there may be ways to allow the input to come in that we haven't quite figured out yet. So, maybe how NREL is doing their database, ...

\section{Evan Mills}

There's an advisory process, I'm not sure how active that is, and how they use it. But I know they did establish an external group of people providing input. It'd be good to ask when you call how that's working.

\section{Norm Bourassa}

So basically we're going to be committing some bandwidth towards our synergistic project with your work. We're going to be dealing with an advisory group pulling in an experts' input group and it would be very useful for me, I'm going to get the minutes and the work you're putting together that comes from this meeting. And so I think the logical way to move forward and make sure that we're moving synergistically is to take a look at what gaps and what kind of complementary scope I can put together so that we can be helping each other move together in a cooperative way. I know there are some voices missing from this discussion that have done a fair amount of research, just on their own, over the last decade and a half and now actually have resources.

\section{Mike MacDonald}

We don't necessarily limit the future input to just those who were in this meeting. One of the things I keep wondering is can we somehow develop a national, interactive development vehicle that would allow all of these folks to make contributions. Someone would have to be a referee to take all the contributions and make them fit together somehow.

\section{Norm Bourassa}

That is the challenge, to put something together that is extensible and that can grow and eventually evolve to everybody's needs.

\section{Mike MacDonald}

So, we're just going to do our piece right now and future development issues are certainly something to keep thinking about. You can ask Mini, and to the extent needed, she can try to arrange meetings with other weatherization folks as the need arises.

\section{Andy Brooks}

What's the timeframe for the actual development? When is it targeted to start and how long do you expect it to take?

\section{Mike MacDonald}

This is just my guesstimate right now, but certainly there have to be phases and I don't know that we're going to figure out all the phases as to how this proceeds. But the test versions of the web-based NEAT and MHEA part of the suite will be available for testing this fall sometime, soon. [Note: internal testing started in the Fall, and external testing is planned for Spring 2011.] The plan for rolling them out is this summer. I expect the MF development to start in spring 2011 and probably proceed for the initial phase through the fall of 2011 and hopefully there will be some components for testing at that time and maybe even a rollout of what might finally be in the tool by early 2012 . That may be accelerated, too. When we give accelerated schedules, I think we're always disappointed by how much we can actually get done in that time.

\section{Evan Mills and Mike MacDonald interaction} Fall 2010 is the single family and mobile home components. Those are existing tools that are ported to web-based. They're stand alone now, but you get into all the operating system hardware issues. They're being ported to web-based right now. EA-QUIP, that AEA has, is web-based right now. Folks are moving in that direction to try to get away from all those operating system hardware issues. Folks don't like to have to keep downloading and installing on their computers and all that security junk. So, those two components will be available for testing shortly and finals by this summer for those.

\section{Nick Dirr}


One major benefit of the web-based which we'll see when we roll out the manufactured homes is that it's much more transparent and easy for any user. You can remotely look in and see how their building's coming along. I think the support for these future tools will be really strong.

Mike MacDonald

Ok well I'd like to thank everyone for a really good session. A lot of good detail here that I think is very helpful. You'll be hearing more from us you know with a lot of verbiage in the fairly near future, and we hope this ends up being really useful for everyone as we move forward.

Any final comments from anyone? No? Everybody's getting ready to switch off...ok thanks very much and you'll hear from us later then. 


\title{
APPENDIX C \\ Transcript of the November 4, 2010 Multifamily National Energy Audit Methods Experts Meeting
}

\author{
Held as a Web Meeting, November 4, 2010
}

Participant List:

\author{
Mike MacDonald \\ Andrew Brooks \\ Nick Dirr \\ Fred Goldner \\ Josh Turgeon \\ Luke Ilderton \\ Glen Salas
}

Brody Vance
Tara Siegel
Mark Ternes
Russ Landry
Cynthia Simonson (host)
Mini Malhotra
Joel Eisenberg

\author{
Asit Patel \\ Jason Ransby-Sporn \\ Robert King \\ Jeff Haberl \\ Evan Markel
}

Comments below do not necessarily represent verbatim comments, but the unaltered premise of comments, credited to individuals, when possible. In some instances, the comments have been modified to reduce repetition of content and extraneous information. Clarifications by the moderator have been inserted as appropriate, but not always, if the content flows consistently without the clarification questions being inserted.

\section{Introduction}

\section{Mike MacDonald}

How could this potentially fit in to what people are already doing and how do we potentially make it even an improvement on what folks have available now? It would be nice if we could have something that was really useful to a wide range of folks. And we're not sure it's going to be limited to just the weatherization program. It may have capabilities for clicking into weatherization program mode and we're not exactly sure how that's going to go. And since we're just working on a development plan we're not really restricted right now. So, you can consider your input as ranging further than just weatherization.

And in a little bit we'll be asking folks for some input on what they've been doing and what tools they've been using and what perceptions they have of the tools they've used. So, we'll get to that in a little bit. So, I think that's enough on the development plan. Any questions on what I've said so far? No? Okay. Cynthia, you want to go to the next one? And Mini, you want to take this one?

\section{Background}

\section{Mini Malhotra}

Yeah, I'll take that. This is Mini Malhotra from ORNL. I'm working in the weatherization group here. As Mike MacDonald mentioned about this effort for US Department of Energy for the development of a national energy audit of multifamily buildings, so this practicum of tools is going to be part of the weatherization assistance suite of tools, which is a DOE sponsored instrument developed by ORNL to help states and agencies implement the weatherization assistance program.

This weatherization assistance suite currently has NEAT and MHEA, and NEAT is for single family homes and MHEA is for manufactured homes or mobile homes. So multifamily will be a new component for this tool. Besides we have two additional modules planned for this suite. One is a health and safety module, which will mostly be a rule-based expert system and the second one will be a non-energy benefits module.

So, the idea is that the entire suite will share a common database and management capabilities so that the Department of Energy or the States can track what's going on and evaluate the effectiveness of the program as a whole. So, as of now we are maintaining the desktop version of the tool which currently has NEAT and MHEA. And we are now on our way to reveal a web-based version of the tool in summer 2011. So, it will use a central location for agencies to work from and it will have the same flexibility and capabilities, maybe more enhancements. This will allow the States and the DOE to access the database and use it to evaluate the program's effectiveness. It will also be easier to keep the agencies up-to-date about any added features or new versions or anything. So, multifamily tool - this will be designed as a web- 
based tool and be incorporated as a web-based version.

This NEAT for the multifamily component comes from the weatherization community, who have been trying using NEAT for individual units of multifamily buildings. There are several limitations. It limits the range of options they can evaluate, otherwise it's a full-fledged multifamily tool. That's why it's time to have a multifamily tool integrated with this suite. NEAT comes from the weatherization community, but we are aiming for, for targeting other programs as well. And we'll, in this meeting, discuss those issues which are beyond weatherization program requirements. So with this I'll turn it over to Mike MacDonald who will help, who will tell us the purpose and the scope and the agenda for this meeting. Mike, you're on.

\section{Purpose and Scope}

\section{Mike MacDonald}

Okay, so as was mentioned this initial effort is to complete a development plan to lay out the potential development path and what some of these capabilities requirements are and what issues are, how we might integrate with other tools that are out there even, who knows? It's wide open at this point.

But, where we want to get the input from this group today is mainly more focused on methods - and a user group that we're going to have a meeting with next week, which a number of you are invited to attend also, to get more of a field use and user interface design. That's on next Wednesday, November tenth. So, the input from both of these meetings will be used to find better how we approach this development plan.

And we also want to get a feel for how this national multifamily tool might be an advancement in energy audit technology, and then, who knows? We'll just have to wait and see what we hear from you folks. And also find out how national contributions to tool development might be handled. The weatherization program will be looking at tool development for the next couple of years. So, after that, who knows, but I think that it would be very helpful to have as much of the tool development documented as possible in a way that we can maybe even get input from folks as the development proceeds. So, we'll see how that irons out as we try to go forward and get this thing smoothed out a little bit.

\section{Proposed Flow of Meeting}

\section{Mike MacDonald}

Alright, questions from anyone? Okay. So what we're looking at for our proposed flow of the meeting - and if folks want to change it, that's fine, we can rearrange stuff as we go along - as you see in your agenda there are some fundamental issues that we laid out that we'd like to get feedback from your folks on first to try to wrestle with some of these things on the front end. And then next go into baseline energy use analysis and see how that fits in with some of these fundamental issues that are raised or discussed. And after we get those two monsters out of the way, then we'll try to get into potentially a little more detail on energy use calculations, energy measures, non-energy measures, financials and reporting. And then after we're all burnt out, possibly after a couple hours if everybody's getting slowed down a lot, blood sugar's low or whatever, we'll have a wrap-up to see where we go from here. So, if folks are reasonably comfortable with that approach, we can jump into the fundamental issues, unless someone would like to make a comment before we start.

\section{Fundamental Issues}

\section{Mike MacDonald}

No comments. Alright, gang, let's go. The fundamental issues, then, initially, there are some tools out there and we'd like to find out a little bit more about what folks have been using. We know there's some issues related to some of these tools and we'd like to see what your folks take is on some of the potential issues and if you can add to these, feel free. We're not trying to limit what can be discussed. But, I think to start out, I'd like to call on folks individually and just get your report, I guess. Just tell folks who you are, who you work for and what kind of multifamily audit work you've been doing, what kind of tools you've been using and what you see some of the issues with the tools, and where you think things could go if we were going to try to improve it. So, looking at this list, can I possibly start with Brody Vance in Wisconsin and get you to tell us those things?

\section{Brody Vance}

Sure, as long as everybody can hear me. $<$ Sounds okay to me.> The programs I manage, one is the Focus on Energy Multifamily program in Wisconsin. And then we're doing a low-income weatherization high-rise building through Wisconsin's DOE's Department of State Facilities. We're going to have the low-income aspect and we have more of the market rate focus on energy 
efforts. Programs run on the focus on energy, anything four units and above, and with the DSF (Department of Facilities) program, twenty units and above. I see anything from small low-rise to high-rise multifamily with what we do. The tools that we use typically depend on how comprehensive the project is, to be honest. Certain things we'll use a simple spreadsheet calculation. If they're only looking to add insulation to an attic, we're not going to model a building. At the same time, if they're going to be adding insulation, possibly domestic hot water, boilers and anything else lighting related, then we may model. What we model with is TREAT and eQuest. Then there are a couple of occasions on new construction where we'll use E-Pro and Trane Trace but that's mainly for new construction. So existing buildings, we're using TREAT. The problem with TREAT that I see the most is when you get into multiple heating systems. It doesn't really like that. If you have an air handler and a hydronic boiler, TREAT kind of freaks out on that, so that's kind of a pain. With eQuest, I don't know some of the limitations there, in terms of what's a big hindrance. I couldn't tell you.

\section{Mike MacDonald}

Alright, alright. Thanks a lot. Jason Ransby-Sporn in Chicago, could you tell us a little bit about what you're doing and what you see and the tools you're using? Is that possible? He's still muted; maybe he's somewhere else. No, Jason? Hello? <He says his microphone is not working. $>$ His microphone's not working, okay. <He's writing on the chat. $>$ I see that, I see that.

Cynthia Simonson:

Jason, try again.

Mike MacDonald

Well, we're getting the music anyway, right?

Cynthia Simonson

And that's coming from Jason's line, so there may be a problem.

\section{Mike MacDonald}

Okay, well, let's move to Dr. Jeff Haberl in Texas. Can you tell us, Jeff, if you guys have been doing any multifamily and if you've seen any issues with tools or are you mostly not doing multifamily?

\section{Jeff Haberl}

Yeah, Mike, we have a code-compliant software that we've developed for the State of Texas for new construction, which is available on our webpage, for multifamily. And of course, Mini knows well about this, she was contributing to it before she left for Oak Ridge there. In addition I would suggest that, to the things that you have said already, I think that going forward with your plan, there needs to be some sort of a comparison. You know, if you do pick a tool or tools, there needs to be some comparison of the accuracy of those tools against some suite of tools or what everybody would agree to be the truth test. And I've already heard an example of that on the previous caller. And the reason why I say this is it's real easy, even for the sophisticated calculations, to just simply give you the wrong answer. And unfortunately, once these things get locked in and people start using them, it causes problems downstream. So I would certainly suggest a period of time when you have some testing of the tools.

The second thing that I wanted to mention, which I like a lot about what you've suggested, is your rulebased approach seems to be the quickest way to getting something up and running that is not going to require a huge amount of analysis. Because I think you're going to get at a good amount of measures that are applicable to a broad base of buildings from the experts that are out there, if they're willing to contribute these to you, with some sort of a parameter or parameterization of how these could be applied to the building. The difficulty of that, then, is going to be how the actual differences [are] going to work [their] way through those rules to the right set of questions and answers so you don't have to go through a bunch of heating system calculations when you're located in a building in the South or that sort of a thing. Having done one of those previously, I can tell you that that's an issue with setting up the tree structure on how this thing's going to select itself.

Long term, it seems to me like you're probably going to end up with tools that are very much broken into results that are pretty much common sense based on the regions and the different types of systems. I would be very careful to imagine applying these tools backwards at a building instead of forwards to a building, such that you start from the utility and the service drops and work your way into the big equipment, instead of starting at the front door of the apartment and working your way through every crack and nook and cranny and window and that sort of a thing. And I could go on and on, but that's my nickel's worth.

\section{Mike MacDonald}


Okay, great. Luke Ilderton in Colorado, isn't that right? Would you be able to offer any input?

\section{Luke Ilderton}

Yes, that's correct. And so actually, I work for an organization called Energy Outreach Colorado and we're an agency of the governor's energy office out here in Colorado. And we run the multifamily program out here and we see various high-rise and low-rise buildings all over the state. An independently energy outreach Colorado runs a low-income demand type management project with all the utilities here in Colorado. And then we also have a program where the city of Denver funds retrofits for non-profits. So we also, I'm involved in all three of those programs. Currently in our multifamily program we use TREAT and EAQUIP. I'll have to agree with Brody's analysis in terms of multiple heating systems are not very friendly to true up and to TREAT and it can give us a headache. And of course, EA-QUIP is a simple calculator and good use for multifamily but it's limited on your inputs. We're currently trying to seek approval from DOE to be able to use DOE2 or eQuest for existing buildings and we use those quite frequently in our other programs.

\section{Mike MacDonald}

Thank you. Glen Salas, would you be able to offer any comments on this approval process and what might happen if folks request to use a new tool like Luke just mentioned? Is that possible?

\section{Glen Salas}

Sure. Well, anybody who's using multifamily tools at all or single family tools does have to go through DOE to get approval. Most of them are fairly routine, but we do like to see for the tools that are in normal use like NEAT, TREAT and EA-QUIP. But we do like to also see examples to see that people actually know how to use them. Luke mentioned that us reviewing eQuest, we just got that a week or so ago and we will be using that. We're going to be going through that. And also, Luke's been kind enough to compare it to, I think it was TREAT, right Luke? And so, we'll be doing the same thing and we're also going to be going in, looking to see how they use the inputs and things like that. But, it's fairly routine and we should be able to turn around most requests within a month.

Mike MacDonald

Okay, thank you.

\section{Glen Salas}

Before I get off the phone, though, I would also like to say to second what Luke and what the first gentleman said about EA-QUIP and TREAT, you know, with multiple heating systems and every building we've done has had multiple heating systems. They just - they're very difficult. And the other thing is, ventilation improvement, they don't handle that very well either.

\section{Mike MacDonald}

Okay, great. Thanks a lot. At this point, how about the AEA folks, choosing someone to speak up and tell us a little bit about what your plans are and maybe any other comments you have on any of these other issues.

\section{Nick Dirr}

This is Nick Dirr and we also have on the call Asit Patel, Andy Brooks and Evan Markel out of AEA. The tools that we primarily use of course is EAQUIP - we're the current keepers of the EA-QUIP software and its online version - and we also use TREAT for buildings, both in weatherization and in other programs that we're involved in on the existing building side.

So, like we did mention earlier, the EA-QUIP version that we're using now is on a web-based platform and we've added a few more upgrades to that, looking at connecting boilers and more options on baseload. In response to Glen's last comment, we also are looking at implementing ventilation measures, especially when a building is drastically over ventilated. So that's where we're currently at with that and EA-QUIP is pretty much, after we finish this last round of doing the ventilation calculations, is in a state we're ready to have a lot of others use. And a lot of people are using it across the country currently.

Back to what Brody said, we agree in the same aspect. Both EA-QUIP and TREAT have their strengths, but you know there [are] situations where developing something that can accommodate other types of systems would be useful. The main one being different types of heating systems. Anything you have to do in EA-QUIP you can do in TREAT. Turning a building's heating system into one plant, so whether it's apartments or maybe they have a central hot water plant for the apartments and then a package unit on the roof, conditioning those corridors, at the moment, you're basically turning the building into one structure and combining the heating system into one heating plant. So, that would definitely be something that would be advantageous to look at incorporating. 
The strength that we're looking at, again, is a user interface, ease of data entry. The one thing that we do have some concerns about is developing a tool that's a one-size-fits-all model. So the complexity of a new tool that may be able to handle every single unique situation may become a very big program. So one thing that may be considered is, if possible, a suite of multifamily tools for the different types of building stock and heating and cooling systems that we see. And picking from that suite for the best application that that region or that State may be dealing with. Anybody else want to add anything from AEA?

\section{Asit Patel}

I agree with what Nick just said and that's one of the comments that we would like to make. Even internally, we have been discussing that, that when we go into the multifamily buildings, even here we have all different shape, size. Obviously, the lowrise works very differently than the high-rise buildings - even within the high-rise buildings, with mechanical ventilation, buildings without mechanical ventilation, and we're trying to integrate that. But as Nick said, maybe we have separate modules in the suite and then depending on what building you are looking at, maybe you select that particular module to do that analysis. That's something that we should look into.

\section{Evan Markel}

I just also wanted to add, different types of fuel bills. It's limited in both the retrofit ability in TREAT and EA-QUIP and that's something that should be looked at and can actually be improved in the suite package. For example, if it's an oil heated building or an electrically heated building with a gas-fire, a domestic hot water maker, what you can put into EA-QUIP is limited there, for the heating fuel bills, it can only be one type of fuel imported into it. A lot of conversions and BTU conversions, taking oil and gas and making it just gas or vice versa.

\section{Asit Patel}

That's also true for even a single, central plant that can have an interruptible service, where you have multiple fuels. And right now, under all softwares we have to do a separate analysis, combining the different fuels into one type of fuel and do the data entry into the software as one single fuel source.

\section{Mike MacDonald}

Can you explain how you to decide to use either TREAT or EA-QUIP?

\section{Nick Dirr}

95 percent of the time, for the building stock we see in the northeast, we will use EA-QUIP. The only situations where we will use TREAT is when there's a lot of multizonal issues going on. Even when we do use TREAT for trying to identify different zones, we end up banging our head against the wall, getting that to work as well. But it does have the capability of doing different zones, thermostat capabilities, where EA-QUIP is treating everything as one zone.

\section{Andy Brooks}

One of EA-QUIP's prime advantages is it's great for buildings that have one central boiler and no cooling. And it's in those situations, which tend to be pretty dominant in New York City, it's a pretty quick and easy tool to use that generates pretty accurate results. Just reiterating the toolbox idea, that every auditor needs to have a toolbox just like when you're out in the field, and there really shouldn't be a one size fits all. Use the right tool for the right application. When you come across a building like that, you don't really want to use an eQuest which can take a month to model the building.

\section{Russ Landry}

We're coming from a different background in that we haven't used either EA-QUIP or TREAT. Our more recent experience has been modeling new construction using eQuest, but before that we had worked on a Focus on Energy program, another energy based, and more fee for service program, for multifamily buildings, none of which was tied to federal weatherization. And we ended up developing our own system which was called Facet, based on an ACCESS database. One of the main features of that was variable specifications of field data that we would collect, so that based on what was in the building, we could load in different specifications and you had the flexibility of adding in multiple items depending on what's in the system and what we would run across in the building. We had also used Metrix to do utility bill analysis, to break out what the end uses were. The things we looked at were space heating and domestic water heating, breaking up gas use. The results of that we would bring into the Facet database and use that as a starting point as we developed recommendations.

Josh Turgeon

We're using TREAT for the most part here in New Hampshire. I have some experience with eQuest. 
And what I see is that TREAT's pretty good and works for a lot of the troubles we see. We don't have any large multifamilies, we're mostly dealing with small multifamilies, and TREAT seems to work. With my limited experience with eQuest, it seems like that might be a little bit too complicated and TREAT might be a little bit too simple. We're going to be doing a lot more solar in addition to the weatherization program and it would be great if a new tool would incorporate solar or a hybrid hot water heater.

\section{Russ Landry}

We've done extensive use of eQuest and I would suggest that if it's going to be used for multifamily as a tool, it requires a lot of assumptions that there's not really guidance on for a lot of measures. I would suggest that if that's going to be a tool that's used a lot, it might be worth some direction on what assumptions you'd make on different measures that would be reasonable. A lot of things we see, the software isn't really built in to deal with too well. For example, controls and the energy savings from boiler control retrofits. You have to assume different changes in the loads or changes in what the average indoor temperature is.

\section{Mike MacDonald}

And the problem with eQuest is that there's so much hidden behind the wall that's hard to get to and hard to understand.

\section{AEA}

Yes, there's so much flexibility and the support for eQuest just isn't there for users who just use it a little bit, once in awhile. Sometimes you don't get the results that you expect based on what you're telling it to do.

\section{Andy Brooks}

I'm out in California now and everybody out here does solar thermal and I just wanted to reinforce what the other gentleman said about the lack of ability to do that. Right now under weatherization we have to use TREAT and at some point in time there was a plan to incorporate solar thermal into TREAT because there are input screens that are grayed out for it. So we have to do either the RETScreen or F-chart outside of the program and then try to make some assumptions about the interactivity between the savings calculations outside and what you're doing with the hot water in TREAT. So some kind of incorporation for not just domestic hot water but comby systems as well would be great. <clarifications from Mike MacDonald) I've been using mostly RETScreen. I think at AEA we use RETScreen for the most part and we also have a much more complicated modeling program called Polysun, but we haven't been using that much. And out here it sounds like most people are using F-charts.

\section{Brody Vance}

We're using RETScreen as well and then as an input into TREAT or eQuest, whatever we need to do, the BTU being offset by the solar thermal system is kind of a black box you just insert into your model. Because there is no way for TREAT to incorporate it and that's one of the areas where it's lacking. So we've used RETScreen to give us that input. With eQuest, it does take a lot of time to run a model but there's so many wizards that you can use if you're needing just a quick and dirty model of a building. So, if you're going to use this to determine what heating system might be best to buy the customer, than using the wizards is great. On another note, if you actually need to put savings to that, like in the case of Wisconsin where we're going to give them an incentive or a reward, then you have to go more into the detail edit and take a week of your modeler's time in order to get something a lot more sound. There's two ways to use eQuest, depending upon what your needs are. $<$ And are the utility programs okay with that level of work? > Yes. Once they're going to put numbers and dollars to it, you better make sure that you've modeled it correctly and that you weren't using any wizards. And with the low-income weatherization work, we're required to use TREAT; we don't have any other options.

\section{Cynthia Simonson}

I want to direct your attention to the chat box. One comment is from Jason answering your question on using the self-developed modeling tools in Excel. Basically they found EA-QUIP to be inaccurate with the multifamily buildings in Chicago. And the second is a question: does anyone have strong feelings about how well any modeling software mentioned deals with steam systems and all the variables associated with them?

\section{$<$ Mike MacDonald - calling on AEA to respond $>$}

\section{Asit Patel}

We know the limitations of the software. What we have focused more on is an absolute understanding of the system and operations and then make adjustments in efficiencies or distribution inefficiencies and we do that with the recommendations and design specs that we do inhouse. Our experience is that regardless of what we 
do, if we leave it to the design engineers outside of the firm, it usually doesn't get addressed, so the only way to address all our needs is to do all our design work in-house. So, knowing what we have looked at in the building, knowing how we have analyzed it, knowing where we want to go, we prepare our specifications and make documents based on that.

$<$ Mike MacDonald - other comments $>$

\section{Nick Dirr}

Because of all the variables you could have steam spilling out of a main or a leaking in the boiler. At the moment we treat that as a thermal efficiency and then as a part of a heating system replacement or a heating system repair. We end up tying in all those things into our heating system specifications for repair or replacement.

\section{Asit Patel}

So far the software that we have used have limitations and don't allow you to input in detail the operating inefficiencies at the building level. The software usually ask for one input for efficiency and if you just enter the measured efficiency, that's very misleading because you can have a short cycling, you can have all kinds of issues. Stand by losses are an enormous impact on systems because we find grossly oversized systems and the software's own limitations in how it addresses that. The way we have started to address that is we lower the input that it allows us and then we address the improvement by making sure that we fix all those inefficiencies.

\section{Nick Dirr}

I think there's about eight or nine states using EAQUIP, at the moment.

\section{Fred Goldner}

What happens in the approach that they're taking or that you're forced to take, with many pieces of software, is you're tricking software into the savings levels that you otherwise believe, if you were doing hand calculations or customized computer algorithms. And you just play around with those one or two inputs that it will let you have to get a group of measures where you want it to be. And I think that's a real frustration for many end users.

\section{Mike MacDonald}

I'm not sure we'll ever get past that. We did have one comment from Minneapolis, that based on the research that they've done up there, they had a feel for what the savings should be for some of these measures up there and they used those rules, those savings percentage data points or rules to estimate their savings.

But what you could do is at least allow the end user or the software user a number of parameters to play with rather than just a simple one or two. Regardless of whether someone knows what they're doing, if they see that they have to put in at least a few different parameters on operations, it gives the sophisticated user a way to control that more finely, a more unsophisticated user gets the message that he or she needs to know a little bit more about that building or system before they start popping in measures of savings that may never be achieved.

\section{Russ Landry}

The kind of multiple ways of looking at things is what we had in the software we developed and we're using as we're developing recommendations. We would bring into that part of the software what the utility use had been by end use and just apply a percentage savings or it could be based on a quantity, for example, if you're looking at lighting, or it could be based on square footage. We had a lot of flexibility. There's sort of an assumed starting point and then that can be changed around. The way we have it, it's clear if someone does something other than default and there's comments on why you did that.

\section{Mike MacDonald}

Please email Mini at malhotram@ornl.gov if you have any more thoughts.

\section{Baseline Utility Bill Analysis}

\section{Mike MacDonald}

The next big area that we wanted to talk about was baseline energy analysis. How critical is it, when to use and what are some of the methodological issues with it to integrate it into the audit procedure?

\section{Fred Goldner}

One of the things that can make a major difference for multifamily is baseload. Let's stay on the thermal side for a moment - your domestic hot water. Most programs will take a look at what's going on in the summer, will take that and try to average four or five summer months and project that evenly throughout the year. But what we know from research is the domestic hot water use is not even throughout the year. There are significant differences. There are published numbers in the 
ASPE design manuals you can use to adjust that. That then knocks down your weather load, so that when you're doing your weather normalization, it's on a different portion and all your savings for your domestic hot water measures are coming off of a bigger chunk, which if you hadn't made that adjustment, you're going to undervalue and overvalue those. I don't use many pre-programmed software. We write many of our own. If I'm using the pre-programmed software, I try to force it. The other part is on weather normalization. I don't believe in the 65 degree day base. I think you need to look at how the building is controlled and what kind of conditions it's operating under. Overvaluing and undervaluing can become in excess of nine percent when you're looking year to year. There's a nine percent error factor. Is that okay with you? It's not okay with me.

\section{Russ Landry}

We would look at each building and try to figure out what the best set for the reference point would be and usually it's well below the 65 degrees. Also, you talked about the seasonal variation in domestic hot water use and it's very significant in some cases. Have you seen much variation beyond the variation in that water temperature for why there is the variation? Because in Minneapolis the water comes from the river where the temperature varies greatly but most suburbs get it from wells which does not vary much.

\section{Fred Goldner}

Right, I would look at that because it can be quite pertinent. There are other factors, as well, like the type of building, who lives there. If you've got singles in the building there may be lower water consumption because they're going to the gym and showering there. Or there may be low consumption because in the summer, folks are leaving and going to their summer homes. There's ways that you've got to look at the data beforehand and bring some adjustments and intelligence to it. Under normal weatherization, looking for balance points is certainly one way to do it. What I'm suggesting is, instead of using straight degree days, do customized degree based days. We even do degree hour with just a few more calculations, nothing a computer can't handle, and we put in the actual set points and times.

\section{Mike MacDonald}

What kind of outdoor temperature data would you use then?

\section{Fred Goldner}

We find it easier to just buy it from Weatherbank.com. It comes in nice, easy to use Excel format.

\section{Mike MacDonald}

Does anyone have any comments on electrical use? Is there a disaggregation needed for electrical, let's say we're not in a cooling climate, I know in a cooling climate we're probably going to have to do an electrical disaggregation. Any comments on electrical?

\section{Fred Goldner}

Gotta do the same thing, even up here in New York. It depends on whether it's a master metered or direct metered building. Master metered building, you've got to disaggregate out the cooling load.

\section{Mike MacDonald}

Is there anyone on the call who has to do anything with appliances, had to estimate energy use?

\section{Josh Turgeon}

Up in New Hampshire, we'll meter a fridge for a few hours but we don't do much more than that. Then we'll reference that to a database online to confirm the usage. It's every refrigerator we see. If they are newer, we'll just take the model number and double check it. If they have an issue, even with a new fridge, we'll meter it. If there's any question, we'll meter every fridge.

\section{Fred Goldner}

What about hydronic system pumping when you get to a moderately or large sized building?

\section{Josh Turgeon}

Here in New Hampshire, the weatherization program can't do anything with multifamily heating systems. So if we can't do anything to it, we don't bother. That's a State requirement. We do some basic analysis, we'll run the numbers for high efficiency, we'll make recommendations to the building owners, but when it comes to something like that it just doesn't fit into our program.

AEA

In New York, we do calculations outside of the modeling tool for hydronic system pumping, mostly with the TREAT model. We do the calculations for what the energy consumption would be based on the horsepower, the draw of the pump, the usage and the way it's being operated. And then you can enter it as an appliance and then model an improvement on that. If you were doing a variables 
feed or something like that, you could model it as an appliance improvement where it's an electrical load reduction. It's not going to do it for you. Basically, you have to run your calculations outside and then mimic them in TREAT. Yes, you're forcing it a bit, but once you've forced it, it's doing an accurate savings projection.

\section{Fred Goldner}

Since we're talking about motors and pump, I would suggest the best tool out there is MotorMaster and if you could integrate it with the new tool you're developing, you're a hundred years ahead of the curve.

$<$ Interaction among group about number of projects that call for motor measures - question to go back to electric $>$

\section{Brody Vance}

In terms of separating out or parsing out cooling load, sometimes we're seeing that there's electrically heated buildings that have baseboard electric strip heat. So in some cases you're trying to normalize weather data for heating with electricity. $<$ harder or easier?> That ends up being harder because all tenants are individually metered, so depending on where they're located in the building, there can be a stack effect. The units below has to keep their temperature higher because they are on the slab and the unit above benefits from that. These buildings can not be master metered.

\section{Josh Turgeon}

Somebody mentioned earlier you might have a high-income person who would go away for several months. In the weatherization program, the reality is that someone might not have been able to afford their heat for several months, so their apartment is an abnormality in the data. And to add on to what was just said about units affecting each other, what I've done in the past is take all that individual usage, add it all up and then divide it by the units, and also to abstract some of that abnormally low usage.

\section{$<$ clarifications $>$}

\section{Mike MacDonald}

What's the interface between the baseline energy use analysis and your actual audit procedure and measures calculations? How do they fit together?

\section{Nick Dirr}

For EA-QUIP, you have to enter your heating fuel bills and so you'll get a month-by-month grasp of the normalized heating baseload and heating load is and then your model needs to match that. You have to make sure that your simulated energy savings correspond with what the building actually uses. Within the software there's a building modeling chart there's a bunch of columns per month and blue will be what the building actually used and yellow will be what the simulated building says it would have used given the weather conditions and how you described your input. Like most modeling tools, you're putting in what you know to be fact and then based on your qualitative assessment and your diagnostics on the building, you're fine-tuning some of the more subjective areas such as ambient air temperature, infiltration, system efficiency, to best match up your model to what the building actually used. We put absolute importance in it. It's one of the primary requirements for modeling our building, that the simulated energy use is within five percent to the best practice of what the building actually used.

\section{Fred Goldner}

As much as I agree with that from a theoretical standpoint, many times I think you get these things to match up purely by coincidence or by unintended failure by the software or author of not understanding the building physics. While I think from an oversight, a procedural standpoint, you should definitely be shooting for that five percent, I don't have a lot of faith in making sure the model matched up because I'm not always sure that the model really understands what it is. And I think you wind up with a lot of coincidences where it's overcompensated in one area and undercompensated in another. And I'm not sure that always gives you accurate savings for the measures that are being piped out in the end. I'm a big believer in the Delta approach. You want to split your usage out to the different loads that you want to affect and then just look at what the difference of a change in a particular system made. I think that will give you greater accuracy in the resultant savings that the building will see.

\section{Asit Patel}

In anything that we do, and we are thinking about putting out a tool that is assisting, people need to understand that anytime we do a training, we are reinforcing that the software tool that you are using is just a tool. It's paramount that the person using the tool is knowledgeable about building science, building systems and the tool itself. You cannot have just anybody sit down in front of a tool and start doing data entry because that will lead to inaccurate assumptions and inaccurate projections. 


\section{Mike MacDonald}

It sounds to me that what you're saying for the reconciliation process is some kind of sensitivity analysis.

\section{Fred Goldner}

No, what I'm saying is, if I go to a building that needs pipe insulation and lighting and combustion efficiency improvements, I don't model the building and try to describe every piece of the building to the software or spreadsheet that I'm using. I break out to the major end uses and then I do a Delta calculation, a change calculation on that particular system. And I believe that is as or more effective than modeling the building down to the nth degree. The tool is only as good as the user, not only the ability of the user with the tool but also in the field. The eye of a trained auditor is the single most important thing.

\section{Mike MacDonald}

That suggests that the training needs to be linked to the tool in a major way and that does occur right now. But I'm not sure there is going to be a base of users at that skill level that will be available to do the amount of work that some folks would like to have done. So, we're probably going to have to find a middle road that gets the job done well enough.

\section{Fred Goldner}

But don't make the software such that the program is taking control, because it is just a tool, no different than a hammer or a screwdriver or a chop saw. The other side of that is, don't make the tool so cumbersome that it takes the user's knowledge out of their hands and it's making the decision.

\section{Andy Brooks}

Getting back to the fuel bill true up, just from a purely practical stand point for the experienced user, I think it helps them be more confident that their model is accurate, so it's not something I would just throw out. It can also be useful to anyone reviewing to see what the variables are that were tweaked.

\section{Energy Use Calculations}

\section{Luke Ilderton}

We're doing more heating systems than anything else, in terms of replacement. Building shell measures have not been extremely cost effective for us with multifamily. This year we're going to be focusing on a vast amount of underventilated multifamily units where there's really poor indoor air quality. We have to propose new measures, we have to calculate the negative energy impact and figure out the best way to either add ventilation or enhance current ventilation that's available. Eighty percent of our multifamilies have unconditioned hallways. It is a challenge. Because all of our heating systems are hydronic, we have some dangerous levels of indoor air quality and it's promoting a lot of sickness and unsafe conditions for the residents.

\section{Andy Brooks}

We have two approaches: If it's underventilated, we fix the problem and it's a health and safety measure. If it's overventilated, then we can run calculations to figure out what the savings would be by reducing the ventilation and count that as an energy savings measure. But we can't do it in EAQUIP and you can kind of do it in TREAT, you can do your outside calculations to come up with a net CFM reduction and then plug that into TREAT.

\section{Luke Ilderton}

For any of us adding ventilation, it's easiest for us to use eQuest. I've found it to be pretty difficult in TREAT. We also run into where an apartment complex might have been market rate and now it's a low-income HUD facility. The duct work might be existing but it's all disconnected, so we might try to recommission that. We need to be able to tell the owners that if we were going to install this, that there will be some energy usage associated with that measure. And it's all under health and safety.

$<$ clarification and request for any other comments $>$

\section{Brody Vance}

If you are going to increase the ventilation to the building, it would be nice if the retrofit model would take into account the increased heat loss associated with that. It should reflect there is going to be a net increase in energy usage both on the electrical side and the thermal side.

\section{Mike MacDonald}

For the Weatherization Program, we're going to have to have the health and safety components integrated. Any comments on the pre- and postsimulation calculations?

$<$ pre and post simulation calculations - minor assumptions and clarifications $>$

\section{Mini Malhotra}

There are many things which are beyond the capability of the simulation engine, so you have to 
have calculations which will give you input for the simulation model and output from the simulation model and you can do some forced calculations to force it to be the way you want. So, you will have to use both these methods for any audit tool.

\section{Fred Goldner}

$<$ clarification $>$ There are some tools that are clearly better. <Agreement for Fred, Mini, and Mike to have an offline conversation.>

\section{Russ Landry}

It sounds like it would be helpful to have some kind of third party keep track of the outside calculations, which could be helpful for anyone reviewing.

\section{Energy Measures}

$<$ No comments on this list; participants can insert comments into spreadsheet and send to Mini/Mike.>

\section{Non-Energy Measures}

\section{Mike MacDonald}

Are there any other health and safety, IAQ, IEQ problems besides ventilation that you've run into?

\section{Nick Dirr}

Is anyone else doing worst-case depressurization testing in the instance of tightening up the envelope for the shell, so we're not over-tightening the building without proper ventilation?

$<$ clarifications from Mike MacDonald throughout comments>

We're doing it from a safety standpoint when we're doing envelope measures, but does anyone do it all of the time? You run the test by inserting a probe in the flue of atmospheric venting equipment and then you run all those other pieces of equipment and then you look at your digital manometer and it will tell you what the potential for backdrafting is. You can use a smoke pencil or a smoke tube to see if it's going to draft properly but we're finding that if you have a building that's marginal to start and you tighten it up, it's a CAZ testing.

\section{Brody Vance}

In Minnesota and Wisconsin, in multifamily buildings we hardly ever see combustion equipment within the individual units. It's a concern in the boiler room and we look to see if there's adequate combustion air supply and just deal with it that way.

\section{Luke Ilderton}

In Colorado, we are about to undertake about fifteen hundred individually heated units and for our final inspection we will go through and do a worst case depressurization test to prevent the situation that you just described.

\section{Josh Turgeon}

We see it quite often in row houses, townhouses settings when they do have individual units. If you have a centralized heating system, you're not going to try to depressurize the building by turning on everybody's bath fan. I'm talking about individual units.

\section{Mini Malhotra}

How many units do you test? Do you go to all the units? What do you do to take out the infiltration between the units?

\section{Josh Turgeon}

In New Hampshire we are required by the State to do tests on every unit, to do every test on every unit. There can be no sampling whatsoever. CAZ on a single family can be complicated enough. In multifamily, it's typically doing the one unit itself.

\section{Brody Vance}

In Wisconsin, we're allowed to do a sample which is typically twenty percent of the units.

\section{Luke Ilderton}

In Colorado, we do every single unit when individual appliances are located inside the unit.

\section{Turgeon ???}

Client education is such an important part of the weatherization program and if you're just sampling units, you're not there doing the audit and going over why we're there, what we're there to do and answering all their questions. If all the units are the same, it can take about eleven minutes, but if each unit is unique, it can take three times as long.

\section{Mike MacDonald}

Is there a need for integration of these non-energy measures or is it like a separate activity?

\section{Nick Dirr}

It's looking at smoke and CO detectors. Any obvious health and safety in terms of code compliance stuff is usually done as part of the report but not included in the actual audit software. I think the only thing that we track from the audit 
software is making sure that we have adequate combustion ventilation for heating systems.

\section{Luke Ilderton \\ Recently we've been finding that we have inadequate pressure in the flues and the boilers and extremely high $\mathrm{CO}$ readings and improper scalding mixing valves that are not code compliant and residents are complaining about the water being too hot so they turn the boiler down and then get calls about inadequate heat. In our initial energy audit we are remedying those situations with some health and safety money because it's probably three months before we're actually installing some of the new measures. So we take the precaution that if the heating systems are not drafting properly, that we don't jeopardize any of the clients in that interim period of procurement and getting all of our subcontracting items in order.}

\section{Mike MacDonald}

Any issues with documentation?

\section{Josh Turgeon}

I guess if you're detecting a certain level of carbon monoxide, we're required to let the occupant, the builder owner, whomever know that they're at a certain level due to safety and from a liability standpoint. Other than that, we don't look at mold or other moisture level things in terms of liability and notification. Lead paint is handled separately.

\section{Josh Turgeon}

Units that have individual control of their thermostats, some that are overheated that open up their windows, our state standards are written in such a way that we can only airseal at the building envelope. I was wondering how you can get that compartmentalization so that you're not getting too much heat from your neighbor. It's an energy savings measure but not something you can quantify.

\section{$<$ clarification and discussion with Mike $>$}

\section{Fred Goldner}

You mentioned that client education is major concern for your weatherization efforts. To the person that's opening the window, we would educate them to just lower their thermostat setting because they're getting some free heat.

\section{Josh Turgeon}

But the thermostat has likely been shut off. But for all the client education in the world, for the price of weatherstripping and caulking, compartmentalization would be a help.
Mike MacDonald

It's a really good point and suggests a research project. I guess we don't have an answer but it's certainly an interesting thing to think about.

\section{Financial Calculations}

\section{Josh Turgeon/Mike MacDonald}

$<$ Brief redirect away from Davis-Bacon wages and calculating cost-effectiveness $>$

\section{Asit Patel}

The majority of the buildings that we deal with have at minimum two rate structures for electricity, one for the common area meters and one for the apartment meters. We would like the tool to be able to use two rate structures to do analysis for two different areas. Also, for the common area or master metered buildings, we would like to see savings calculations be part of the overall SIR.

\section{Fred Goldner}

If you do not use actual energy rate structures, your tool cannot handle it and all you're doing is something like average annual costs per kilowatt hour. Most of the measures, you're lying to the client that you're giving the report to. Savings are forty to sixty percent over or under projected if you just use average rates. You not only have to do what Asit mentioned, but also take in more complex, real world rate structures. $<$ Does anybody do any kind of sensitivity analysis?> The best tool I have heard of for that is Crystal Ball. Speak to Steve Kromer.

\section{Reporting}

\section{???}

I would suggest the tool be able to send output to an editable format, to a Word or Excel, so it can be customized for presentation.

\section{Wrap-Up}

\section{Mike MacDonald}

Would you like to see a near final draft of the development plan that you could make comments on? < Yes.> If anyone does not want to receive that, let Mini know. Otherwise, we'll assume we can send it out for comment. It will probably be early December and there won't be a lot of time to get comments back, just so you're warned. There may be a week or ten days to get comments back and we'll try to get a final out by the end of December. 
We're going to start writing the development plan in early December.

Joel Eisenberg

I want to emphasize that we're working on a health and safety audit that is supposed to be a companion to the other audits that exist. 